\title{
Impacts of Western Area Power Administration's Power Marketing Alternatives on Retail Electricity Rates and Utility Financial Viability
}

Decision and Information Sciences Division

Argonne National Laboratory

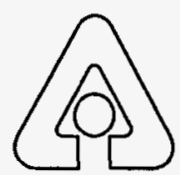

Operated by The University of Chicago, under Contract W-31-109-Eng-38, for the United States Department of Energy 


\section{Argonne National Laboratory}

Argonne National Laboratory, with facilities in the states of Illinois and Idaho, is owned by the United States Government, and operated by the University of Chicago under the provisions of a contract with the Department of Energy.

This technical memo is a product of Argonne's Decision and Information Sciences (DIS) Division. For information on the division's scientific and engineering activities, contact:

Director, Decision and Information

Sciences Division

Argonne National Laboratory

Argonne, llinois 60439-4815

Telephone (708) 252-5464

Presented in this technical memo are preliminary results of ongoing work or work that is more limited in scope and depth than that described in formal reports issued by the DIS Division.

Publishing support services were provided by Argonne's Information and Publishing Division (for more information, see IPD's home page: http://www.jpd.anl.gov/).

\section{Disclaimer}

This report was prepared as an account of work sponsored by an agency of the United States Government. Neither the United States Government nor any agency thereof, nor any of their employees, makes any warranty, express or implied, or assumes any legal liability or responsibility for the accuracy, completeness, or usefulness of any information, apparatus, product, or process disclosed, or represents that its use would not infringe privately owned rights. Reference herein to any specific commercial product, process, or service by trade name, trademark, manufacturer, or otherwise, does not necessarily constitute or imply its endorsement, recommendation, or favoring by the United States Government or any agency thereof. The views and opinions of authors expressed herein do not necessarily state or reflect those of the United States Government or any agency thereof. 


\section{Impacts of Western Area Power Administration's Power Marketing Alternatives on Retail Electricity Rates and Utility Financial Viability}

by E. Bodmer, R.E. Fisher, and R.C. Hemphill

Policy and Economic Analysis Group,

Decision and Information Sciences Division,

Argonne National Laboratory, 9700 South Cass Avenue, Argonne, Illinois 60439

March 1995

DISTRIBUTION OF THIS DOEUUVENTIS UNLIMITED

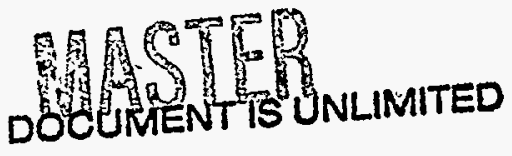

Work sponsored by United States Department of Energy,

Western Area Power Administration

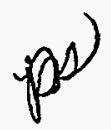


This report is printed on recycled paper. 


\section{FOREWORD}

This report is one of a series of technical memorandums prepared to support an environmental impact statement (EIS) on power marketing prepared by Argonne National Laboratory for the U.S. Department of Energy's Western Area Power Administration (Western). Western markets electricity produced at hydroelectric facilities operated by the Bureau of Reclamation. The facilities are known collectively as the Salt Lake City Area Integrated Projects (SLCA/IP) and include dams equipped for power generation on the Colorado, Green, Gunnison, and Rio Grande rivers and on Plateau Creek in the states of Arizona, Colorado, New Mexico, Utah, and Wyoming.

Western proposes to establish a level of commitment (sales) of long-term firm electrical capacity and energy from the SLCA/IP hydroelectric power plants; the impacts of this proposed action are evaluated in the EIS. Of the SLCA/IP facilities, only the Glen Canyon Dam, Flaming Gorge Dam, and Aspinall Unit (which includes Blue Mesa, Morrow Point, and Crystal dams) are influenced by Western's power scheduling and transmission decisions. For this reason, the impacts of hydropower operations at these three facilities were examined in the EIS.

The technical memorandums present detailed findings of studies conducted by Argonne National Laboratory specifically for the EIS. These studies are summarized in the EIS, and the results were used to assess environmental impacts related to alternative commitment levels. Technical memorandums were prepared on a number of socioeconomic and natural resource topics. Staff members of Argonne National Laboratory's Decision and Information Sciences Division and Environmental Assessment Division prepared these technical memorandums and the EIS as part of a joint effort managed by the Environmental Assessment Division. 


\section{CONTENTS}

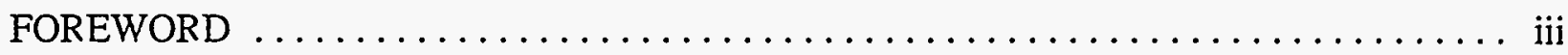

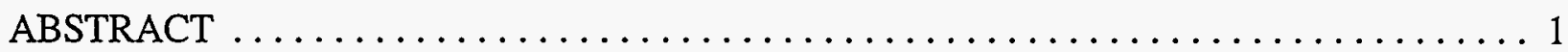

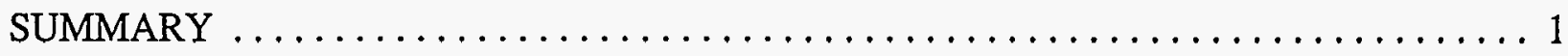

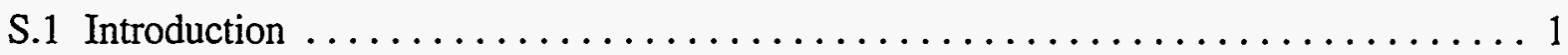

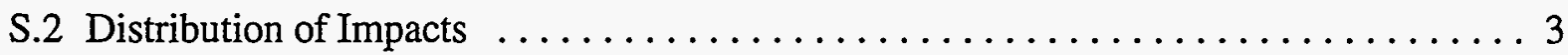

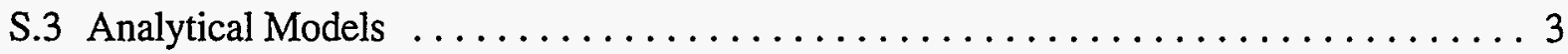

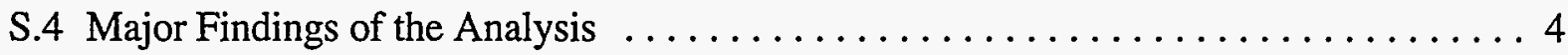

S.5 Outline of Report ................................ 6

1 OVERVIEW OF CLASSIFICATION OF UTILITY SYSTEMS, MARKETING

ALTERNATIVES, AND GENERAL MODELING APPROACH $\ldots \ldots \ldots \ldots \ldots \ldots 7$

1.1 Structure of the Electricity Industry in the Southwest $\ldots \ldots \ldots \ldots \ldots \ldots \ldots \ldots$

1.2 Capacity and Energy Allocations $\ldots \ldots \ldots \ldots \ldots \ldots \ldots \ldots \ldots \ldots \ldots \ldots$

1.2.1 Marketing Commitment Alternatives $\ldots \ldots \ldots \ldots \ldots \ldots \ldots \ldots \ldots . \ldots . \ldots \ldots$

1.2.2 Dam Operation Options $\ldots \ldots \ldots \ldots \ldots \ldots \ldots \ldots \ldots \ldots \ldots$

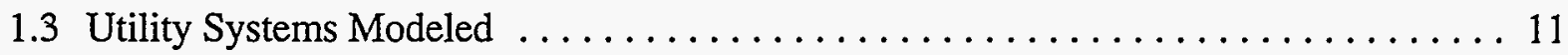

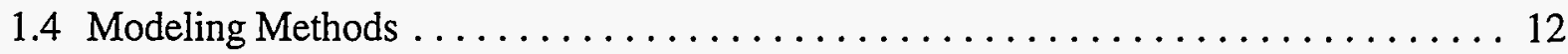

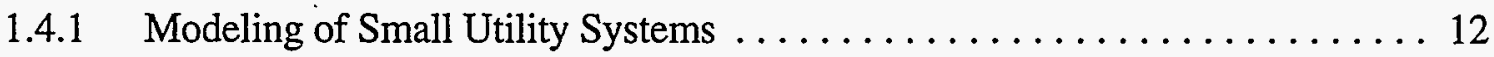

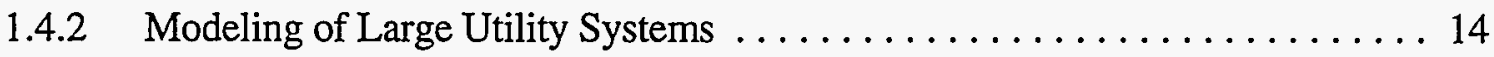

1.4.3 Modeling of End-Use Customers $\ldots \ldots \ldots \ldots \ldots \ldots \ldots \ldots \ldots \ldots$

2 FACTORS THAT INFLUENCE THE RETAIL RATES CHARGED

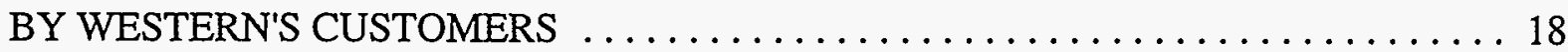

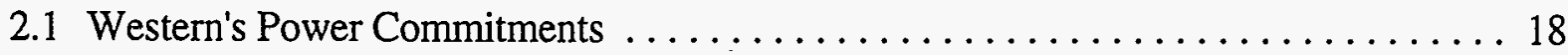

2.1.1 Western's Capacity Commitment $\ldots \ldots \ldots \ldots \ldots \ldots \ldots \ldots \ldots \ldots \ldots \ldots \ldots \ldots$

2.1.2 Western's Energy Commitment ........................ 19

2.1.3 Western's Energy and Capacity Purchases and Sales ............. 19

2.1 .4 Load Factor . . . . . . . . . . . . . . . . . . . . . . . . . 20

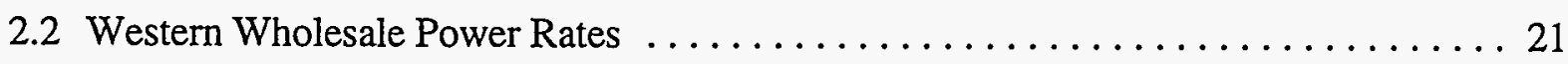

2.3 Cost of Replacement Power ............................ 28

2.3.1 Cost of Alternative Power: Method 1 - Power Systems Models ...... . . 28

2.3.2 Cost of Alternative Power: Method 2 - Power Contract Analysis . . . . . . . 31

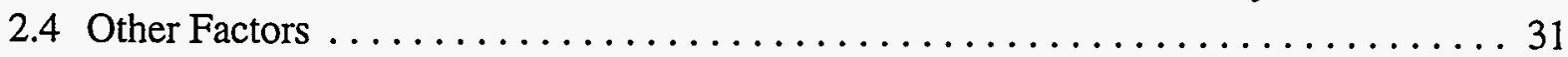

2.4.1 Growth in Demand for Electric Power $\ldots \ldots \ldots \ldots \ldots \ldots \ldots \ldots \ldots$ 


\section{CONTENTS (Cont.)}

2.4.2 Price Elasticity of Demand by Customer Class ................ 33

2.4.3 Relative Sales Proportions by Customer Class $\ldots \ldots \ldots \ldots \ldots \ldots \ldots . \ldots \ldots$

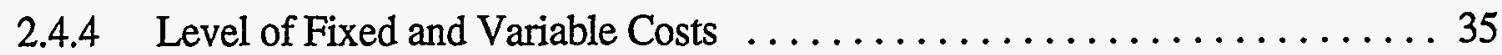

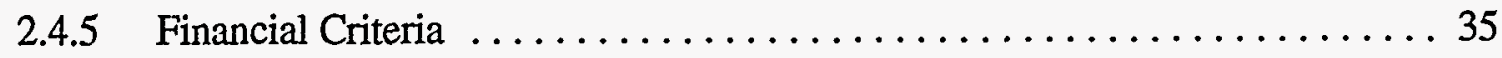

3 RETAIL RATE AND DEMAND IMPACTS ON UTILITY SYSTEMS, GEOGRAPHIC AREAS, AND REPRESENTATIVE SYSTEMS $\ldots \ldots \ldots \ldots \ldots \ldots 36$

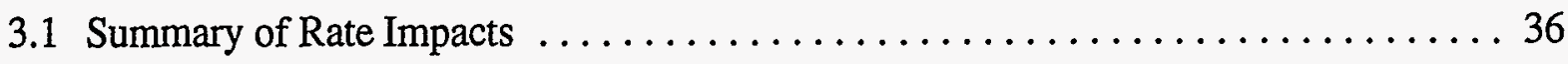

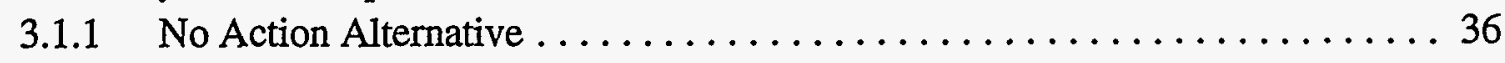

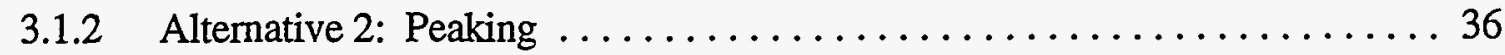

3.1.3 Alternative 4: Low Capacity and Energy $\ldots \ldots \ldots \ldots \ldots \ldots \ldots \ldots \ldots \ldots \ldots \ldots \ldots \ldots \ldots \ldots \ldots$

3.1.4 Alternative 5: Baseload ........................... 37

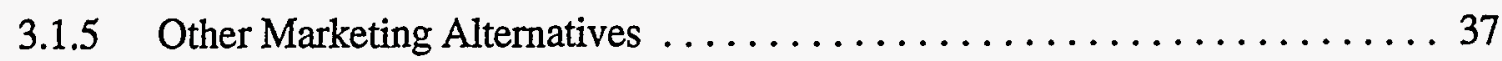

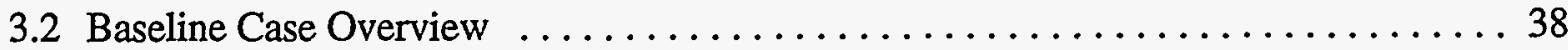

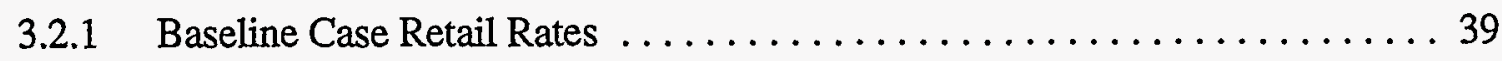

3.2.2 Baseline Case Retail Sales $\ldots \ldots \ldots \ldots \ldots \ldots \ldots \ldots \ldots \ldots \ldots \ldots . \ldots \ldots 1$

3.2.3 Capacity Reliance and Energy Reliance $\ldots \ldots \ldots \ldots \ldots \ldots \ldots \ldots 41$

3.3 Impacts on Retail Rates of Individual Utility Systems $\ldots \ldots \ldots \ldots \ldots \ldots \ldots 43$

3.3.1 Alternative NA-B: No Action Alternative/Low Fluctuating

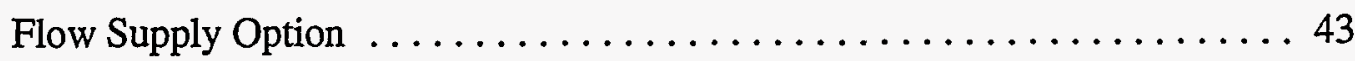

3.3.2 Alternative NA-C: No Action Alternative/Steady Flow

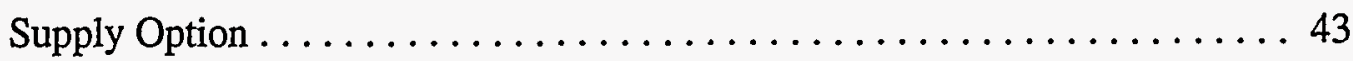

3.3.3 Alternative 2-A: Peaking Alternative/Full Flexibility

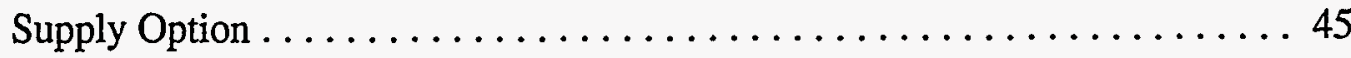

3.3.4 Alternative 2-B: Peaking Alternative/Low Fluctuating Flow

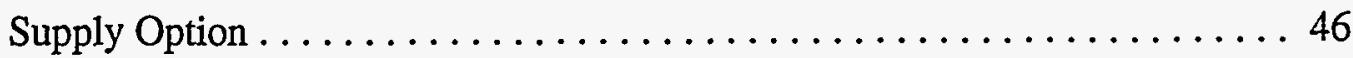

3.3.5 Alternative 2-C: Peaking Alternative/Steady Flow

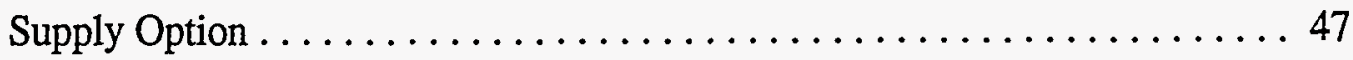

3.3.6 Alternative 4-A: Low Capacity and Energy Alternative/Full Flexibility Supply Option $\ldots \ldots \ldots \ldots \ldots \ldots \ldots \ldots \ldots \ldots \ldots \ldots \ldots$

3.3.7 Alternative 4-B: Low Capacity and Energy Alternative/ Low Fluctuating Flow Supply Option $\ldots \ldots \ldots \ldots \ldots \ldots \ldots \ldots . \ldots \ldots$

3.3.8 Alternative 4-C: Low Capacity and Energy Alternative/ Steady Flow Supply Option $\ldots \ldots \ldots \ldots \ldots \ldots \ldots \ldots \ldots \ldots \ldots \ldots \ldots \ldots$

3.3.9 Alternative 5-A: Baseload Alternative/Full Flexibility Supply Option .......................... 52 


\section{CONTENTS (Cont.)}

3.3.10 Alternative 5-B: Baseload Alternative/Low Fluctuating Flow Supply Option .............................. 53

3.3.11 Alternative 5-C: Baseload Alternative/Steady Flow Supply Option . ..... 54

3.4 Impacts on Retail Rates by Geographic Region $\ldots \ldots \ldots \ldots \ldots \ldots \ldots \ldots \ldots$

3.4.1 No Action Alternatives NA-B and NA-C $\ldots \ldots \ldots \ldots \ldots \ldots \ldots \ldots$

3.4.2 Alternative 2: Peaking .............................. 55

3.4.3 Alternative 4: Low Capacity and Energy $\ldots \ldots \ldots \ldots \ldots \ldots \ldots \ldots \ldots$

3.4.4 Alternative 5: Baseload .......................... 58

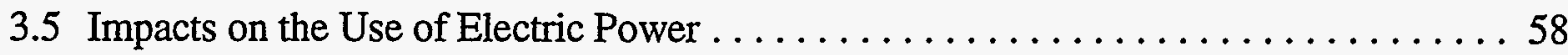

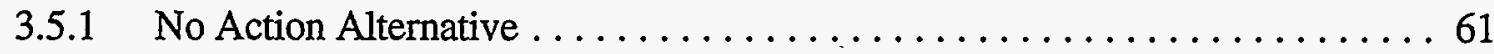

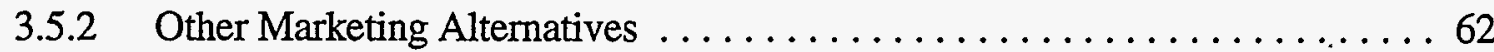

3.5.3 Overall Average Impacts . . . . . . . . . . . . . . . . . . . . 62

3.6 Impacts on Representative Utility Systems . . . . . . . . . . . . . . . . 62

3.6.1 Relative Reliance on Western for Capacity and Energy . . . . . . . . . 65

3.6.2 Retail Rates over Time . ...........................68 68

3.6.3 Annual Rate Impacts Relative to the Baseline Case $\ldots \ldots \ldots \ldots \ldots 68$

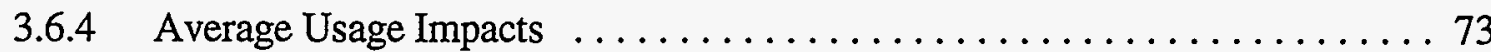

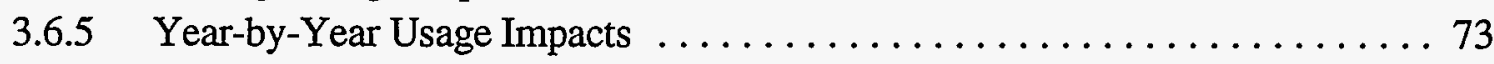

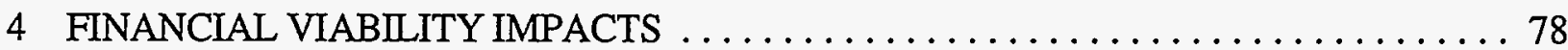

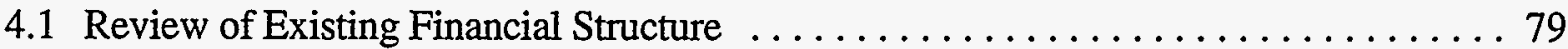

4.2 Determination of Utility Systems That Have

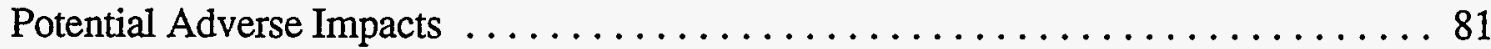

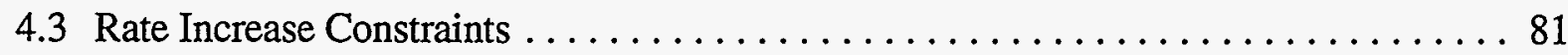

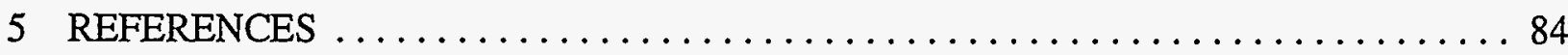

\section{TABLES}

1 Aggregate Capacity and Energy Commitment Levels $\ldots \ldots \ldots \ldots \ldots \ldots$

2 Capacity and Energy of Operational Alternatives $\ldots \ldots \ldots \ldots \ldots \ldots \ldots \ldots \ldots \ldots$

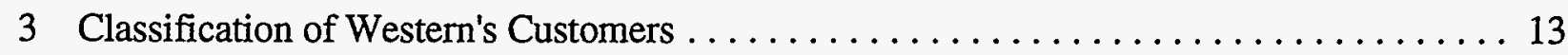

4 Western's End-Use Customers .................................. 17 


\section{TABLES (Cont.)}

5 Methods for Computing the Cost of Replacement Power $\ldots \ldots \ldots \ldots \ldots \ldots \ldots$

6 Impacts for the Steady Flow Supply Option $\ldots \ldots \ldots \ldots \ldots \ldots \ldots \ldots \ldots \ldots \ldots \ldots \ldots \ldots$

7 Baseline Case Retail Rates and Sales for Systems Receiving Power from Western ...... 40

8 Baseline Coverage Ratio by Reliance Level $\ldots \ldots \ldots \ldots \ldots \ldots \ldots \ldots \ldots \ldots \ldots$

9 Coverage Ratio by Utility Category and Marketing Alternative $\ldots \ldots \ldots \ldots \ldots \ldots 2$

\section{FIGURES}

1 Simultaneous Modeling of Retail and Wholesale Systems . . . . . . . . . . . . . 16

2 Western Aggregate Firm Capacity Allocations in Marketing Alternatives .......... 19

3 Western Aggregate Energy Allocation in Marketing Alternatives $\ldots \ldots \ldots \ldots \ldots \ldots$

4 Western Purchases and Sales in Marketing Alternatives $\ldots \ldots \ldots \ldots \ldots \ldots \ldots \ldots \ldots$

5 Western Aggregate Load Factor in Marketing Alternatives $\ldots \ldots \ldots \ldots \ldots \ldots . \ldots 22$

6 Western All-in Rates for Various Combinations of Marketing Alternatives

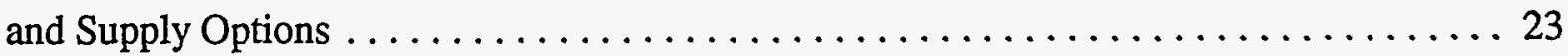

7 Percentage Change in Western All-in Rates for Combinations of Marketing

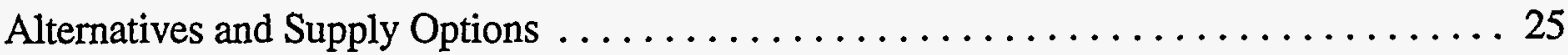

8 Western Demand Charges for Combinations of Marketing Alternatives and

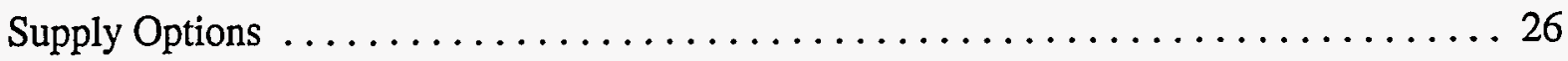

9 Western Energy Charges for Combinations of Marketing Alternatives and

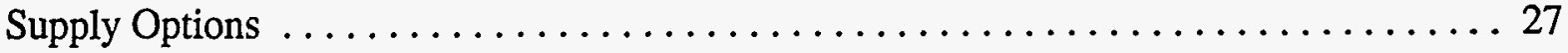

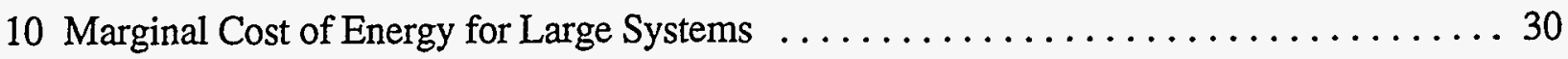




\section{FIGURES (Cont.)}

11 Power Costs for Alternative Suppliers $\ldots \ldots \ldots \ldots \ldots \ldots \ldots \ldots \ldots \ldots \ldots \ldots \ldots \ldots \ldots \ldots$

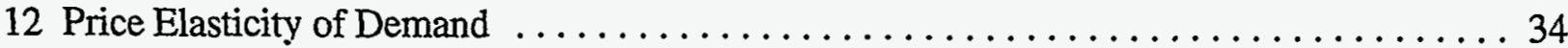

13 Relative Energy and Peak Reliance $\ldots \ldots \ldots \ldots \ldots \ldots \ldots \ldots \ldots \ldots \ldots \ldots \ldots$

14 Impacts of Alternative NA-C: No Action Alternative/Steady Flow

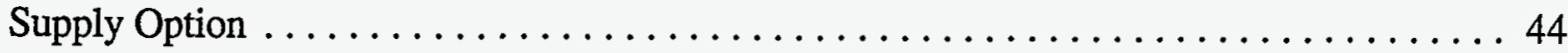

15 Impacts of Alternative 2-A: No Action Alternative/Steady Flow Supply Option

16 Impacts of Alternative 2-A: Peaking Alternative/Full Flexibility Supply Option . . . . . . 46

17 Impacts of Alternative 2-B: Peaking Alternative/Low Fluctuating Flow Supply Option

18 Impacts of Alternative 2C: Peaking Alternative/Steady Flow Supply Option . . . . . . 48

19 Impacts of Alternative 4-A: Low Capacity and Energy Alternative/Full Flexibility Supply Option

20 Impacts of Alternative 4-B: Low Capacity and Energy Alternative/Low Fluctuating

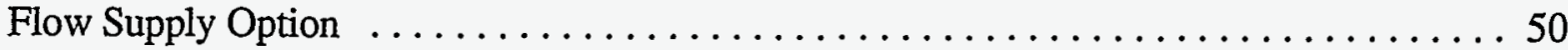

21 Impacts of Alternative 4-C: Low Capacity and Energy Alternative/Steady Flow

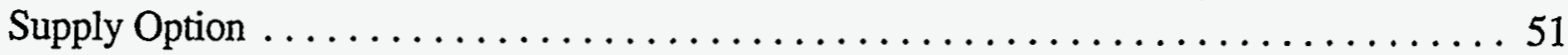

22 Impacts of Alternative 5-A: Baseload Aiternative/Full Flexibility Supply Option . . . . . . 52

23 Impacts of Alternative 5-B: Baseload Alternative/Low Fluctuating Flow

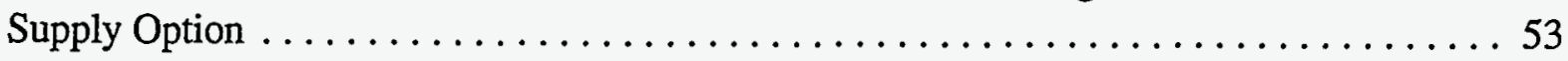

24 Impacts of Alternative 5-C: Baseload Alternative/Steady Flow Supply Option . . . . . . . 54

25 Regional Rate Impacts of the No Action Alternative $\ldots \ldots \ldots \ldots \ldots \ldots$

26 Regional Rate Impacts of Alternative 2 : Peaking $\ldots \ldots \ldots \ldots \ldots \ldots \ldots \ldots$ 


\section{FIGURES (Cont.)}

27 Regional Rate Impacts of Alternative 4: Low Capacity and Energy . . . . . . . . . . 59

28 Regional Rate Impacts of Alternative 5: Baseload $\ldots \ldots \ldots \ldots \ldots \ldots$

29 Demand Impacts of the No Action Alternative $\ldots \ldots \ldots \ldots \ldots \ldots \ldots \ldots \ldots \ldots$

30 Impacts on Demand for Electricity $\ldots \ldots \ldots \ldots \ldots \ldots \ldots \ldots \ldots \ldots \ldots \ldots \ldots \ldots \ldots \ldots$

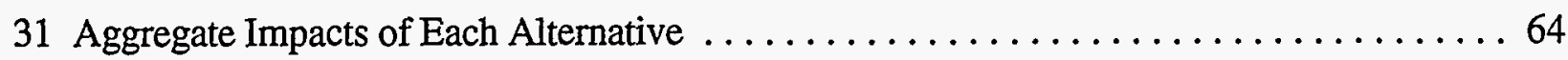

32 Percent Reliance for Representative Large System $1 \ldots \ldots \ldots \ldots \ldots \ldots$

33 Percent Reliance for Representative Small System $1 \ldots \ldots \ldots \ldots \ldots$

34 Average Rate Impacts over 25 -Year Period for Large Systems . . . . . . . . . . . . 69

35 Average Rate Impacts over $25-$ Year Period for Small Systems $\ldots \ldots \ldots \ldots \ldots \ldots$

36 Annual Rate Impacts over Time for Large Systems $\ldots \ldots \ldots \ldots \ldots \ldots \ldots \ldots \ldots$

37 Annual Rate Impacts over Time for Small Systems . . . . . . . . . . . . 72

38 Average Usage Impact over 25-Year Period for Small Systems . . . . . . . . . . . 74

39 Average Usage Impact over 25-Year Period for Large Systems . . . . . . . . . . . 75

40 Annual Index of Usage over Time for Small Systems $\ldots \ldots \ldots \ldots \ldots \ldots \ldots$

41 Annual Index of Usage over Time for Large Systems $\ldots \ldots \ldots \ldots \ldots \ldots \ldots \ldots$ 


\title{
IMPACTS OF WESTERN AREA POWER ADMINISTRATION'S \\ POWER MARKETING ALTERNATIVES ON \\ RETAIL ELECTRICITY RATES AND \\ UTILITY FINANCIAL VIABILITY
}

by

E. Bodmer, R.E. Fisher, and R.C. Hemphill

\begin{abstract}
Changes in power contract terms for customers of Western's Salt Lake City Area Office affect electricity rates for consumers of electric power in Arizona, Colorado, Nevada, New Mexico, Utah, and Wyoming. The impacts of electricity rate changes on consumers are studied by measuring impacts on the rates charged by individual utility systems, determining the average rates in regional areas, and conducting a detailed rate analysis of representative utility systems. The primary focus is an evaluation of the way retail electricity rates for Western's preference customers vary with alternative pricing and power quantity commitment terms under Western's long-term contracts to sell power (marketing programs). Retail rate impacts are emphasized because changes in the price of electricity are the most direct economic effect on businesses and residences arising from different Western contractual and operational policies. Retail rates are the mechanism by which changes in cost associated with Western's contract terms are imposed on ultimate consumers, and rate changes determine the dollar level of payments for electric power incurred by the affected consumers.
\end{abstract}

\section{SUMMARY}

\section{S.1 INTRODUCTION}

In 1988, the National Wildlife Federation and other groups filed a lawsuit against the Western Area Power Administration (Western) after Western proposed new contractual terms for sales of electric power to customers of its Salt Lake City Office. Because of the lawsuit, Western announced its intention to complete an environmental impact statement (EIS) to evaluate the manner in which it establishes terms for power contracts with its customers. This technical memorandum 
addresses the portion of the Western EIS that evaluates electricity price and financial viability impacts on Western's customers from alternative contractual terms.

Changes in power contract terms for customers of Western's Salt Lake City Office affect electricity rates for business and residential consumers of electric power in Arizona, Colorado, Nevada, New Mexico, Utah, and Wyoming. This technical memorandum discusses impacts on electricity rates for consumers in these states by measuring impacts on rates charged by individual utility systems, determining average rates in regional areas, and conducting detailed rate analyses of representative utility systems. The primary focus is an evaluation of the way retail electricity rates for Western's preference customers ${ }^{1}$ vary with alternative pricing and power quantity commitment terms in Western's long-term contracts to sell power. Retail rate impacts are emphasized because changes in the price of electricity are the most direct economic impacts on businesses and residences arising from different contractual and operational policies. Retail rates are the mechanism by which changes in cost associated with Western's contract terms are imposed on ultimate consumers, and rate changes determine the dollar level of payments for electric power incurred by consumers. ${ }^{2}$

Because retail rate impacts affect the level of disposable income that is available for purchasing goods and services (other than electric power) and because rates affect the costs of operating businesses, rate impacts influence the level of economic activity in the geographic region served by Western. Changes in Western's contract terms also have indirect impacts on the level of electricity consumption and the financial viability of utility systems. The demand for electric power changes with alternative Western contract terms because consumers of electricity adjust their use of electric power in response to price changes (based on price elasticity of demand). Furthermore, emerging competitive pressures in the electric utility industry may limit the flexibility that utility systems have in increasing rates for ultimate retail consumers. The financial viability of utility systems can therefore be affected by changes in Western's contract policies because changes in costs of service that are initially absorbed by the utility system may not be able to be passed on directly to retail consumers.

1 Preference customers are entities that are allocated a portion of Western's electric generating capacity in the Colorado River Storage Project. Customers with preference status are generally customer-owned cooperative systems, municipally owned systems, governmental entities, or nature environmental agencies. Investor-owned utilities do not have preference status.

2 The rate impacts presented in this report are derived from the same database as were the rate impacts presented in the preliminary draft environmental impact statement (PDEIS). However, the PDEIS segregated Western's customers according to classifications of high and low reliance. Because of space limitations in the PDEIS, only selected results were presented. In this report, however, we are able to present more complete information. Therefore, the presentation of data in this report differs from the presentation in the PDEIS, and the rate impact statistics are not the same. 


\section{S.2 DISTRIBUTION OF IMPACTS}

At a fundamental level, changes in Western's marketing programs involve allocation of resources to different constituencies. Resource allocation issues include distribution of the capacity of Western's electricity generation facilities to preference customers, allocation of delivered energy in different monthly and annual time periods, overall allocations of power committed to preference and nonpreference customers, and allocation of generating capacity based on the manner in which water is stored in reservoirs. Because of the importance of allocation considerations in the Western EIS, a basic objective of the rate and financial viability analysis is to address impacts of alternative marketing policies on different utility systems, in different geographic areas, in different time periods, and on different groups that provide financing to preference customers.

To evaluate the distribution of impacts from changes in Western's marketing programs, results of the rate analysis are arranged on the following bases:

- The distribution of retail rate impacts for alternative utility systems;

- The distribution of rate impacts by geographic area;

- The distribution of impacts on rates and usage over time resulting from the chosen marketing alternative for representative utility systems; and

- The impacts on the financial viability of utility systems.

\section{S.3 ANALYTICAL MODELS}

The analysis of rate impacts and financial viability is based on a series of analytical models of the (1) cost structures of utility systems that purchase power from Western, (2) financial conditions of the utilities that purchase power from Western, (3) present status of electricity rates of the utility systems that are Western's customers, and (4) status of Western's project repayment. A description of these models and the databases that were used is given in the finance portion of the technical research plan (Fisher and Bodmer 1993). All the analytical models directly incorporate changes in Western's contract terms, including allocation of seasonal capacity and energy from Western's electricity generating facilities, the prices Western charges its preference customers for reserving capacity and delivering energy, and the cost incurred by preference customers for replacing Western capacity and energy from alternative (non-Western) sources. 


\section{S.4 MAJOR FINDINGS OF THE ANALYSIS}

The major findings from the analysis of the way changes in Western's marketing programs affect retail rates and the financial viability of preference customers include the following:

- Retail rates for consumers of certain preference customers of Western could increase by as much as $70 \%$ relative to the socioeconomic baseline ${ }^{3}$ under power contract scenarios that incorporate restrictions on the physical operation of Western's hydroelectric facilities (restrictive supply options). (Retail rates are the prices paid by ultimate business and residential customers for the use of electricity, whereas wholesale rates are the prices charged by Western to utility systems that supply energy.)

- Retail rate impacts from changes in power contract terms for Western's preference customers when the operational conditions of the hydroelectric facilities are held constant range from decreases of $10 \%$ to increases of $40 \%$. The impact depends largely on the relative reliance of the utility system on Western to meet its power needs.

- For customers that rely on Western to meet more than $20 \%$ of their power needs, supply options that restrict Western's flexibility to use reservoirs in generating electricity increase retail rates by $5-20 \%$ compared with supply options that impose no physical limitations on the flexibility of dam operation. The restrictive supply options have the largest rate impact when combined with the no-action marketing alternative. The rate impacts of restrictive supply options are minimized for the peaking marketing alternative.

- The marketing alternative that has the most significant impact on retail rates relative to the baseline case is the one in which power contracts reduce capacity committed to customers by $48 \%$ and energy allocations remain approximately unchanged. In this alternative, referred to as the baseload marketing alternative, the weighted average retail impact is a $3 \%$ increase in rates, and the maximum impact is a 50\% increase without additional physical restrictions on dam operations. ${ }^{4}$ In cases where dam operations are restricted, the average impact is an $8 \%$ increase, the maximum impact is a $60 \%$ increase, and the aggregate annual dollar impact on electric bills is approximately $\$ 161$ million. The geographic area that is most significantly affected on an absolute basis is

3 The socioeconomic baseline case includes assumptions consistent with the contract terms that existed from February 1978 through April 1989 as well as full operational flexibility of the hydroelectric facilities.

4 The representative annual impacts referred to here apply to the year 2000. 
rural Utah, where consumers pay $\$ 40$ million more in electric bills on an annual basis and where rates increase by $20 \%$.

- The marketing alternative that has the second most significant impact is the one in which Western customers receive $43 \%$ of capacity commitment and $58 \%$ of the energy committed to the baseline case. In this marketing commitment alternative, referred to as the low-capacity, low-energy alternative; the average retail rate impact on preference customers is a $3 \%$ increase in the case in which dams are allowed maximum flexibility. In the scenario in which dam operation is restricted, the average rate impact of this alternative is a $6 \%$ increase, and the maximum impact is a 50\% increase. The geographic area that is most significantly affected by these contract terms on an absolute basis is rural Utah, where in the restrictive operational scenario aggregate bills increase by $\$ 40$ million and rates increase by $16 \%$.

- Different Western marketing alternatives affect utility systems in different ways. For example, in the no-action alternative, the area most affected on a percentage basis is urban Utah, and the area most affected on an absolute basis is urban Colorado. This result contrasts with the results for the low and baseload alternatives, in which the most affected area is rural Utah. Differences in the impacts arise because some utility systems are affected most by reduced long-term capacity commitments, others are affected most by changes in the amount of monthly and annual energy allocation, and still others are affected most by changes in wholesale power rates that are included in Western's power contracts.

- One of the key influences on the retail rates of Western's preference customers is the pricing in Western's wholesale power contracts (i.e., the rate paid by utility systems to Western). In cases without restrictions on the operation of hydroelectric facilities, Western's demand charge increases by as much as $\$ 4.20 / \mathrm{kW} \cdot \mathrm{mo}(113 \%)$ for the no-action alternative compared with the baseload marketing alternative. If the impact of reduced flexibility in dam operations is accounted for, Western's all-in wholesale rates (including energy and demand charges) increase by as much as $86 \%$.

- Because of price elasticity of demand, Western's marketing alternatives and dam operation options can have significant impacts on the demand for electricity. Demand is reduced by as much as $14 \%$ for utility systems under the baseload marketing alternative. 
- Marketing commitment alternatives can cause financial distress for certain municipal and cooperative systems that receive significant levels of capacity and energy from Western. The systems that are most significantly affected are relatively large systems that do not have much financial flexibility.

\section{S.5 OUTLINE OF REPORT}

The remainder of this technical memorandum is divided into four sections. Section 1 provides an overview of the marketing commitment alternatives, dam options, and utility systems that were modeled. Section 2 reviews some of the factors that influence the retail rate impacts of the marketing alternatives. Section 3 describes the impacts of changes in Western's marketing programs on rates and demand for electricity. Section 4 evaluates how the financial viability of certain of Western's preference customers is affected by different marketing alternatives. The finance portion of the technical research plan documents the modeling approach and the data used to compute the rate impacts (Fisher and Bodmer 1993). 


\section{OVERVIEW OF CLASSIFICATION OF UTILITY SYSTEMS, MARKETING ALTERNATIVES, AND GENERAL MODELING APPROACH}

In analyzing the retail rate impacts of Western's marketing programs, a voluminous amount of data has been generated through the creation of rate and financial simulation models of individual utility systems. Three distinct modeling techniques were used to project the rates of the different types of utility systems that purchase power directly from Western for 12 combinations of marketing commitment alternatives and dam operation options. In addition, rate calculations were made for retail utility systems that indirectly receive power from Western. Finally, regression based on interpolation analysis was used to evaluate the impacts of nine more combinations of marketing commitment alternatives and dam operation options.

Because of the large number of scenarios analyzed and the different modeling techniques applied, this section includes an overview of the classification of utility systems and marketing alternatives that have been evaluated. The following discussion provides a context for the analysis of the factors that drive the rate changes (described in Section 2) and the review of rate and usage impact results (described in Section 3). This section reviews (1) the structure of the electricity industry in the southwestern United States, (2) Western's marketing commitment alternatives and dam operation options, (3) the classification of utility systems for purposes of the retail rate impact study, and (4) methods of modeling different classes of Western customers.

\subsection{STRUCTURE OF THE ELECTRICITY INDUSTRY IN THE SOUTHWEST}

If all generation, transmission, and distribution facilities in the Southwest were owned by a single entity, the marginal transmission cost of serving all ultimate retail customers were zero, and all prices were set equal to marginal cost, retail rates would change based on physical operation of generating facilities, and Western's marketing policies would be irrelevant. However, in the real world, ownership of generating assets varies, different entities own transmission assets, physical limitations on transmission exist that limit all possible power flows, existing power contractual arrangements affect decision making and cost of service, and alternative financing mechanisms are used for different types of utility systems.

Differences in ownership of generating assets imply that different utility systems and retail customers have different stakes in Western's allocation of capacity and energy (for example, if a system has excess capacity, its position is very different from that of a company with deficient capacity). Ownership of transmission assets by alternative entities means that wheeling costs affect 
the delivered cost of power, whether or not there is any positive marginal cost of transmitting power. ${ }^{5}$ Physical limits on the transmission grid imply that it is not possible to move power from any generating facility to any retail customer. Finally, existing contractual obligations affect the way entities are affected by changes in the availability and cost of power from Western.

The objective of this analysis is to evaluate how actual electric retail rates are affected by changes in Western's contract terms. In measuring rate impacts, it is necessary to take account of existing institutional arrangements related to ownership of assets, contractual commitments, the location of generation and transmission facilities, rate-setting conventions, and financial structure. For example, for many utility systems that are customers of Western, the analysis measures the cost of replacing power that is no longer committed by Western on the basis of the terms of actual power contracts that are in place (alternative suppliers [see discussion of alternative contracts in Section 2]).

\subsection{CAPACITY AND ENERGY ALLOCATIONS}

\subsubsection{Marketing Commitment Alternatives}

Contracts between Western and its preference customers dictate the maximum amount of power that a preference customer can use at a single point in time (capacity or contract rate of delivery), the maximum amount of power that can be provided by Western over the course of a month (energy), and the pricing for capacity and energy. ${ }^{6}$ The key components of Western's contracts include long-term (15-year) commitments of allocated capacity and energy by season, demand charges (expressed in terms of dollars per kilowatt capacity per month $[\$ / \mathrm{kW} \cdot \mathrm{mo}]$ ), and energy charges (expressed as dollars per level of energy use [\$/MWh or mills/kWh]).

The rate impact and financial viability analysis is based on evaluation of seven different capacity and energy contract marketing commitment alternatives paired with three dam operation options (supply options) that represent physical operation of Colorado River Storage Project ${ }^{7}$ dams. $^{\text {. }}$ The seven marketing commitment alternatives evaluated include different variations of capacity and energy allocation to preference customers (Table 1). The aggregate quantities of power allocated to preference customers for each of the marketing commitment alternatives are described in Section 2.

5 The true marginal cost of transmission related to incremental bulk power contracts is zero because transmission capacity is a by-product of building the system for reliability.

6 Western's customers have flexibility in the manner in which energy is used subject to minimum restrictions, and capacity and energy are differentiated for the summer and winter.

7 The Colorado River Storage Project includes hydroelectric power from the Glen Canyon Dam (1,356 MW), the Flaming Gorge Dam (144 MW), the Blue Mesa Dam (96 MW), the Morrow Point Dam (46 MW), and other facilities (79 MW). 
TABLE 1 Aggregate Capacity and Energy Commitment Levels

\begin{tabular}{|c|c|c|c|c|}
\hline Alternative & Description & $\begin{array}{c}\text { Total } \\
\text { Capacity } \\
(\mathrm{MW})\end{array}$ & $\begin{array}{c}\text { Total } \\
\text { Energy } \\
(\mathrm{GWh})\end{array}$ & $\begin{array}{l}\text { Modeling } \\
\text { Method }\end{array}$ \\
\hline NA & No action & 1,291 & 5,700 & Direct \\
\hline 1 & High capacity, high energy & 1,449 & 6,156 & Regression \\
\hline 2 & $\begin{array}{l}\text { Peaking: high capacity, } \\
\text { low energy }\end{array}$ & 1,450 & 3,330 & Direct \\
\hline 3 & $\begin{array}{l}\text { Moderate capacity, } \\
\text { moderate energy }\end{array}$ & 1,225 & 4,000 & Regression \\
\hline 4 & Low capacity, low energy & 550 & 3,300 & Direct \\
\hline 5 & $\begin{array}{l}\text { Baseload: low capacity, } \\
\text { high energy }\end{array}$ & 625 & 5,475 & Direct \\
\hline 6 & $\begin{array}{l}\text { Moderate capacity, } \\
\text { moderate energy }\end{array}$ & 1,000 & 4,750 & Regression \\
\hline
\end{tabular}

Four alternatives were modeled directly by using financial and rate simulation models: the No Action (NA) Alternative, Alternative 2 (peaking, with high capacity and low energy allocation), Alternative 4 (low capacity and energy), and Alternative 5 (baseload, with low capacity and high energy). Alternative 1 (high capacity and energy) and Alternatives 3 and 6 (moderate capacity and energy) were evaluated by using regression-based interpolation techniques. The four marketing alternatives that were analyzed by simulation models include evaluation of the impacts on usage on the basis of the projected annual price of electricity by customer class. The regression analysis develops mathematical equations to predict the rate impacts for each utility system on the basis of power allocations and operational assumptions of the marketing contract commitment and dam operation option.

\subsubsection{Dam Operation (Supply) Options}

The amount of power Western commits to its preference customers does not necessarily correspond to the amount of energy and capacity produced by Western's hydroelectric generating facilities. However, once the physical operation of the dams is established, the amount of Western energy purchases and sales required to meet the contract energy and capacity commitment level is determined. Depending on the level of capacity and energy committed to preference customers in the 
power contract terms, Western must either sell excess energy to other utility systems, or it must purchase required capacity and energy to meet the commitment level.

Because of the relation between allocations of power commitments and operation of the hydroelectric facilities, three supply options were evaluated in addition to the marketing commitment alternatives. The supply options involve different assumptions about the way the dams operate in generating electric energy during a specified period. These assumptions dictate how quickly the generating turbines can ramp up to meet demand during peak time periods through the use of water stored at the reservoirs. The three dam operation (or supply) options are low flexibility (run-of-river, or steady flow), where no water is stored in reservoirs (i.e., water is continually released from the dams); moderate flexibility (low fluctuating flow); and full flexibility, where water is stored in reservoirs and dams operate at a wide range of release levels to match the load characteristics of Western customers.

The full-flexibility supply option consists of historical flows at the Glen Canyon Dam, yearround fluctuating flows at the Flaming Gorge Dam, and fluctuating flows at the Aspinall Unit. The moderate-flexibility (low fluctuating flow) supply option consists of hourly and daily ramp rate restrictions at the Glen Canyon Dam, year-round fluctuating flows at Flaming Gorge Dam, and fluctuating flows at the Aspinall Unit. The low-flexibility (steady flow) supply option consists of seasonally adjusted steady flows at Glen Canyon Dam, seasonally adjusted steady flows at Flaming Gorge Dam, and steady flows at the Aspinall Unit. ${ }^{8}$ Maximum capacity, energy, and load factors for the three dam operation options are summarized in Table 2.

TABLE 2 Capacity and Energy of Operational Alternatives ${ }^{\mathrm{a}}$

\begin{tabular}{clcccc}
\hline & & $\begin{array}{c}\text { Summer } \\
\text { Capacity } \\
\text { OpW) }\end{array}$ & $\begin{array}{c}\text { Winter } \\
\text { Capacity } \\
\text { (MW) }\end{array}$ & $\begin{array}{c}\text { Annual } \\
\text { Energy } \\
\text { (GWh) }\end{array}$ & $\begin{array}{c}\text { Summer Load } \\
\text { Factor (\%) }\end{array}$ \\
\hline A & Full flexibility & 1,550 & 1,475 & 6,346 & 47 \\
B & $\begin{array}{l}\text { Low fluctuating flow } \\
\text { (moderate flexibility) }\end{array}$ & 1,137 & 1,104 & 6,346 & 64 \\
C & Steady flow (low flexibility) & 613 & 522 & 6,436 & 100 \\
\hline
\end{tabular}

a These data are derived from Veselka et al. (1995).

8 The amount of energy generation also depends on the hydrologic conditions of the Colorado River. Less energy is produced in drought years than in years when there is a significant amount of rainfall. In measuring the way retail rates change with alternative marketing commitments in this task, we have assumed normal water flows. 
Seven marketing commitment alternatives and three supply options were paired; a total of $21(7 \times 3)$ combination marketing/operational alternatives were analyzed through simulation models and regression analysis. In Section 3, detailed results are presented for $12(4 \times 3)$ combinations of marketing alternatives and supply options.

\subsection{UTILITY SYSTEMS MODELED}

Although Western sells energy to both preference and nonpreference customers (nonpreference customers are primarily investor-owned utility companies), this analysis focuses on retail rate impacts on preference customers. Rates for energy sold to nonpreference customers are based on the assumptions that the market is one in which Western competes with other supply resources and power sales transactions are short term. Because of the nature of competitive wholesale electricity markets for short-term energy, alternative non-Western power can generally be purchased at the market clearing prices. This situation implies that changes in Western allocation do not have a significant impact on the ultimate retail rates of nonpreference utility systems that purchase Western's energy.

Western's preference customers range from irrigation districts to American Indian reservations to Air Force bases to various types of municipal and cooperatively owned utility systems that supply residential, commercial, and industrial customers. Municipal systems include cities ranging in size from the City of Colorado Springs (population 281,140) to the Town of Santa Clara (population 2,322 ) and also include associations of municipalities, such as the Utah Associated Municipal Power Systems. Cooperative systems include generation and transmission cooperatives such as the Tri-State Generation and Transmission Association and distribution cooperatives such as the Dixie Escalante Electric Cooperative.

For purposes of analyzing the impacts of marketing alternatives on retail rates, Western's preference customers have been classified into three general groups:

- End-use retail customers, which receive capacity and energy from Western. These customers are direct retail consumers that do not resell electricity or very small distribution utilities that do not report data to the Energy Information Administration (EIA). Examples of end-use retail consumers include Utah State University and Williams Air Force Base.

- Small utility systems, which provide electric power to retail consumers and also receive power directly from Western. Examples of small utility systems include the City of Holyoke and the Farmers Electric Cooperative. Most utilities within this category meet the majority of their energy requirements through purchases from Western as well as other sources rather than their own 
generation assets. These utility systems are generally relatively small in size, with annual revenues ranging from $\$ 100,000$ to $\$ 32,000,000$. The cost of producing electricity for the small utility is computed on the basis of actual historical costs, a database of alternative contract terms, and the cost of Western capacity and energy.

- Large utility systems, which purchase power from Western and often resell power to distribution utility systems rather than directly to retail consumers. These systems generally secure power from their own generating plants as well as from purchased power sources. Large utility systems include transmission and generation cooperatives, municipal joint action agencies, and large municipal systems. An example of a large utility system is the Utah Municipal Power Agency and its members, which include Manti City, Provo City Corp., Salem City Corp., Nephi City Corp., Spanish Fork City Corp., and the Town of Levan. Production costs for the large utility systems are based on projections developed by the Argonne National Laboratory (ANL) power systems models (Veselka et al. 1995).

Table 3 shows the classification of Western preference customers according to these criteria.

\subsection{MODELING METHODS}

\subsubsection{Modeling of Small Utility Systems}

Small utility systems purchase capacity and energy directly from Western (and other sources) and sell electricity to residential, commercial, and industrial consumers. These systems are generally municipal and cooperative utilities that are small in comparison to investor-owned utilities, generation and transmission cooperatives, and joint action agencies in the southwest region of the United States. Production costs for the small systems are computed from historical data and a database of contract prices available from alternative suppliers. Power systems modeling has not been performed for these systems. Retail rate projections for small systems are developed on the basis of forecasts of financial statements, energy sales, peak demand, nonproduction costs, and production costs for each system. Annual retail rate levels are computed by dividing the revenue required to meet a specified financial criterion by the level of retail sales and by allocating (on a proportional basis) changes in retail rates to alternative customer classes on the basis of the existing rate structure. 
TABLE 3 Classification of Western's Customers

\begin{tabular}{|c|c|c|}
\hline $\begin{array}{l}\text { End-Use Retail Customers } \\
\text { and Very Small Systems } \\
\end{array}$ & Small Systems & $\begin{array}{l}\text { Large Systems with } \\
\text { Indirect Systems They Supply }\end{array}$ \\
\hline $\begin{array}{l}\text { Arizona } \\
\text { None }\end{array}$ & $\begin{array}{l}\text { Lan } \\
\text { Safford }\end{array}$ & $\begin{array}{l}\text { Arizona Public Power Association: } \\
\text { Arizona Electric Power Cooperative } \\
\text { City of Mesa } \\
\text { Electrical District } 2 \\
\text { San Carlos Irrigation Project }\end{array}$ \\
\hline $\begin{array}{l}\text { Colorado } \\
\text { Central Valley Water } \\
\text { Conservation District }\end{array}$ & $\begin{array}{l}\text { City of Center } \\
\text { City of Holyoke } \\
\text { City of Fleming } \\
\text { Holyoke } \\
\text { Fort Morgan } \\
\text { Glenwood } \\
\text { Aspen } \\
\text { Gunnison } \\
\text { Delta } \\
\text { Yuma } \\
\text { Wray }\end{array}$ & $\begin{array}{l}\text { Tri-State Generation and Transmission Association: } \\
6 \text { member distribution cooperatives } \\
\text { Colorado-Ute Electric Association: } \\
14 \text { member distribution cooperatives } \\
\text { Colorado Springs Department of Public Utilities: } \\
\text { City of Estes Park } \\
\text { City of Fort Collins } \\
\text { City of Longmont } \\
\text { City of Loveland }\end{array}$ \\
\hline $\begin{array}{l}\text { New Mexico } \\
\text { University of New Mexico } \\
\text { Cannon Air Force Base } \\
\text { DOE-Albuquerque Operations } \\
\text { Office } \\
\text { Holloman Air Force Base } \\
\text { Sandia/Kirkland }\end{array}$ & $\begin{array}{l}\text { City of Aztec } \\
\text { Farmers Electric } \\
\text { Cooperative } \\
\text { City of Los Alamos } \\
\text { City of Lea } \\
\text { Raton } \\
\text { Truth or } \\
\text { Consequences } \\
\text { Aztec }\end{array}$ & $\begin{array}{l}\text { Plains Generating and Transmission: } \\
13 \text { distribution companies }\end{array}$ \\
\hline $\begin{array}{l}\text { Utah } \\
\text { Defense Depot Ogden } \\
\text { Hill Air Force Base } \\
\text { Toole Army Depot } \\
\text { University of Utah } \\
\text { Utah State University } \\
\text { Central Utah Water } \\
\text { Conservation District } \\
\text { Kanab } \\
\text { Washington }\end{array}$ & $\begin{array}{l}\text { Deseret } \\
\text { Dixie Escalante } \\
\text { Cooperative } \\
\text { City of Enterprise } \\
\text { Helper } \\
\text { Brigham } \\
\text { Price } \\
\text { Hurricane } \\
\text { Blanding }\end{array}$ & $\begin{array}{l}\text { Deseret Generating and Transmission Cooperative } \\
\text { Utah Municipal Power Agency: } \\
\text { Manti City } \\
\text { Salem City Corp. } \\
\text { Provo City Corp. } \\
\text { Nephi City Corp. } \\
\text { Spanish Fork City Corp. } \\
\text { Town of Levan } \\
\text { Utah Associated Municipal Power System: } \\
\text { Utah Municipalities }\end{array}$ \\
\hline $\begin{array}{l}\text { Wyoming } \\
\text { None }\end{array}$ & Torrington & $\begin{array}{l}\text { Wyoming Municipal Power Agency: } \\
\text { City of Cody } \\
\text { Fort Laramie } \\
\text { Guernsey } \\
\text { Lingle } \\
\text { Lusk } \\
\text { Powel } \\
\text { Wheatland }\end{array}$ \\
\hline
\end{tabular}


For small utility systems, the direct rate impact of a change in Western's wholesale contract terms can be represented in simple terms by the following formula:

$$
\begin{aligned}
\text { Rate Impact = } & \text { Change in Western Rate } \times \text { Baseline Western } \\
& \text { Capacity and Energy }+ \text { Change in Western } \\
& \text { Capacity and Energy } \times \text { Cost of Alternative Supply. }
\end{aligned}
$$

Significant information that provides the basis for developing forecasts of small utility systems includes the following databases:

- Retail revenues, energy sales, and cost of service from EIA Form 861, Rural Electrification Agency (REA) Form 7, and responses from ANL questionnaires to individual utility systems;

- Western's allocations of capacity and energy based on the marketing alternatives and supply option scenarios (the combination of Western's allocation and sales data allows computation of the weighted average reliance on Western power for each system);

- Western's wholesale power rates for capacity and energy based on repayment studies for each combination of contract commitment alternatives and supply scenarios;

- Projected pricing for energy and capacity that are available to individual utility systems from alternative sources;

- Historical cost of service and financial data to verify the consistency of historical rates with projections;

- Price elasticity coefficients by customer class; and

- Load projections (described in Morey and Ungson [1993]).

\subsubsection{Modeling of Large Utility Systems}

The modeling of large utility systems involves projecting costs of both the wholesale entities that receive power from Western (such as Tri-State Generation and Transmission Association and the Utah Associated Municipal Power System) and the retail distribution systems that purchase power 
from the wholesale utilities. ${ }^{9}$ To accomplish simultaneous modeling of the retail distribution systems and the wholesale systems, retail revenues and energy sales are aggregated for the distribution utilities that purchase from cach wholesale system. Costs for the distribution systems are then derived by comparing the cost of energy sold by the wholesale systems to the aggregated retail energy revenues of the retail systems. This procedure is illustrated in Figure 1.

The diagram illustrates that if Western's rates or commitment levels change, the production cost of the wholesale system changes, and power costs change on a proportional basis for each of the member distribution retail utility systems. For each of the large utility systems, the modeling involves development of historical and projected financial statements and integration of power costs from the power systems analysis (Veselka et al. 1995).

Modeling of rate impacts for large systems incorporates the seven databases for small systems described earlier as well as the following information derived from the power systems analysis:

- Annual capital expenditures and plant in-service amounts based on the timing and the cost of capacity additions from the optimal expansion path;

- The cost of nonfixed production-related operation and maintenance, the costs of non-Western purchase contracts, and the cost of fuel on an annual basis for each marketing commitment alternative; and

- Long- and short-run avoided costs (short-run costs are based on evaluating how variable costs change with changes in load, and long-run costs are based on the need for and cost of constructing new facilities on a levelized basis).

The modeling of both large and small systems was performed by using the Public Utility Planning System, which was developed by the authors. A description of the rate model and sample outputs is included in the finance portion of the technical research plan (Fisher and Bodmer 1993).

\subsubsection{Modeling of End-Use Customers}

Table 4 shows the customers that have been classified as end-use customers for purposes of the rate impact analysis. The amount of Western capacity and energy allocation represented by enduse customers is approximately $10 \%$ of Western's total allocation. This analysis is based on the rate impact formula given in Section 1.4.1.

9 Two large systems - Colorado Springs and Farmington — provide both wholesale and retail functions. 


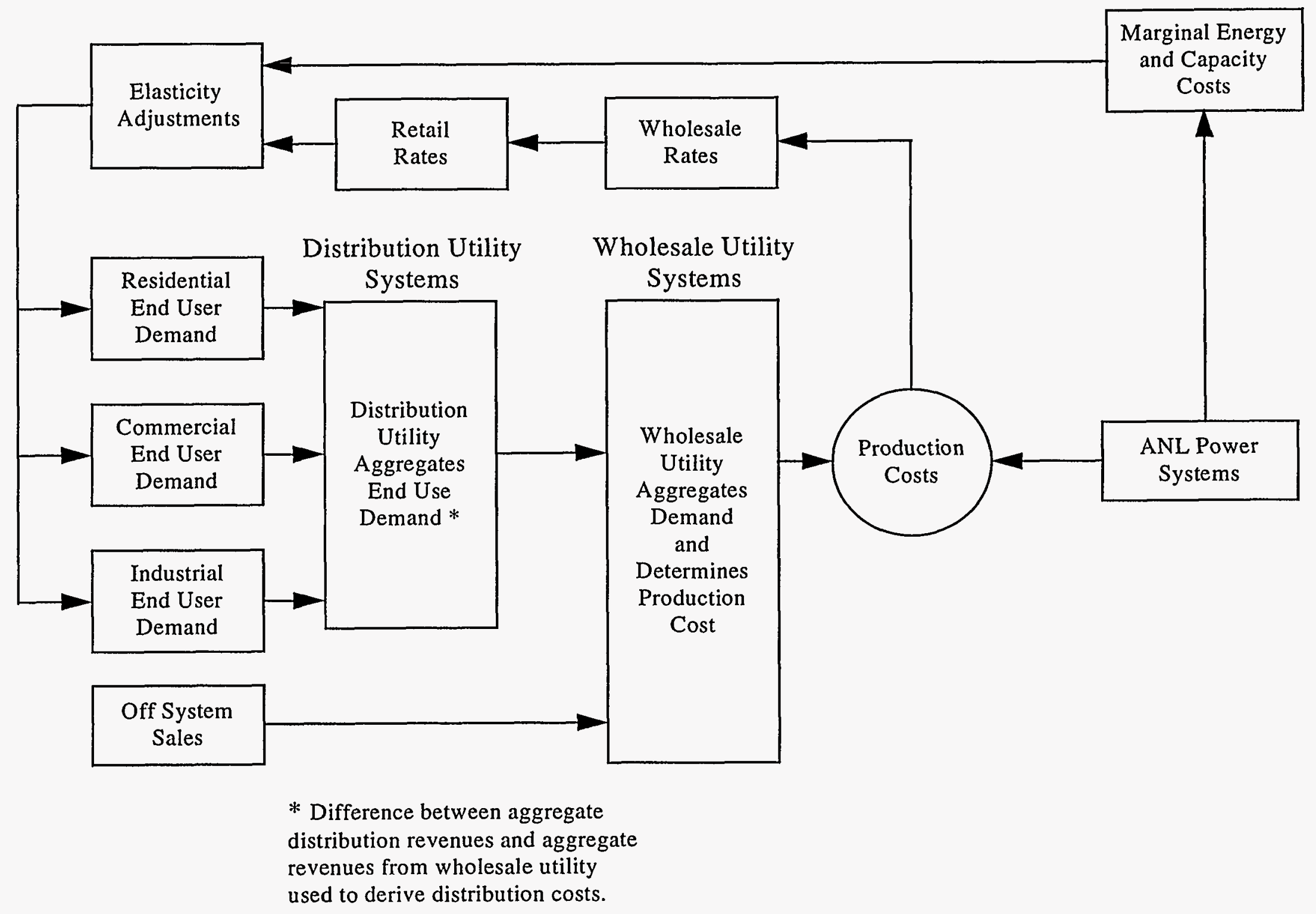

FIGURE 1 Simultaneous Modeling of Retail and Wholesale Systems 
TABLE 4 Western's End-Use Customers

\begin{tabular}{llcl}
\hline \multicolumn{1}{c}{ Arizona } & Colorado & New Mexico & Utah \\
\hline Chandler Heights & Colorado River & Cannon Air Force & Defense Depot Ogden \\
Electrical District 5-M & Commission & Base & Hill Air Force Base \\
Electrical District 7 & Colorado River & DOE-Albuquerque & Toole Army Depot \\
Ak-Chin & Irrigation and & Operations Office & University of Utah \\
Maricopa County No. 1 & Power & Holloman Air Force & Utah State University \\
Navajo Tribal & Frederick & Base & Central Utah Water \\
Ocotillo Water & Pueblo Army & Sandia/Kirkland & Conservation District \\
Conservation District & Depot & Central Valley & Kanab \\
Page & Willwood & Water Conserva- & Washington \\
Queen Creek Irrigation & & tion District & \\
District & & Gallup & \\
Roosevelt Irrigation & & & \\
District & & & \\
San Carlos Irrigation & & & \\
Project & & & \\
Williams Air Force Base & & & \\
Yuma Proving Grounds & & & \\
Roosevelt County & & & \\
\hline
\end{tabular}




\section{FACTORS THAT INFLUENCE THE RETAIL RATES CHARGED BY WESTERN'S CUSTOMERS}

This section analyzes the factors that cause retail rates charged by Western's preference customers to change. Determinants of rate impacts addressed in this section include the following:

- Western's commitments of capacity and energy in its power contracts;

- Western's prices for capacity and energy in its power contracts;

- Costs of energy and capacity from non-Western sources; and

- Other factors, including load growth and price elasticity.

\subsection{WESTERN'S POWER COMMITMENTS}

\subsubsection{Western's Capacity Commitment}

Because the cost of Western capacity for preference customers is substantially lower than the cost of capacity available from other sources, the amount of capacity that Western allocates to its preference customers is an important determinant of ultimate rate impacts. Figure 2 shows the capacity provided by Western in aggregate for the marketing commitment alternatives that were analyzed. ${ }^{10}$ Figure 2 demonstrates that Alternatives 1 and 2 have capacity levels above those of the No Action Alternative; Alternatives 4, 5, and 6 have commitments below those of the No Action Alternative; and Alternative 3 has capacity allocations similar to those of the No Action Alternative. The impact of differences in Western's capacity commitment on the cost of service for individual utility systems depends on the cost that utility systems incur to replace capacity. For example, utility systems that have surplus generating capacity will experience smaller rate impacts from loss of capacity than systems that incur significant demand charges to replace the lost Western capacity.

10 There are some cases in which the utility systems were municipalized after 1978 and therefore were not included in the 1978 criteria; an example is Aspen, Colorado. 


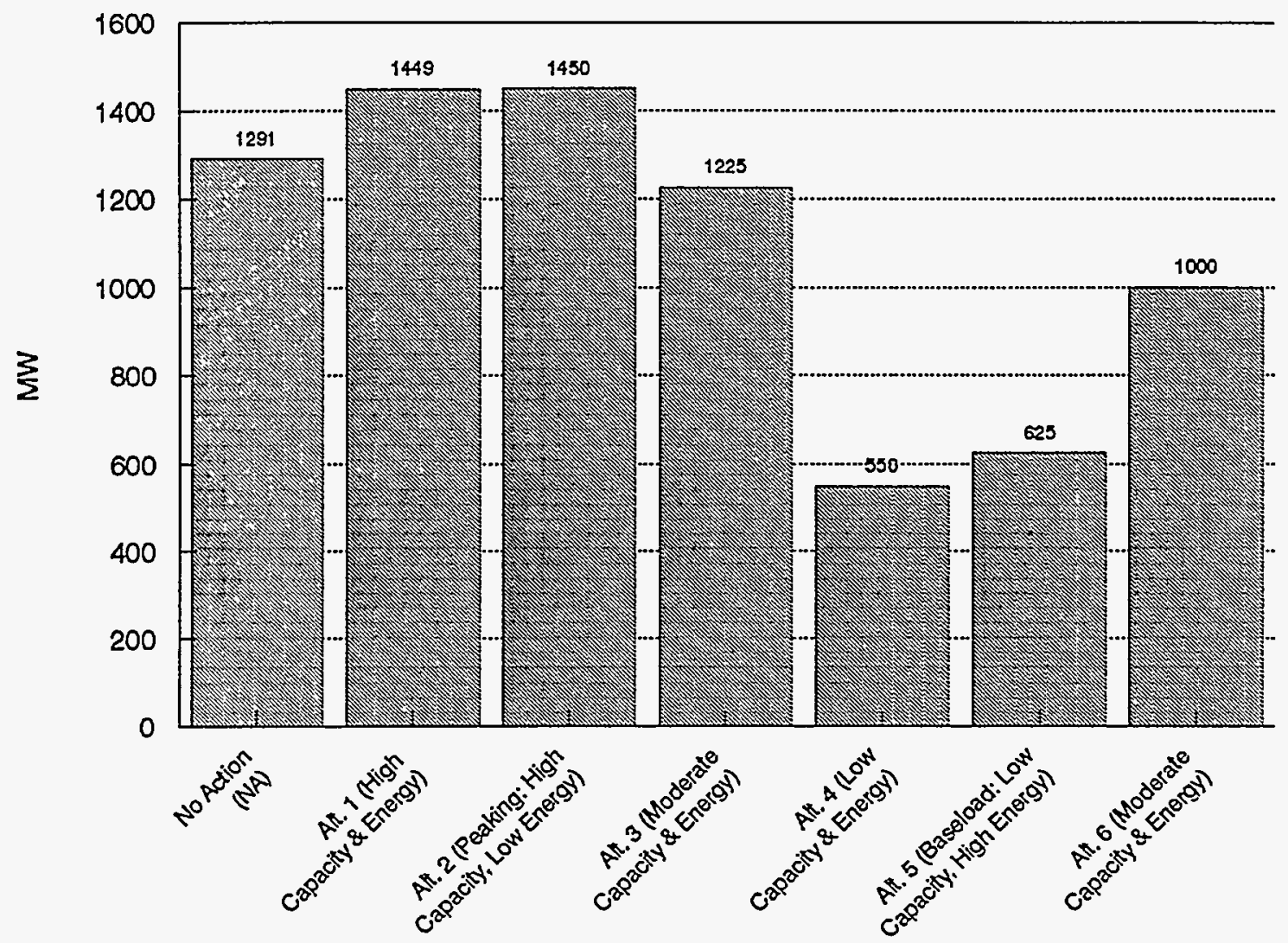

FIGURE 2 Western Aggregate Firm Capacity Allocations in Marketing Alternatives

\subsubsection{Western's Energy Commitment}

As is the case with the capacity that Western has committed to its firm preference customers, energy sold to Western's firm customers in its power contracts can be secured at costs that are substantially below that of energy that is provided from other suppliers. Figure 3 shows the aggregate energy committed to preference customers under the various marketing alternatives. The figure demonstrates that Alternative 1 provides more energy than the No Action Alternative, while the remaining five alternatives provide less energy. The impact of energy commitment changes on individual utility systems depends on the cost of replacing Western energy with energy from other sources.

\subsubsection{Western's Energy and Capacity Purchases and Sales}

The relationship between marketing commitments in long-term contracts and physical operations of Western's dams determines the amount of capacity or energy that Western will have to purchase from or sell to off-system utilities. The cost of energy and capacity purchases to Western 


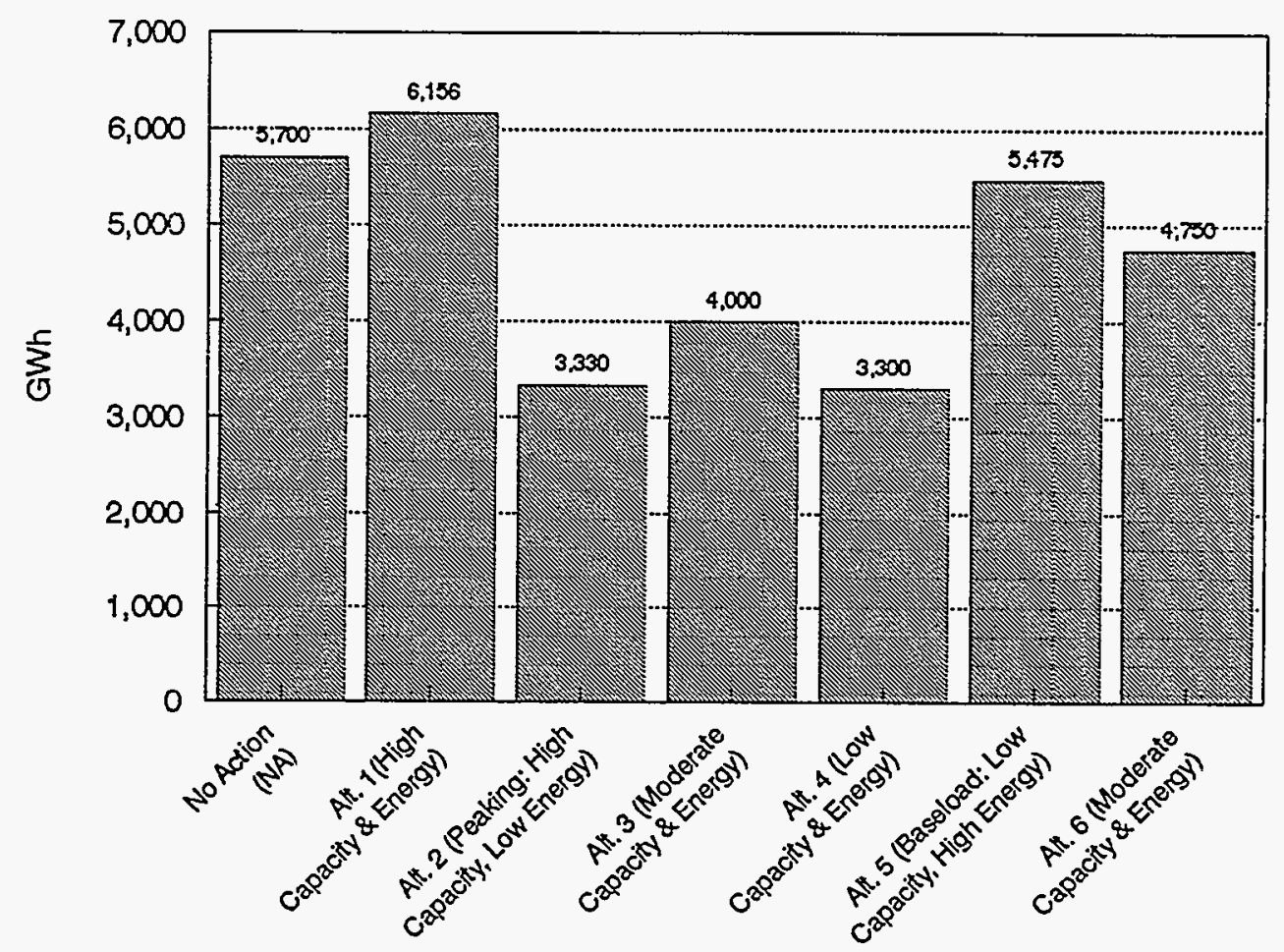

FIGURE 3 Western Aggregate Energy Allocation in Marketing Alternatives

and the price realized by Western for sales of excess energy are important determinants in computing Western's wholesale rates in the repayment study. Assumptions for the sales price realized by Western for excess sales and for the purchase cost incurred by Western for power were based on the Veselka et al. (1995) analysis and current wholesale market conditions that reflect surplus capacity. Figure 4 illustrates the energy sales and purchases and the capacity purchases from the various combinations of marketing commitment and supply option alternatives that were directly analyzed. This chart demonstrates that Alternatives 2 and 4 allow Western to make excess sales, while the No Action Alternative and Alternative 5 require Western to purchase capacity from off-system sources.

\subsubsection{Load Factor}

The relationship between capacity and energy is expressed in terms of load factor - the average hourly energy used or produced over a period of time divided by the maximum amount of energy used or produced during an hour in the period. The load factor inherent in Western's contract commitments is important in determining the relative impacts on individual utility systems. If the cost of replacement capacity (expressed in dollars per kilowatt per month as a demand charge) is expensive relative to replacement energy (expressed as an energy charge in dollars per megawatt-hour), customers will prefer a high load factor, all else being equal. If replacement energy is expensive 


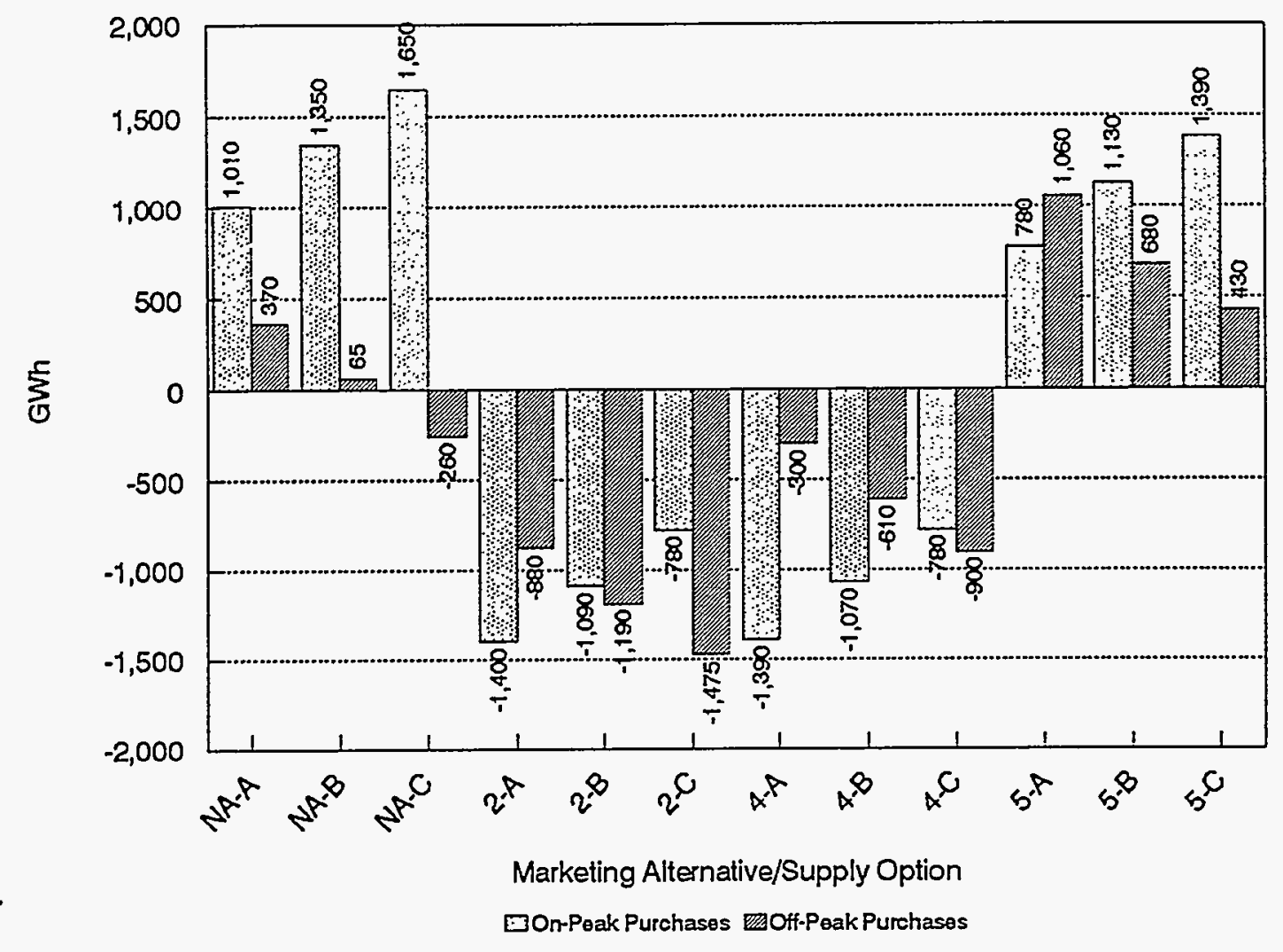

FIGURE 4 Western Purchases and Sales in Marketing Alternatives

relative to replacement capacity, a low Western load factor may be preferred. Figure 5 shows that Alternatives 1,2, and 3 have lower load factors than those of the baseline case (no action with full flexibility or NA-A), while Alternatives 4, 5, and 6 have higher load factors.

\subsection{WESTERN WHOLESALE POWER RATES}

The rates Western sets for capacity and energy must be sufficiently high to both cover Western's operating costs and repay capital costs incurred for constructing Western's generating and transmission facilities. By law, Western must set rates at the lowest possible level consistent with sound business principles. Western determines the rate level necessary to cover its costs by using a procedure referred to as a repayment sutyd. Since Western power is a component of cost of service for preference customers, the level of Western's wholesale rates obviously affects the ultimate retail rates for utility systems that receive capacity and energy from Western. As discussed earlier, Western's pricing in its contracts with preference customers includes both a reservation charge $(\$ / \mathrm{kW} / \mathrm{mo})$ for capacity and an energy charge $(\$ / \mathrm{MWh})$ for energy delivered. 


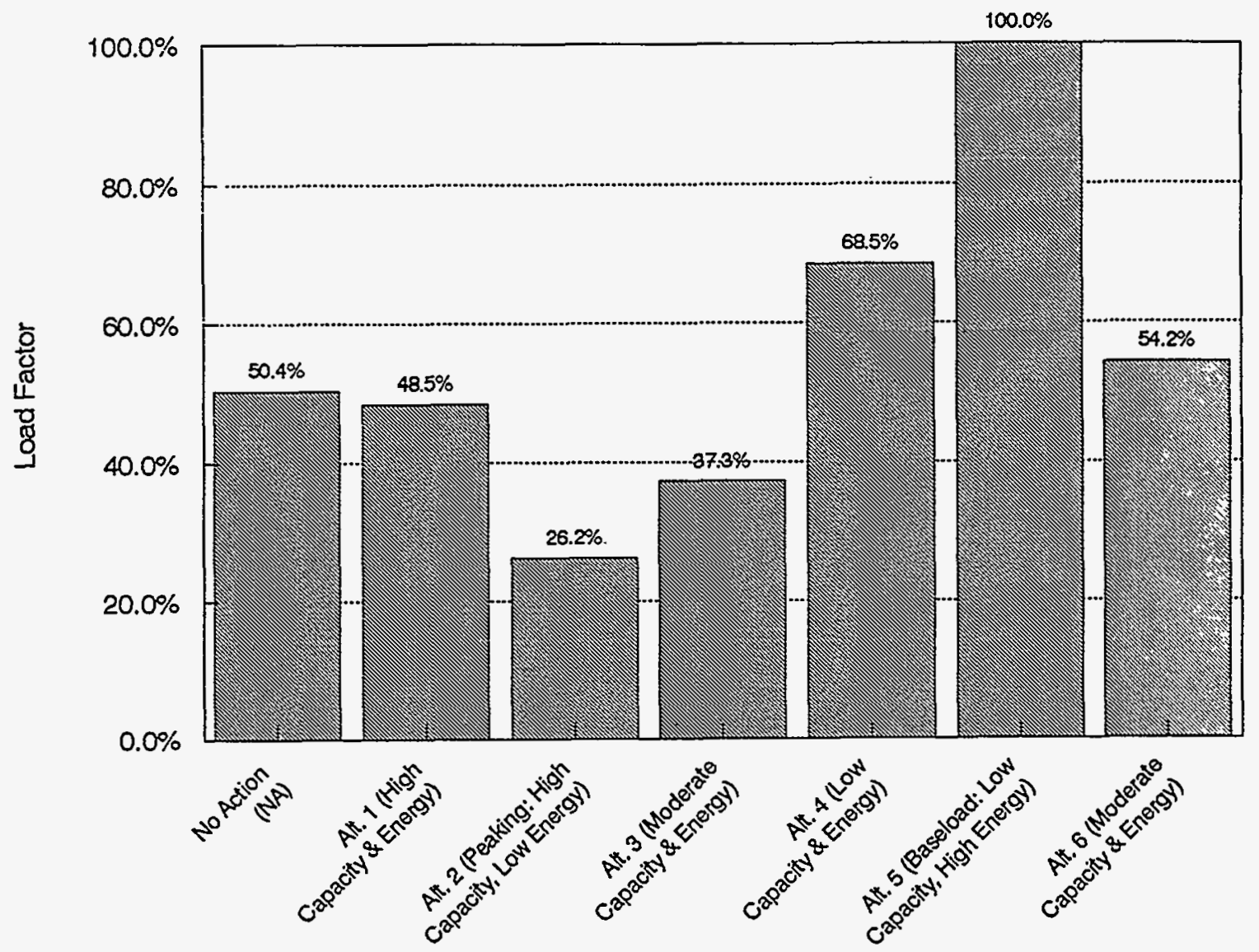

FIGURE 5 Western Aggregate Load Factor in Marketing Alternatives

Argonne National Laboratory has worked with Western in developing repayment studies associated with the different marketing and dam operation options (Bodmer and Fisher 1993). Key determinants of the study include the level of sales to firm customers, the revenues received from excess sales, the costs of firm capacity, the cost of operating and maintaining Western's facilities, and the cost of constructing the Western generating and transmission facilities. Western's rates are inflated on the basis of the relative amount of costs related to items with varying inflation, such as operation and maintenance expenses, and items that do not vary with inflation, such as interest costs.

Figure 6 shows the Western rates that result from the repayment studies under selected marketing commitment alternatives for the three different supply option scenarios. The rates shown in Figure 6 are computed on the basis of total required Western revenues to meet repayment obligations divided by total Western energy sales consistent with minimizing rates. In other words, the "all-in" rates shown in Figure 6 include both energy charges and demand charges divided by total energy commitment. The graphs show that all-in rates for capacity and energy are generally highest for the No Action Alternative and Alternative 5 (baseload) and lowest for Alternative 4 (low energy and capacity). 

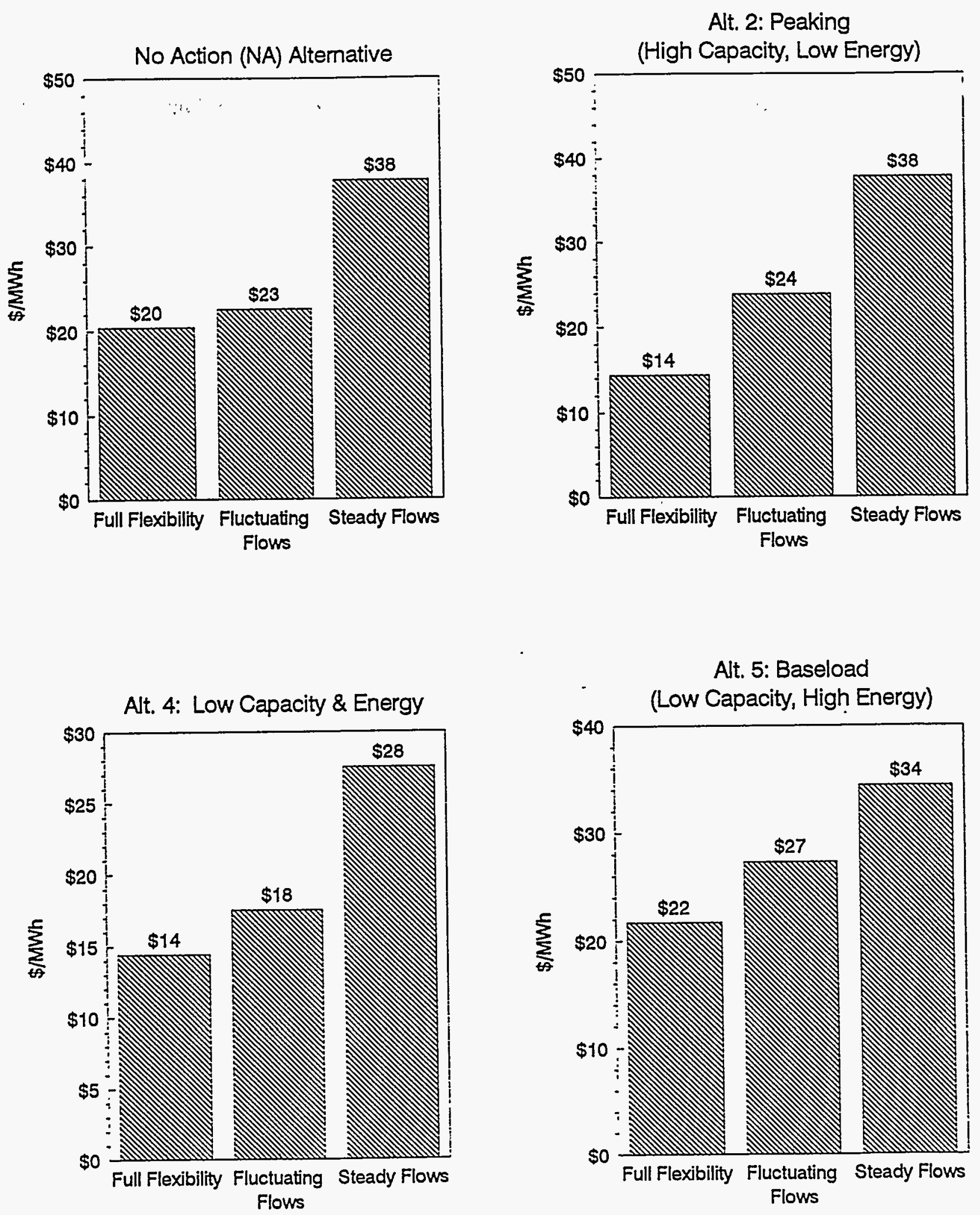

FIGURE 6 Western All-in Rates for Various Combinations of Marketing Alternatives and Supply Options 
Figure 7 is based on data similar to the data shown in Figure 6, except that percentages relative to the No Action Alternative with full flexibility (NA-A) and the No Action Alternative for each supply option are presented: for each combination of marketing alternative and supply option, the bar on the left is the percentage rate change relative to the No Action Alternative with full flexibility, and the bar on the right is the percentage change relative to the No Action Alternative with the same supply option as the alternative being compared. For example, the bar for the Alternative 5 (baseload) with steady flow shows percentages relative to the No Action Alternative with steady flow case. The chart shows that rates for the steady flow supply option are 35-86\% above those for the No Action Alternative with the full flexibility supply option. If the supply conditions are held constant, rate changes relative to the No Action Alternative with full flexibility vary from a decline of $30 \%$ for Alternative 4 (low capacity and energy) to an increase of $21 \%$ for Alternative 5 (baseload).

In modeling the impacts of marketing commitment alternatives, the average Western wholesale rates must be separated into demand charges and energy charges. In fact, comparison of average combined rates for demand and energy can be somewhat misleading because of differences in the capacity and energy that are sold under the different alternatives. For example, if two alternatives have the same overall revenue per kilowatt-hour, but one alternative commits a high level of capacity while another alternative commits a low level of capacity, the value to preference customers of the alternative with the high-capacity commitment is greater even though rates are the same. Specifically, the average rate for the peaking alternative is very different from the average rate for the baseload marketing alternative because the peaking alternative has a higher capacity value. Because there is far less energy in the peaking alternative and more capacity, the value in the peaking alternative is understated when average rates are compared.

To model rate impacts, the average wholesale rates are separated into demand charges and energy charges. The procedure used is to divide the overall rate by two and attribute one-half of the average rate to the energy charge and one-half to a demand charge. The demand charges are based on spreading the required revenue over the allocated capacity. Figure 8 shows the demand charges for the various marketing alternatives, and Figure 9 shows the energy charges based on this procedure. Because of the lower capacity allocated in the baseload alternative (Alternative 5), the demand charges are highest in this alternative. The high capacity allocated in the peaking alternative (Alternative 2) implies that demand charges are low in this case.

Figure 9 demonstrates that the energy charges are consistent with overall rates. Energy charges and demand charges are low in the low-capacity, low-energy alternative (Alternative 4) because Western does not have to purchase capacity and energy from off-system sources. 

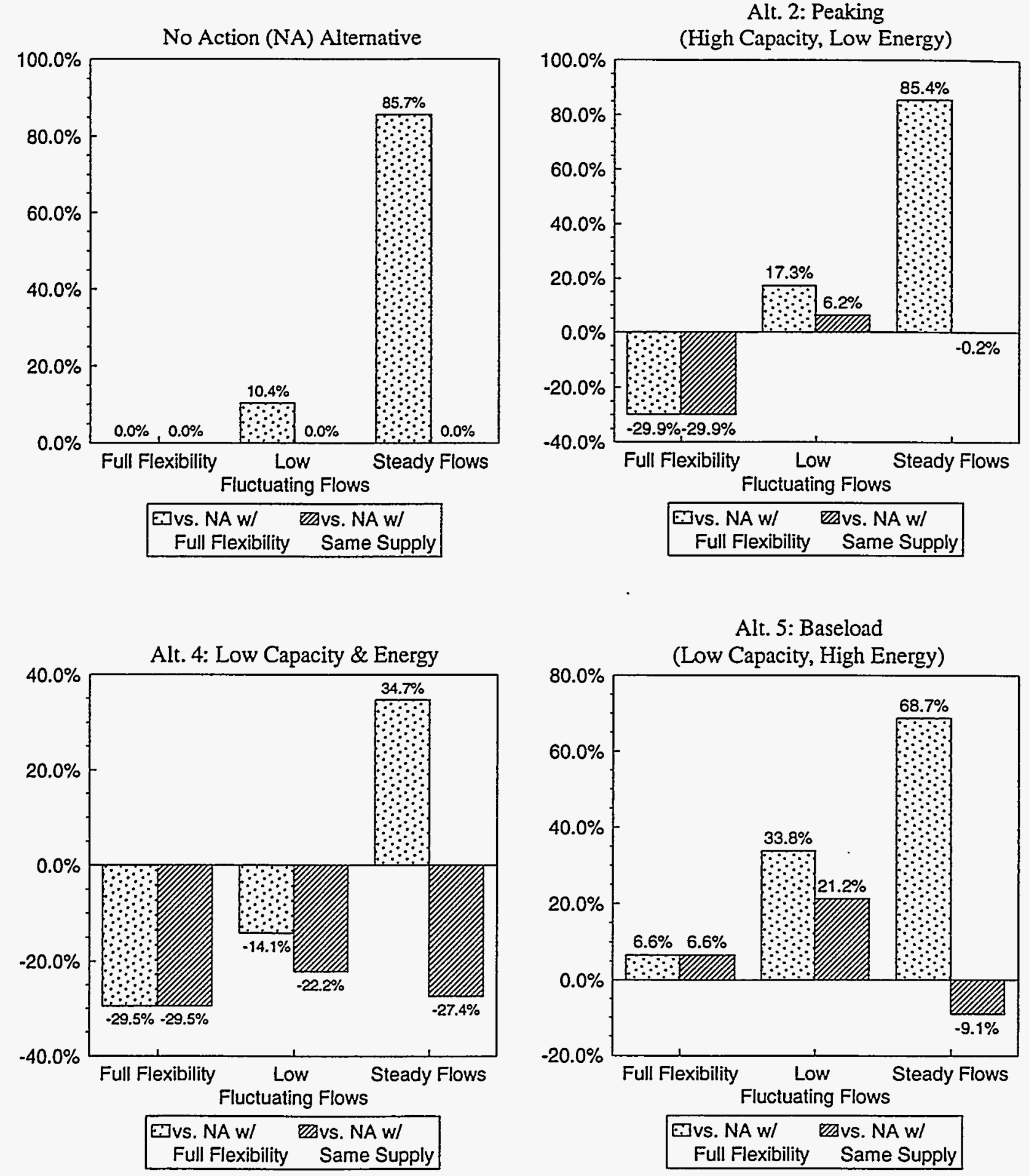

FIGURE 7 Percentage Change in Western All-in Rates for Combinations of Marketing Alternatives and Supply Options 

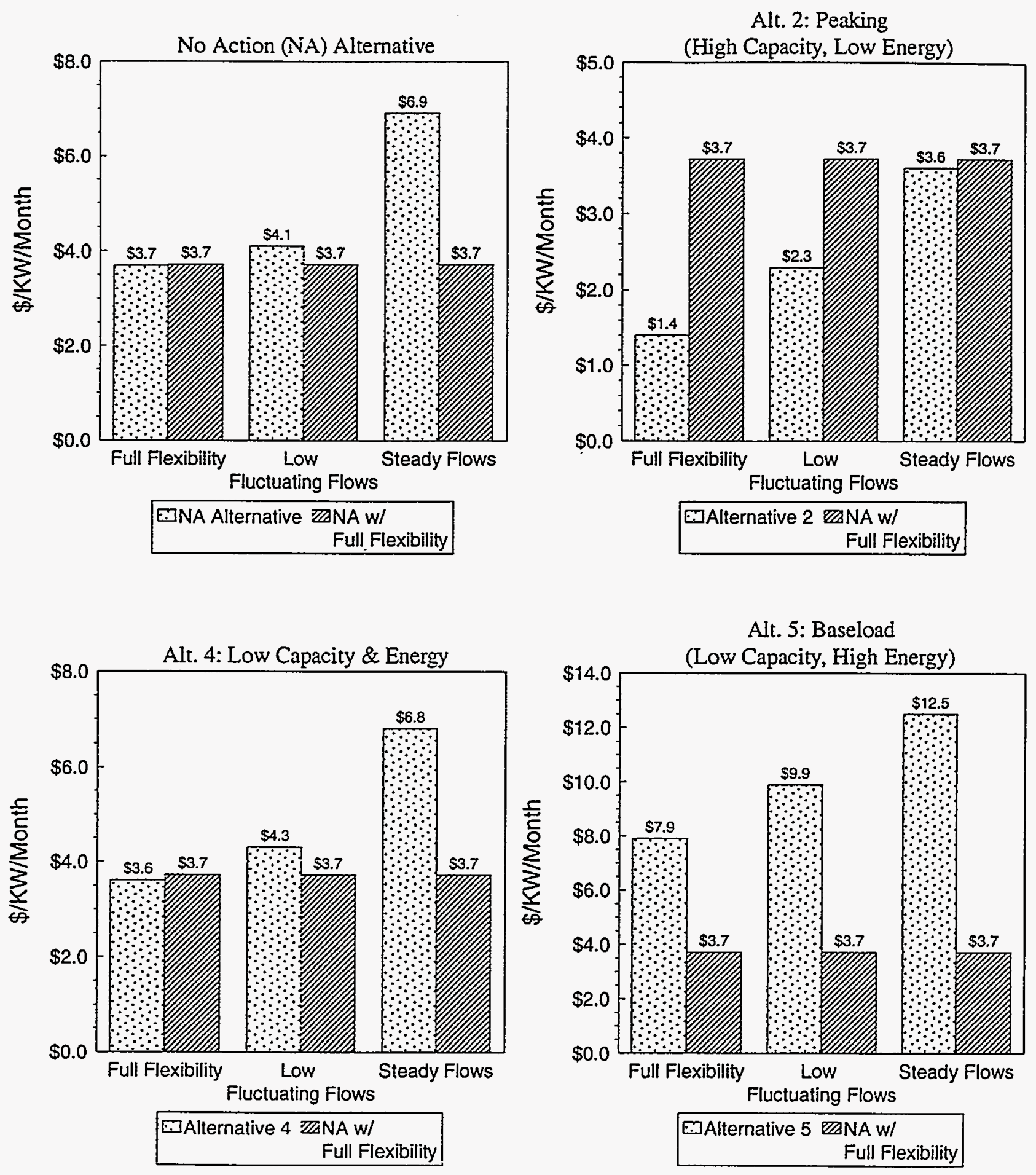

FIGURE 8 Western Demand Charges for Combinations of Marketing Alternatives and Supply Options 

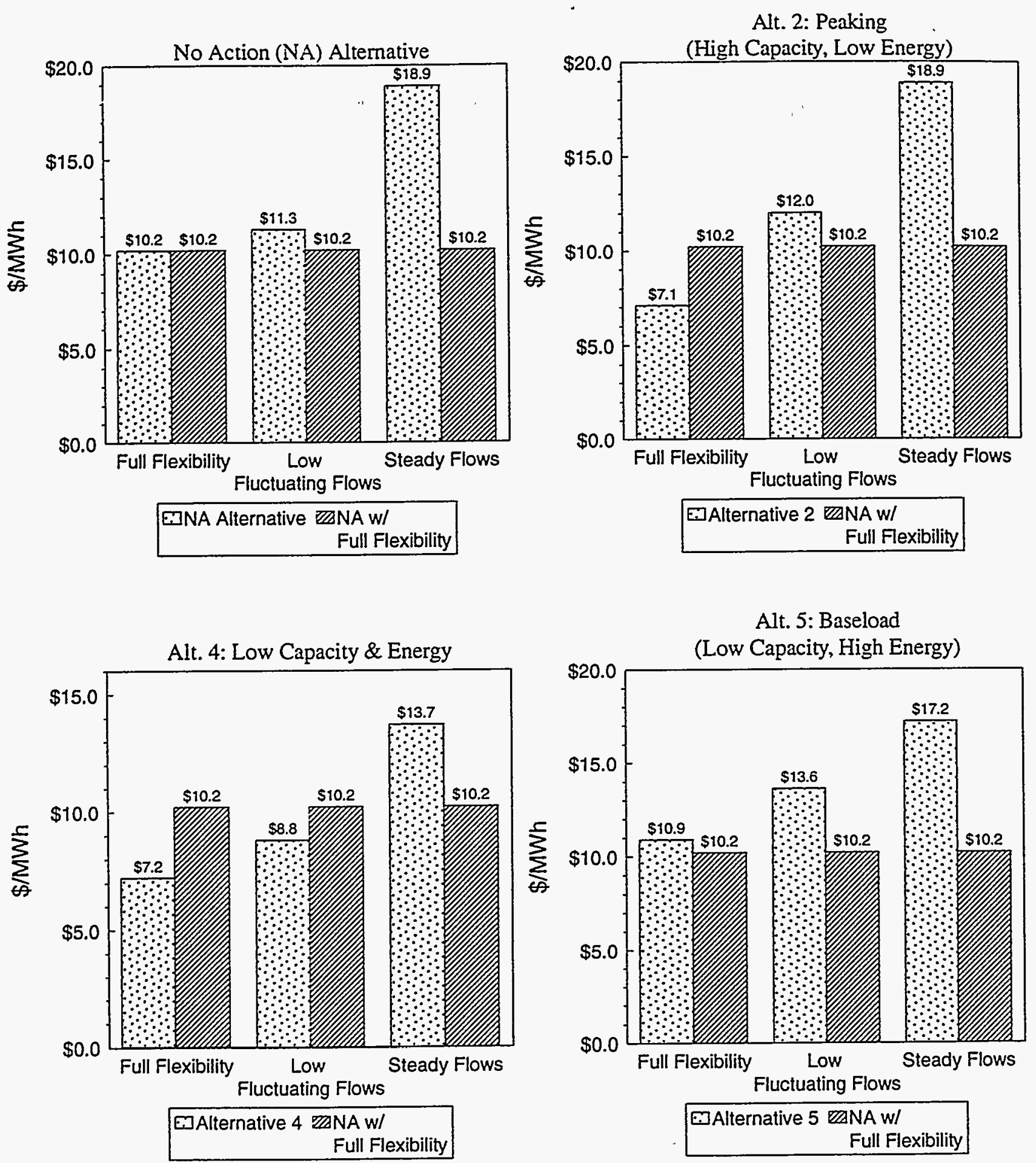

FIGURE 9 Western Energy Charges for Combinations of Marketing Alternatives and Supply Options 


\subsection{COST OF REPLACEMENT POWER}

The impacts on cost of service and retail rates on Western's preference customers from changes in allocations of energy and capacity are influenced by the costs of securing additional capacity or energy to replace power that is no longer provided by Western. In turn, the cost of replacing power varies for Western's preference customers, depending on the means by which utility systems secure incremental power resources and the existing capacity or contract status of the utility system in terms of its balance between supply and demand. This section reviews the methods used for quantifying the cost of replacing power for alternative utility systems.

Two basic approaches were developed to quantify the costs of replacing Western power for preference customers. The first method involves the use of information from power system models of the utility systems that purchase capacity and energy from Western. These power system models determine total production costs, short-run marginal costs, capacity expansion paths, and total capacity costs on a system-by-system basis. The second method uses information about existing contracts with suppliers of capacity and energy to project the cost of capacity and energy. ${ }^{11}$ Table 5 shows statistics on the way the two methods were used in measuring the cost of alternative power.

\subsubsection{Cost of Alternative Power: Method 1 - Power Systems Models}

The utilities classified as large systems use data from power systems models to determine the cost of replacement power. As described in Veselka et al. (1995), the power system models provide information on total energy generation, total fuel cost, total new capacity added, the cost of new capacity, and operation and maintenance expenses related to production of power.

The impact of changes in allocations of Western capacity and energy can be measured by the marginal cost of energy (short-run marginal cost) and the marginal cost of capacity. Figure 10

11 An issue has arisen as to whether alternative suppliers have monopolistic power over the small utility systems and therefore whether the prices that are set include transfers of wealth. The argument is that if prices of alternative suppliers reflect monopoly profits, rate impacts could be overstated in the sense that alternative power costs (and therefore utility system rate impacts) are above the overall societal impacts. However, we dispute the notion that alternative supplier rates include monopoly profits. Prices set above cost are not part of the database for the small utility systems. The contract cost of supply may be below marginal costs because of the Federal Energy Regulatory Commission policies that mandate that wholesale rates be capped at embedded cost in cases where market power can be exerted by the supplying utility.

The alternate supplier analysis is based on the best information available on contract costs (Onstad 1992). The objective is for projected rates to reflect reality and to involve transfers that understate societal impacts only in rare cases where the marginal cost is above embedded cost. In those cases, there are dollar transfers that flow away from the (investor-owned) supplying utility, and rate impacts on Western's preference customers would be increased by assuming full avoided cost. 
TABLE 5 Methods for Computing the Cost of Replacement Power

\begin{tabular}{lccc}
\hline & $\begin{array}{c}\text { Power Systems Models } \\
\text { Used To Quantify } \\
\text { Cost of Replacement } \\
\text { Power }\end{array}$ & $\begin{array}{c}\text { Database of Demand } \\
\text { Charges and Energy } \\
\text { Charges for Alternative } \\
\text { Suppliers }\end{array}$ & Total \\
\hline $\begin{array}{l}\text { Number of systems modeled that } \\
\text { directly receive Western power }\end{array}$ & 12 & 33 & 45 \\
Amount of Western capacity (MW) & 932 & 108 & 1,040 \\
Total load (MW) & 7,898 & 284 & 8,181 \\
\hline
\end{tabular}

shows the marginal cost of energy for large utility systems based on Veselka et al. (1995). This cost is computed by comparing the total production costs from two scenarios where the quantity of energy changes but the amount of capacity is similar.

Figure 10 shows that the large systems that are modeled have relatively low marginal energy costs, ranging from $\$ 14.00 / \mathrm{MWh}$ to $\$ 24.20 / \mathrm{MWh}$. These low marginal energy costs are based on the abundant amounts of baseload coal and hydroelectric capacity in the region. The following discussion from Standard and Poor's credit review of the cooperative utility industry (S\&P 1991, p. 16) illustrates the issue:

Plains' power supply comes primarily from its fully scrubbed 230 megawatt Plains Escalante Generating Station unit (60\%), and federally allocated power supplies (about 33\%). Favorable system operations and fuel supply contracts keep Plains' cost of production low at 20.4 mills per kilowatt hour $(\mathrm{kWh})$ and total costs at $53.3 \mathrm{mills} / \mathrm{kWh}$ in 1989.

The marginal capacity cost depends on the timing of the need for new capacity and its cost. In general, the new capacity is gas-fired combined cycle or combustion turbines. The timing of new capacity varies depending on the load and capacity status of the system. Some systems require capacity almost immediately and have a relatively high marginal capacity cost, while other systems do not need capacity for a number of years and have a low capacity cost. The low marginal capacity costs of systems with surplus capacity has important implications on the analysis. The following excerpt from S\&P (1991, p. 2) demonstrates how utility systems with surplus capacity may have a zero effective marginal capacity cost: 


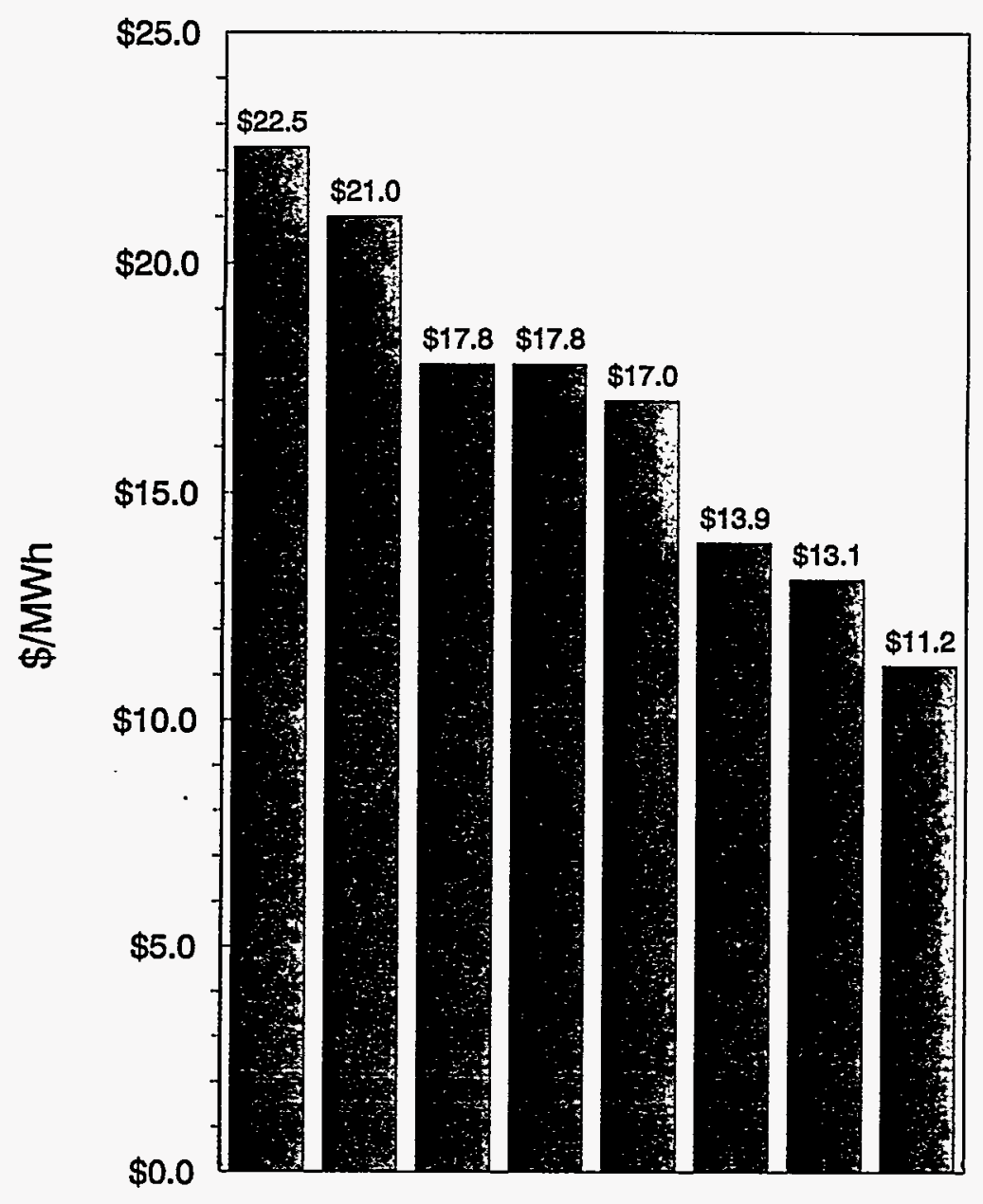

FIGURE 10 Marginal Cost of Energy for Large Systems

In many cases, generating units such as Deseret Generation \& Transmission Cooperative's Bonanza unit and Hoosier Energy Rural Electric Cooperative's Merom station were almost entirely surplus to the co-ops' own needs because rapid economic declines or significantly scaled-back load forecasts occurred following the commencement of construction. While Hoosier has mitigated the effects of its surplus capacity through a long-term block power sale to VEPCO, Deseret's surplus remains a carrying cost borne by its member systems, and the layoff of its power is dependent on the availability of transmission to bring the power to markets where it is needed.

The marginal cost of capacity and energy is used in modeling the impacts of price elasticity of demand. After the direct impact on energy usage and peak demand is evaluated on the basis of the direct price impact, the marginal costs are used to quantify the cost impacts of charges in energy and capacity costs associated with the demand changes. For example, if the marginal energy cost is 
\$20/MWh and the marginal capacity cost is zero, when demand is reduced because of price increases, the energy costs change by $\$ 20$ multiplied by the reduction in energy.

\subsubsection{Cost of Alternative Power: Method 2 - Power Contract Analysis}

For cases where power systems models have not been developed (i.e., the small systems), the cost of replacement power is derived by an analysis of the cost of power that can be purchased from alternative suppliers to Western. Each utility system is paired with an alternative supplier on the basis of transmission paths and existing contractual arrangements. The alternative supplier contract costs are derived from a survey of utility system contract terms prepared by the Colorado River Electricity Distributors Association ${ }^{12}$ and implicitly include both transmission reservation charges and energy costs.

The graph in the top left of Figure 11 shows the range in demand charges for alternative suppliers, and the one in the top right demonstrates the energy charges for the alternative suppliers (Western's rates are shown for comparative purposes). The bottom graphs illustrate the range of all-in combined energy and capacity rates ${ }^{13}$ for load factors of $50 \%$ and $65 \%$. The graph shows that all-in rates of alternative supply at a $65 \%$ load factor vary from $\$ 75 / \mathrm{MWh}$ to $\$ 32 / \mathrm{MWh}$. Since the Western wholesale rate is $\$ 15 / \mathrm{MWh}$, the loss of Western's energy and capacity allocation is obviously very significant for most systems.

\subsection{OTHER FACTORS}

A number of factors other than Western capacity and energy allocations, Western wholesale power rates, and the cost of replacement power influence the magnitude of retail rate impacts from changes in Western's power contract terms. These factors include the following:

- The rate of growth in demand for electric power,

- The price elasticity of demand by customer class,

- The proportion of sales to alternative customer classes,

- The relative level of fixed costs and variable cost for utility systems, and

- The financial criteria used to determine required revenues.

\footnotetext{
12 The costs of alternative contracts were derived from Onstad (1992).

13 All-in rates are based on a 730-h month, where the sum of energy payments and demand payments is divided by total energy usage.
} 
Demand Charges

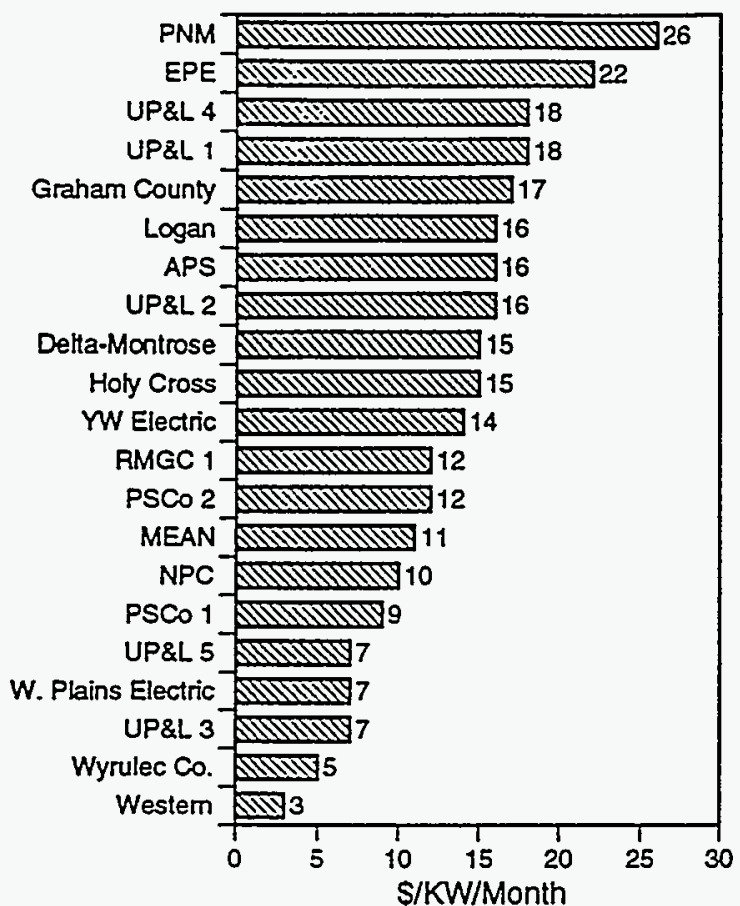

All-in Cost of Replacement Power $50 \%$ Load Factor

\begin{tabular}{|c|c|}
\hline PNM & 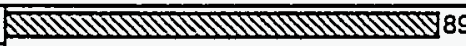 \\
\hline Graham County & 86 \\
\hline EPE & SUI 80 \\
\hline UP\&L 4 & 78 \\
\hline UP\&L 1 & 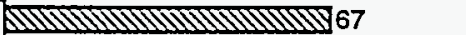 \\
\hline Logan & 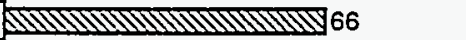 \\
\hline Delta-Montrose & 63 \\
\hline APS & 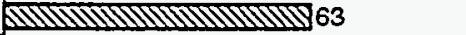 \\
\hline Holy Cross & Мापूบ 63 \\
\hline UP\&L 2 & S10 \\
\hline YW Electric & 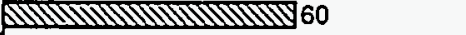 \\
\hline PSCO 1 & 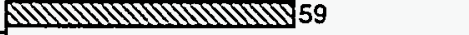 \\
\hline RMGC 1 & 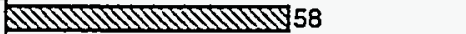 \\
\hline PSCO 2 & 5 \\
\hline NPC & 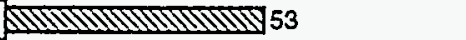 \\
\hline MEAN & 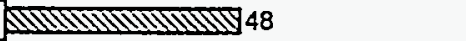 \\
\hline UP\&L 5 & 47 \\
\hline W. Plains Electric & 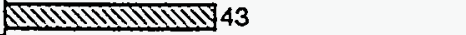 \\
\hline UP\&L 3 & МपМाओपण 36 \\
\hline Wyrulec Co. & 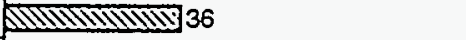 \\
\hline Westem & Мाप以ण 18 \\
\hline & $\frac{1}{20}$ \\
\hline & \$/MWh \\
\hline
\end{tabular}

Energy Charges

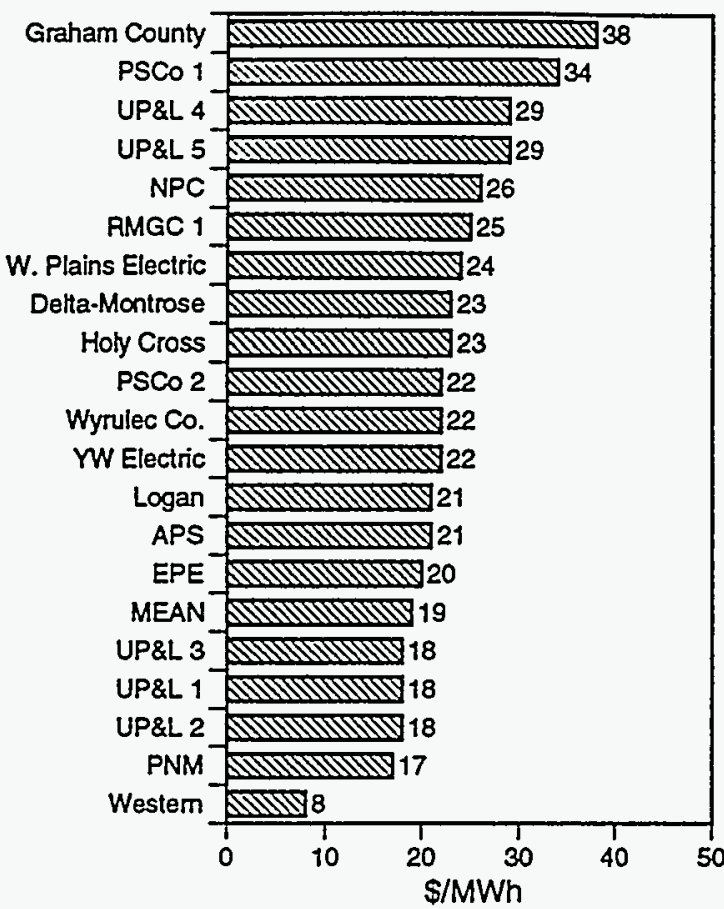

All-In Cost of Replacement Power $65 \%$ Load Factor

Graham County 75

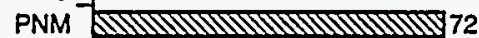

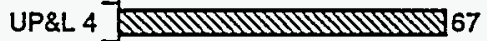

EPE 66

UP\&L 1 56

Logan 56

Delta-Montrose 54

APS MIIILIIIIIIII 54

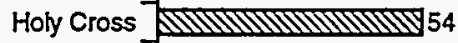

PSCO 1 53

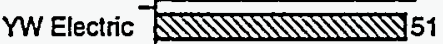

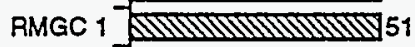

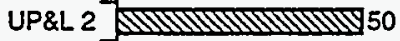

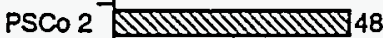

NPC - 47

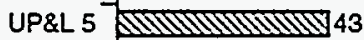

MEAN MIIILIIIIIU 41

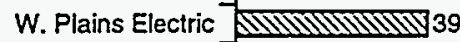

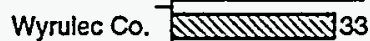

UP\&L 3 IIULIULUW 32

Western

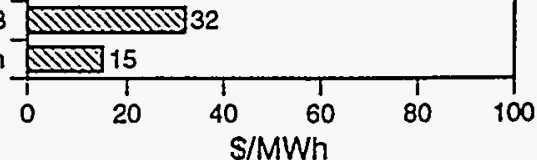

FIGURE 11 Power Costs for Alternative Suppliers 


\subsubsection{Growth in Demand for Electric Power}

The rate of demand growth for individual utility systems affects the impacts on rates from alternative marketing programs for preference customers because the percentage of reliance on Western over time varies with load growth and the cost of alternative power is influenced by growth rates in demand. For example, if the demand of a utility system grows at a fast rate, the percentage reliance on Western will diminish, but if load does not grow, the percentage reliance on Western remains constant. If the system currently has excess capacity, the load growth determines the point at which the system moves from surplus to deficit and requires new capacity. Variation in load growth for alternative systems is described in Morey and Ungson (1993).

\subsubsection{Price Elasticity of Demand by Customer Class}

For utility systems that receive Western power, changes in Western power contract terms represent changes in cost of service. The cost changes affect retail rates, and rate changes influence usage of electric power through the mechanism of price elasticity of demand. If price elasticity of demand is high, the cost of service changes has a large impact on electricity use; if price elasticity is low, there is a relatively low impact on use from cost changes. Changes in demand for electricity, in turn, create subsequent price increases because fixed costs must be recovered on the basis of lower energy sales. The impacts of alternative marketing programs on the level of sales are shown in Section 3.

As part of the EIS, ANL developed estimates of elasticity of demand for each utility system that serves retail consumers. Figure 12 shows the price elasticity of demand estimates for residential, commercial, and industrial customers of Western. For residential consumers, the elasticity varies from -0.19 to -0.70 , with a median value of -0.42 . For commercial customers, the range is from -0.11 to -0.80 , with a median of -0.48 . For industrial consumers, the range is from -0.17 to -1.00 , with a median value of -0.68 . A complete description of the econometric models used to compute the price elasticity figures is included in Morey and Ungson (1993).

\subsubsection{Relative Sales Proportions by Customer Class}

The customer class proportions of individual utility systems are important in evaluating the impacts of changes in Western's marketing programs for two reasons. First, the amount of energy sales and revenues realized by residential, commercial, and industrial retail consumers determines the expenditure impacts for purposes of the regional economic impact analysis. Second, given that the price elasticity of demand differs for different customer classes, the customer class proportions are important in determining the impacts of price elasticity on electricity use. 

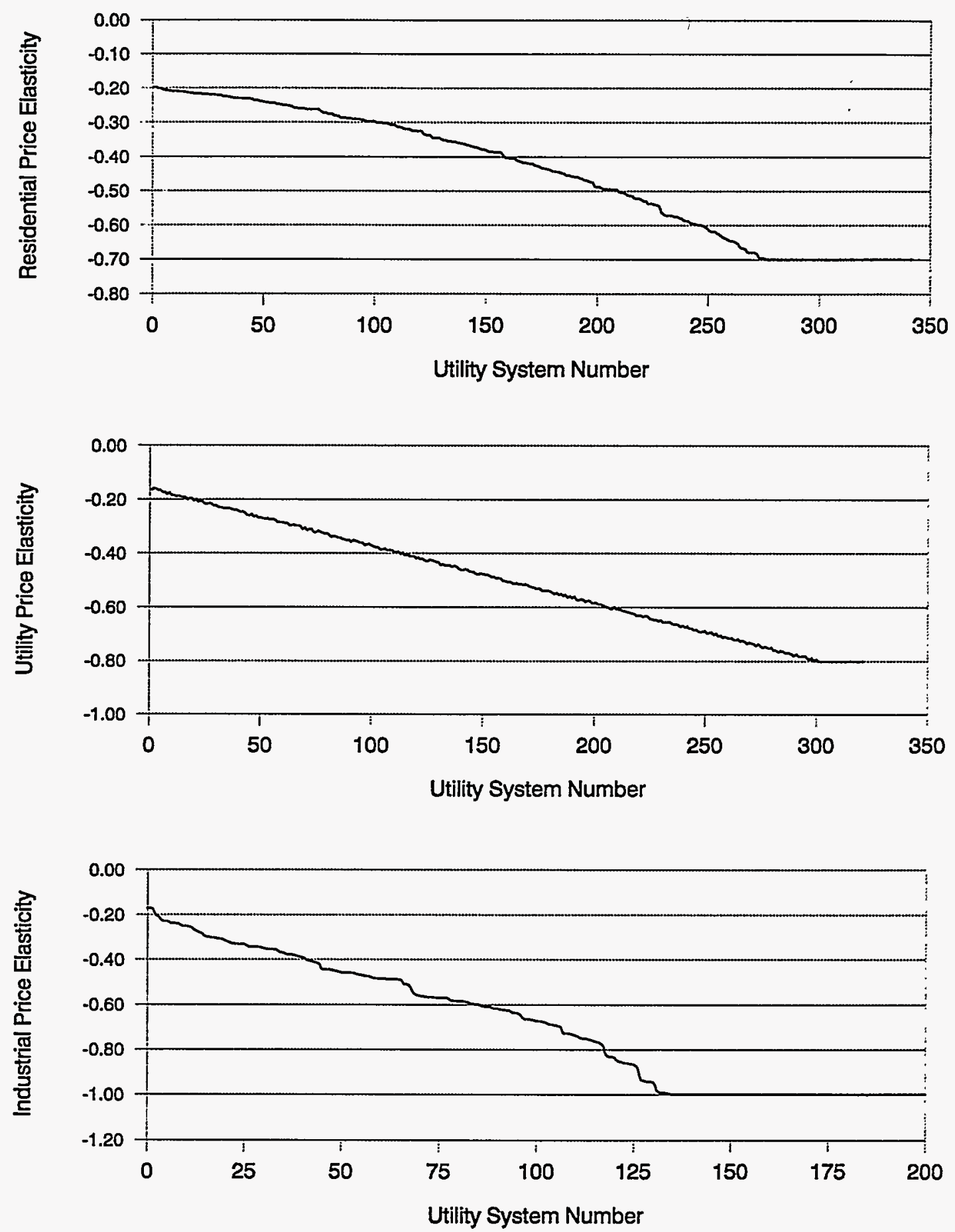

FIGURE 12 Price Elasticity of Demand 


\subsubsection{Level of Fixed and Variable Costs}

As stated earlier, the price elasticity of demand has a primary influence on electricity demand as well as a secondary influence, because price increases are required to cover fixed costs over a smaller base of energy sales. The magnitude of the price impacts depends on the relative level of fixed and variable costs at the utility system. If all costs are variable, and if marginal costs equal average costs, a reduction in sales will not result in a significant price change because variable costs will decline to offset the declines in energy sales. On the other hand, if costs are primarily fixed, reductions in energy demand imply that fixed costs must be recovered over a smaller base of sales and that rates must be increased to recover the fixed costs.

\subsubsection{Financial Criteria}

Financial criteria, such as the times interest earned ratio (TIER), rate of return, or level of net margin, are used to derive the amount of capital costs that are allocated over time to collect revenues. The financial criteria influence the level and timing of rates as well as the impact of marketing commitment alternatives on rates. When rates are limited to a maximum based on competitive criteria, the rate impacts of alternative marketing programs may be zero. 


\section{RETAIL RATE AND DEMAND IMPACTS ON UTILITY SYSTEMS, GEOGRAPHIC AREAS, AND REPRESENTATIVE SYSTEMS}

This section presents the impacts of alternative marketing programs on the retail rates of Western's preference customers. The distribution of retail rate and usage impacts is reviewed, the geographic impacts are summarized, and representative utility systems are discussed.

\subsection{SUMMARY OF RATE IMPACTS}

The impacts of changes in Western's power allocations are summarized according to alternative. The rate impacts discussed here are annual percentage impacts and annual impacts on electric bills in dollars for the year 2000. Subsequent sections describe the way these results were derived.

\subsubsection{No Action Alternative}

The No Action Alternative has been analyzed together with full flexibility (baseline case), low fluctuating flow, and steady flow operating assumptions. In the No Action Alternative combined with the low fluctuating flow operating assumption, retail rates increase by a maximum of $2.5 \%$ and an average of $1 \%$. In the No Action Alternative combined with the steady flow assumption, rates increase by an average of 5\% and a maximum of $20 \%$. The geographical area most affected by alternative supply options in the No Action Alternative on an absolute basis is urban Colorado, where bills increase by $\$ 33$ million annually. On a percentage basis, the area most heavily affected is urban Utah.

\subsubsection{Alternative 2: Peaking (High Capacity, Low Energy)}

Alternative 2 is based on Western capacity allocations that are similar to those of the No Action Alternative but with lower energy allocations. Because of reduced capacity commitments, Western's demand charges for Alternative 2 are below the rates for the No Action Alternative. In comparison with the No Action Alternative, assuming full operational flexibility, retail rates increase by an average of $0.3 \%$ and a maximum of $15 \%$. If dams are assumed to operate with low fluctuating flows, the average rate impact is $1.5 \%$; relative to the baseline case, the maximum impact is $20 \%$. If dams operate with steady flows, the average rate impact is $4 \%$ and the maximum impact is $30 \%$. In Alternative 2, the most heavily affected area on an absolute and a percentage basis is urban Utah, where the percentage impact is $10 \%$ and the absolute annual impact on electric bills is $\$ 38$ million. 


\subsubsection{Alternative 4: Low Capacity and Energy}

Alternative 4 is based on an allocation of capacity and energy that is below the No Action Alternative. The rates are 22-30\% lower than those in the No Action Alternative when the dam operation option is held constant. Under full flexibility conditions, retail rates that result from Alternative 4 average 3\% above those of the No Action Alternative, 5 small systems have a rate impact of more than $20 \%$, and 15 of the 45 systems modeled have a rate impact of more than $10 \%$. In the low fluctuating flow scenario, rates average 3\% above those of the baseline case, 6 systems have a rate impact of more than $20 \%$, and 15 systems have a rate impact of more than $10 \%$. In the steady flow scenario, the average rate impact is $6 \%$ above the baseline case, 10 systems have a rate impact of more than $20 \%$, and 18 systems have an impact of more than $10 \%$. For the low capacity and energy alternative, the area with the greatest relative and absolute impact is rural Utah, where the percentage rate impact is $23 \%$ and the bill impact is $\$ 45$ million per year.

\subsubsection{Alternative 5: Baseload (Low Capacity, High Energy)}

Alternative 5 includes energy commitments similar to those of the No Action Alternative, but the capacity allocations are reduced by $52 \%$. Western wholesale rates in this alternative are 6-70\% above those of the baseline case. If the dams are allowed to operate at full flexibility, average retail rates are $3 \%$ above those of the baseline case, 5 of the 45 systems modeled have a rate impact of more than $20 \%$, and 15 of the systems have an impact of more than $10 \%$. If the dams operate under the low fluctuating flow scenario, the average rate impact is $5 \%$ above the baseline case, 15 systems have a rate impact of more than $10 \%$, and 6 systems have an impact of more than $20 \%$. In the steady flow supply option, the average rate impact is $8 \%, 10$ systems have a rate impact of more than $20 \%$, and 18 systems have an impact of more than $10 \%$. For all supply scenarios, the geographic area most heavily affected on a relative and an absolute basis is rural Utah, where the percentage impact is $20 \%$ and the absolute bill impact is $\$ 41$ million per year.

Table 6 shows a summary of the impacts for each alternative for the steady flow supply option.

\subsubsection{Other Marketing Alternatives}

Alternative 1, with high capacity and energy, and Alternatives 3 and 6, which allocate somewhat lower levels of capacity and energy than the No Action Alternative, were modeled by regression techniques. The results from these alternatives are presented in the Western EIS. 


\section{TABLE 6 Impacts for the Steady Flow Supply Option}

\begin{tabular}{lcccc}
\hline $\begin{array}{c}\text { Marketing } \\
\text { Alternative }\end{array}$ & $\begin{array}{c}\text { Maximum } \\
\text { Impact } \\
(\%)\end{array}$ & $\begin{array}{c}\text { Average } \\
\text { Impact } \\
(\%)\end{array}$ & $\begin{array}{c}\text { Area with } \\
\text { Maximum } \\
\text { Impact }\end{array}$ & $\begin{array}{c}\text { Bill Increase } \\
\text { in Area with } \\
\text { Maximum } \\
\text { Impact }\left(\$ 10^{6}\right)\end{array}$ \\
No Action (NA) & 20 & 5 & Urban Colorado & 33 \\
2: Peaking & 30 & 4 & Urban Utah & 38 \\
4: Low capacity and energy & 60 & 6 & Rural Utah & 45 \\
5: Baseload & 70 & 8 & Rural Utah & 41 \\
\hline
\end{tabular}

Alternative 1 has impacts similar to the No Action Alternative. Alternatives 3 and 6 have impacts that lie between the other cases. ${ }^{14}$

\subsection{BASELINE CASE OVERVIEW}

The ultimate rate impact on utility systems that results from changes in the way Western allocates its power is affected by the cost and availability of alternative power, the pricing of Western energy and capacity, the responsiveness of demand to price changes, and various other factors described in Section 2. The percentage rate impacts also depend on the level of existing rates. For example, if a utility system has surplus baseload generating capacity and high retail rates, the rate impact in terms of percentage change in rates from reductions in Western capacity may be relatively small because of the low cost of alternative capacity and because of reductions in Western wholesale rates. On the other hand, if a utility system receives a high proportion of its energy requirements from Western and has low retail rates, it may experience significant percentage rate impacts from replacing Western capacity.

14 The regression analysis is based on a separate equation for each utility system for each supply option derived from the marketing alternatives modeled. The independent variables are the level of energy and capacity in the marketing alternative, and the dependent variable is the retail rate of the utility system in the supply option:

Retail Rate $_{\text {Year, Supply Option, Utility System }}=\mathbf{A}+\mathbf{B} \times$ Capacity $_{\text {Marketing Alt }}+\mathbf{C} \times$ Energy $_{\text {Marketing Alt. }}$

$A, B$, and $C$ are estimated by regression for each system for each supply option. Levels of energy and capacity are plugged into the equation to derive the rate impact. 
The range of impacts on retail rates and usage for different utility systems in the alternative marketing and operational scenarios is presented in this section. Before the range of impacts in terms of absolute and percentage changes is demonstrated, the baseline case is reviewed. Retail rates and retail electricity usage in the baseline case are illustrated on a system-by-system basis, and the relative reliance of utility systems on Western in meeting peak demand and energy requirements is demonstrated.

\subsubsection{Baseline Case Retail Rates}

Table 7 shows the retail rates of small and large utility systems sorted according to the 1993 estimated retail rate level. The retail rates shown in Table 7 are the weighted average revenue per kilowatt-hour for all retail customer classes. For large systems, the weighted average retail rates of all member distribution systems are presented. ${ }^{15}$ For example, in the case of the Tri-State Generation and Transmission Association, the retail rate is the weighted average retail rate of its 24 member systems. Retail rates range from $2 \phi / \mathrm{kWh}$ to $10 \phi / \mathrm{kWh}$. The median level retail rate is $7.1 \phi / \mathrm{kWh}$, and the average rate is $7.03 \phi / \mathrm{kWh}$. The irrigation districts have low rate levels because of low distribution costs and good load factors.

Retail rates must cover the total cost of service, including distribution costs and administration expenses, as well as the cost of producing bulk power, which includes generation and transmission costs. Although retail rates of utility systems must cover costs in addition to bulk power costs, the low cost of Western's wholesale power is demonstrated in Table 7. In 1990, the average cost of Western power to its firm customers including demand and energy charges ${ }^{16}$ was only $1.29 \phi / \mathrm{kWh}$. Western's all-in rate compares with the running cost of a coal plant (not including fixed capital costs), which ranges from $1.3 \phi / \mathrm{kWh}$ to $2.5 \phi / \mathrm{kWh}$, and the running cost of a natural gas plant, which ranges from $2.2 \phi / \mathrm{kWh}$ to $4.0 \phi / \mathrm{kWh}$. Since the Western wholesale power rates include charges for both capacity and energy, it is generally advantageous for utility systems to use as much power from Western as possible.

15 Retail rates of individual retail members vary. Retail rate impacts on individual systems are accounted for by using a procedure that allocates the impacts for the large system to the individual distribution utility. Since the wholesale rate changes are generally identical for each member of the wholesale system, the distributional impacts do not differentiate members in this section of the analysis.

16 This calculation is based on a demand charge of $\$ 3.44 / \mathrm{kW} / \mathrm{mo}$, an energy charge of $\$ 3.44 / \mathrm{MWh}$, and a load factor of $50 \%$. 
TABLE 7 Baseline Case Retail Rates and Sales for Systems Receiving Power from Western

\begin{tabular}{|c|c|c|}
\hline Utility System & $\begin{array}{l}\text { Retail Rates } \\
\text { (mills/kWh) }\end{array}$ & $\begin{array}{l}\text { Retail Sales } \\
\text { (GWh) }\end{array}$ \\
\hline \multicolumn{3}{|l|}{ Small Systcms } \\
\hline Lamar & 105.85 & 58.36 \\
\hline City of Truth or Consequences & 102.55 & 37.41 \\
\hline City of Safford & 102.54 & 41.92 \\
\hline Delta & 93.60 & 31.87 \\
\hline Farmers Electric Cooperative & 89.90 & 531.94 \\
\hline Town of Thatcher & 89.65 & 9.92 \\
\hline Helper & 85.03 & 11.29 \\
\hline Aspen & 82.82 & 55.14 \\
\hline City of Fleming & 81.40 & 1.73 \\
\hline Gunnison & 81.00 & 51.75 \\
\hline Wray & 79.30 & 15.30 \\
\hline Haxton & 76.51 & 5.31 \\
\hline Yuma & 75.53 & 17.16 \\
\hline Price & 75.42 & 53.84 \\
\hline Glenwood Springs & 71.41 & 76.73 \\
\hline Brigham City & 71.32 & 83.46 \\
\hline City of Raton & 71.06 & 47.75 \\
\hline City of Enterprise & 70.27 & 5.49 \\
\hline Aztec & 66.00 & 23.76 \\
\hline Oak Creek & 65.42 & 3.72 \\
\hline Electric District Number Six (Pinal) & 65.06 & 93.68 \\
\hline City of Center & 63.40 & 10.29 \\
\hline City of Los Alamos & 61.45 & 507.23 \\
\hline Dixie Escalante Cooperative & 61.79 & 115.72 \\
\hline Hurricane & 58.50 & 25.83 \\
\hline Blanding & 57.58 & 18.04 \\
\hline City of Lea & 54.93 & 684.05 \\
\hline Holyoke & 48.11 & 115.72 \\
\hline Torrington & 46.94 & 66.08 \\
\hline Fort Morgan & 43.59 & 102.66 \\
\hline Electric District Number Three (Pinal) & 38.28 & 117.48 \\
\hline Electric District Number Five (Maricopa) & 31.61 & 42.83 \\
\hline $\begin{array}{l}\text { Electric District Number Four (Pinal) } \\
\text { Salt River Project }\end{array}$ & 21.00 & 70.46 \\
\hline
\end{tabular}




\begin{tabular}{lrr}
\hline \multicolumn{1}{c}{ Utility System } & $\begin{array}{r}\text { Retail Rates } \\
\text { (mills/kWh) }\end{array}$ & $\begin{array}{c}\text { Retail Sales } \\
\text { (GWh) }\end{array}$ \\
\hline & & \\
Large Systems & & \\
Colorado-Ute Electric Association & 87.55 & $3,749.82$ \\
Plains Generating and Transmission & 86.93 & $1,916.32$ \\
Farmington & 84.17 & 475.42 \\
Wyoming Municipal Power Agency & 72.72 & 111.84 \\
Utah Associated Municipal Power System & 72.49 & $1,403.09$ \\
& & \\
Deseret Generating and Transmission Cooperative & 69.52 & $1,378.39$ \\
Platte River Power Authority & 69.46 & $1,609.98$ \\
Utah Municipal Power Agency & 68.29 & 592.45 \\
Arizona Public Power Agency & 66.69 & $2,066.76$ \\
Tri-State Generation and Transmission Association & 65.41 & $3,774.68$ \\
Colorado Springs & 51.71 & $3,099.51$ \\
\hline
\end{tabular}

\subsubsection{Baseline Case Retail Sales}

Table 7 shows the range of retail sales for large and small utility systems that receive direct power allocations from Western. For the large systems, the data reflect the accumulation of sales for figure for the Tri-State Generation and Transmission Association is the accumulated retail sales for retail systems that purchase all of their energy from the wholesale (large) system. For example, the 24 member distribution systems. Table 7 demonstrates that annual retail sales of systems that receive power allocations range from 3,774,000 MWh (Tri-State) to 1,729 MWh for the City of Fleming. The large systems have substantially higher levels of sales than the small systems in aggregate and on a utility-by-utility basis. Therefore, in presenting the rate impacts of individual utility systems, it should be emphasized that the large systems affect more retail consumers than the small systems.

\subsubsection{Capacity Reliance and Energy Reliance}

The impacts of changes in Western power contract commitments are influenced by the relative reliance of utility systems on Western for capacity needs during peak periods and for energy output. Figure 13 shows the relative reliance on Western energy and the relative reliance on Western capacity to meet peak demand for large and small preference customers. The utility systems are sorted in order of energy reliance, and the peak reliance is shown on the vertical axis. Figure 13 demonstrates that there is a substantial variance in the relative amount of Western energy and demand 


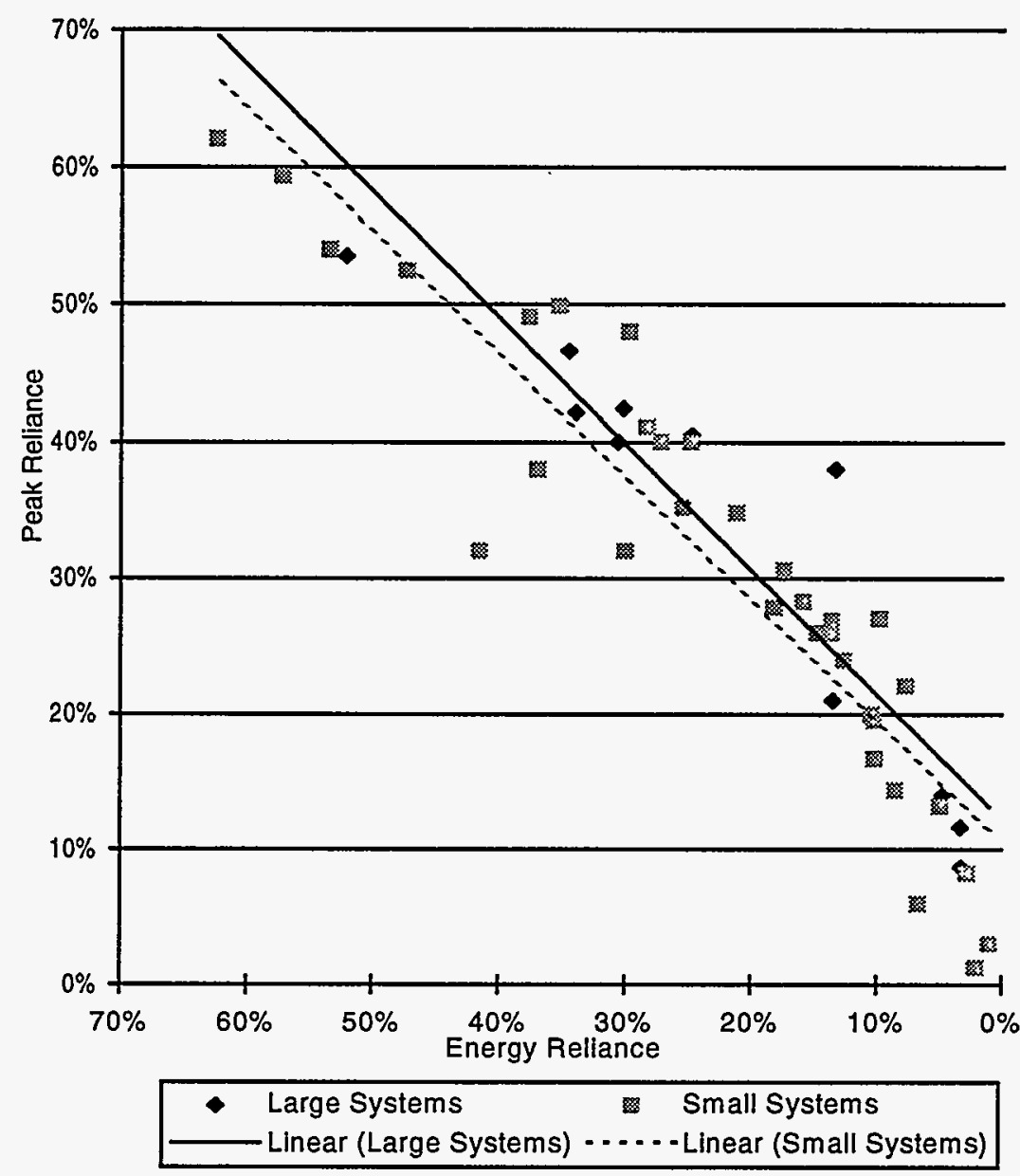

FIGURE 13 Relative Energy and Peak Reliance

that is supplied to retail utility systems. The reliance on Western as a percentage of total energy supplied varies from almost nothing to $65 \%$. The median level of energy and peak reliance is approximately $20 \%$, and the average energy reliance level is $21 \%$. If the relative Western energy and capacity reliance are similar, the points on Figure 13 should approximate a 45-degree line. Deviations from a 45-degree line are a result of the different load factors of retail utility systems (load factor is defined as the average energy usage over a year divided by the peak demand). For example, if the load factor is very high, the peak reliance will be more than the relative energy reliance. The graph demonstrates that for most preference customers of Western, the percentage of reliance on Western energy is similar to the reliance on Western capacity relative to peak load.

For purposes of presenting the distribution of rate impacts across systems, the relative energy reliance is defined as the average of the percent reliance on Western to meet energy requirements and the percent reliance on Western to meet peak demand. 


\subsection{IMPACTS ON RETAIL RATES OF INDIVIDUAL UTILITY SYSTEMS}

To demonstrate the distribution across utility systems of rate impacts that result from changes in Western's wholesale contract terms, changes in rates as compared with those of the baseline case are presented. The impacts are shown in absolute and percentage terms for each combination of marketing alternative and supply option directly modeled. ${ }^{17}$ The percentage of reliance on Western (the average of energy and peak reliance) is shown on each graph because impacts on retail rates due to changes in Western's marketing programs vary directly with the degree to which the system relies on Western for its power needs.

\subsubsection{Alternative NA-B: No Action Alternative/Low Fluctuating Flow Supply Option}

Alternative NA-B has the same energy and capacity allocations as those of the baseline case, but the Western wholesale rates are somewhat higher because of restrictions on dam operations (the dams are operated with low fluctuating flows rather than with full flexibility). As shown in Section 2, the all-in Western wholesale rate is 10\% higher in this case than in the baseline case. Figure 14 demonstrates the rate impact for Alternative NA-B compared with the socioeconomic baseline case in the year 2000. The top graph shows the change in retail rates on a mills per kilowatt-hour basis (one mill is one-tenth of a cent; 10 mills represent $1 \phi / \mathrm{kWh}$ ) for the year 2000 , and the bottom graph shows the percentage change in retail rates in the year 2000.

The top graph of Figure 14 shows that the impact of Alternative NA-B relative to the baseline case ranges between 0 and $0.2 \% / \mathrm{kWh}$ and that the median impact is $0.05 \% / \mathrm{kWh}$. The bottom graph demonstrates that in terms of percentage rate changes, the range is between 0 and $2.5 \%$, and the median impact is an increase of about 1\%. For a given level of reliance on Western, the results in terms of changes in rates are reasonably consistent across utility systems. In other words, increases in reliance are highly correlated with increased rate impacts. Since the major variable that changes in this scenario is Western's price of allocated power, the rate changes are expected to be proportional to relative reliance on Western. Graphs for the years 1994 and 2008 are similar.

\subsubsection{Alternative NA-C: No Action Alternative/Steady Flow Supply Option}

As with Alternative NA-B, the No Action Alternative combined with the steady flow supply option (Alternative NA-C) has the same capacity and energy commitments as those of the baseline

17 The absolute impacts are not deflated to 1993 dollars, which implies that in today's dollars, the absolute impacts would be lower. 

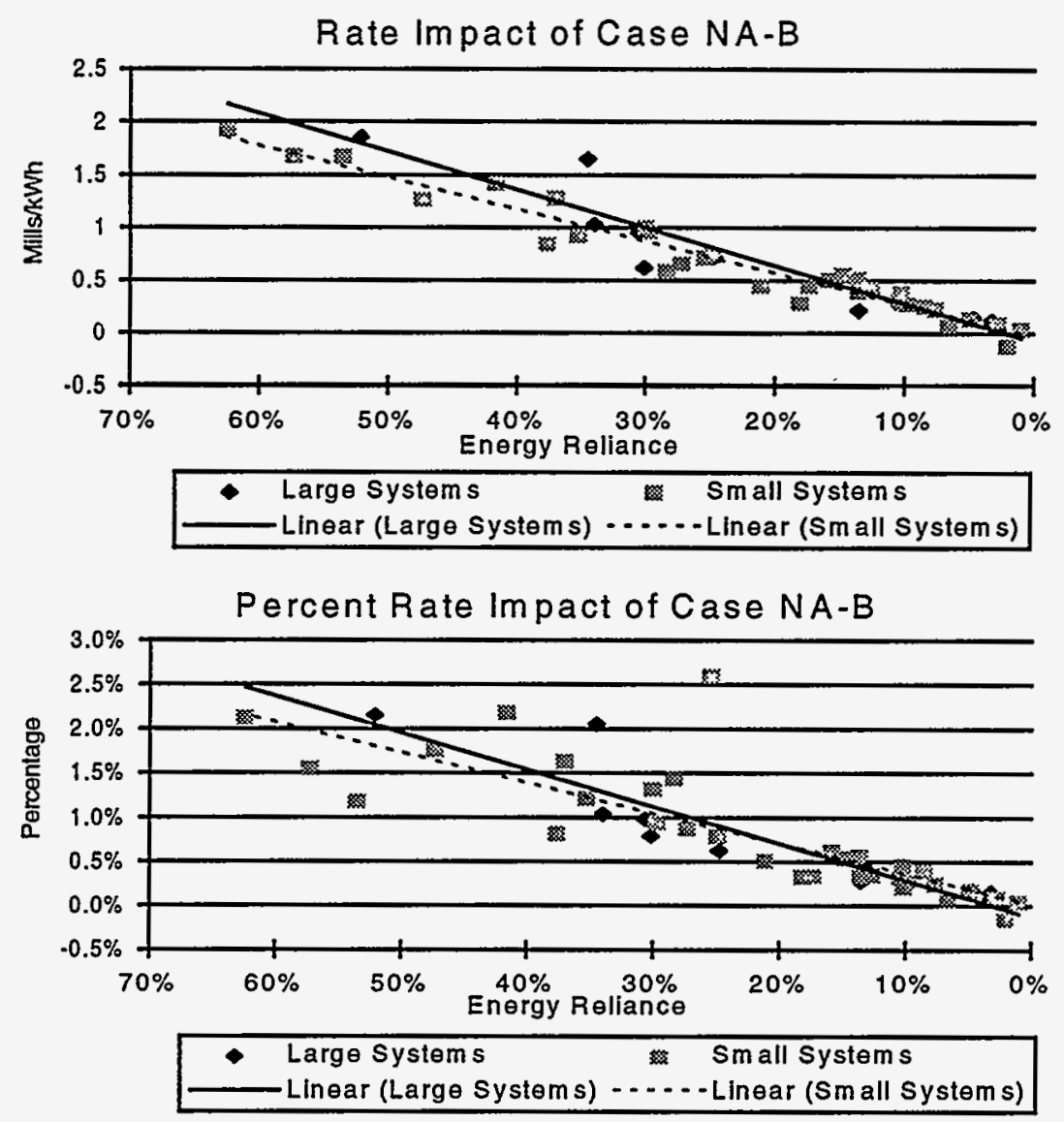

FIGURE 14 Impacts of Alternative NA-B: No Action Alternative/Steady Flow Supply Option

case for individual preference customers. The difference between Alternatives NA-C and NA-B and the baseline case is the operational characteristics of the hydroelectric generating facilities. Alternative NA-C is based on steady flows instead of the full flexibility that is assumed in the baseline case. The different operational assumptions affect Western's wholesale rates for capacity and energy. As shown in Section 2, Western's wholesale rates in this scenario are $86 \%$ above those of the baseline case.

Figure 15 shows the impacts on retail rates in the year 2000 for Alternative NA-C compared with the baseline case. The top graph demonstrates that the impacts of Alternative NA-C range from virtually nothing to increases of as much as much as $1.5 \mathrm{~d} / \mathrm{kWh}$. The median rate impact is approximately $0.5 \% / \mathrm{kWh}$. The bottom graph shows that the Western wholesale rate changes associated with this case have a maximum impact of $20 \%$ and a median impact of approximately $5 \%$. 

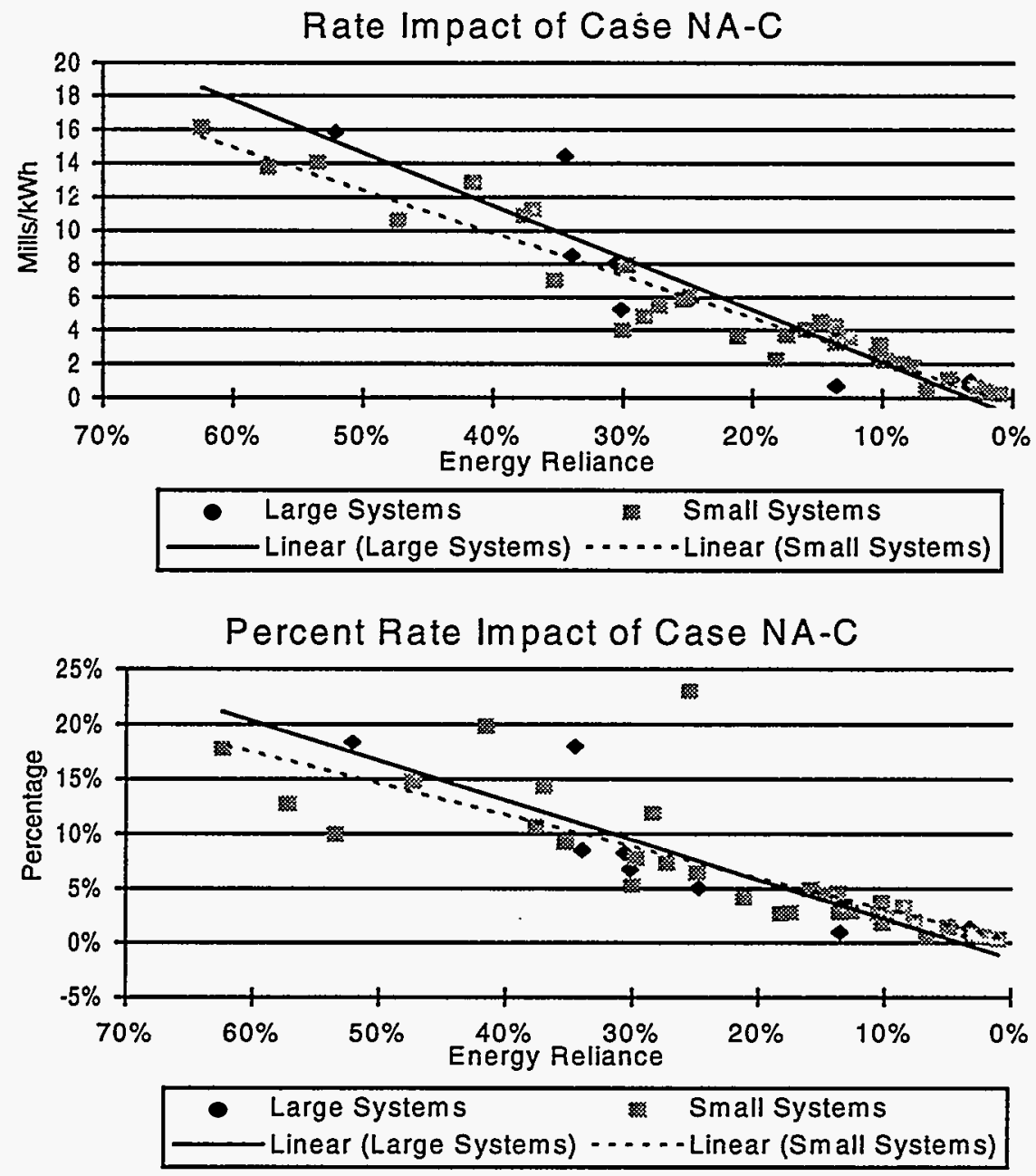

FIGURE 15 Impacts of Alternative NA-C: No Action Alternative/Steady Flow Supply Option

\subsubsection{Alternative 2-A: Peaking Alternative/Full Flexibility Supply Option}

Figure 16 illustrates the rate impacts of Alternative 2-A compared with those of the baseline case. In Alternative 2-A, the dams are assumed to operate at full flexibility; however, the energy allocations in contracts between Western and its preference customers are reduced by $42 \%$ compared with the baseline case, while capacity allocations are increased by $14 \%$. The reduced energy allocation allows Western to lower its energy charge from $\$ 10.20 / \mathrm{MWh}$ to $\$ 7.10 / \mathrm{MWh}$ and its demand charge from $\$ 3.70 / \mathrm{kW} / \mathrm{mo}$ to $\$ 1.40 / \mathrm{kW} / \mathrm{mo}$ relative to the baseline case. However, in this scenario, Western's preference customers must secure energy from other sources. Customers with high marginal costs of energy tend to experience rate increases, while customers with low marginal energy costs experience rate decreases. More systems experience rate decreases than increases in this marketing alternative. 

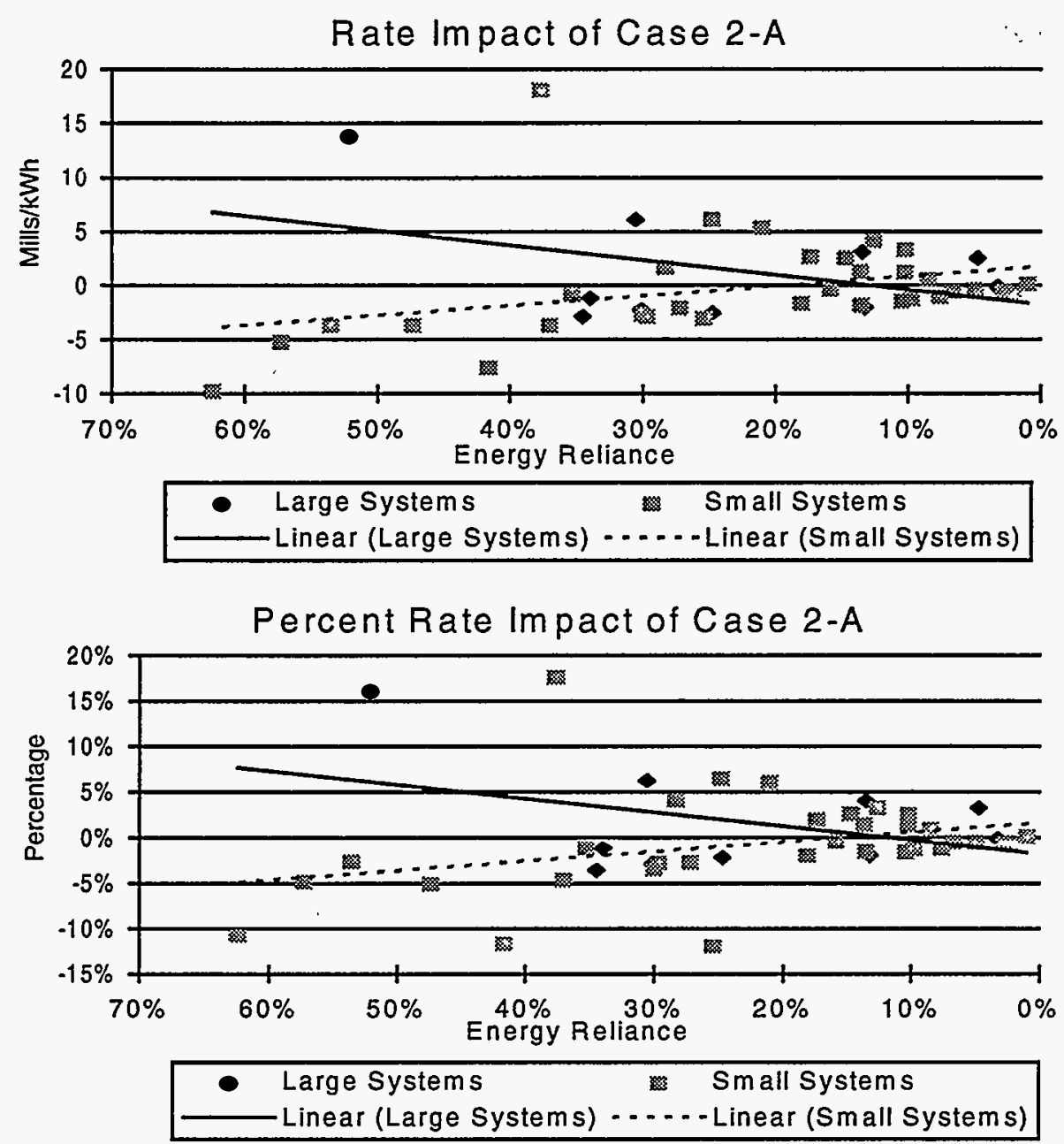

FIGURE 16 Impacts of Alternative 2-A: Peaking Alternative/Full Flexibility Supply Option

The top graph of Figure 16 shows that some customers benefit from the reduced energy allocations of Alternative 2-A because of lower Western rates, while other customers experience rate increases. The retail rate impacts range from a $1.5 \phi / \mathrm{kWh}$ increase to a $1 \phi / \mathrm{kWh}$ decrease. The bottom graph shows that the rate impacts range between $+15 \%$ and $-10 \%$ and that the majority of impacts are between $\pm 5 \%$.

\subsubsection{Alternative 2-B: Peaking Alternative/Low Fluctuating Flow Supply Option}

Figure 17 illustrates the rate impacts of Alternative 2-B in 2000. This case includes the peaking alternative in terms of the allocation of capacity and energy in Western's contracts combined with the low fluctuating flow operational assumption. In this scenario, Western's wholesale rates are increased by $17.3 \%$ relative to those of the baseline case (although demand charges are reduced by $\$ 1.40 / \mathrm{kW} / \mathrm{mo}$ [ $\$ 3.70$ minus $\$ 2.30]$ ). Energy allocations to customers are reduced by $42 \%$, while 

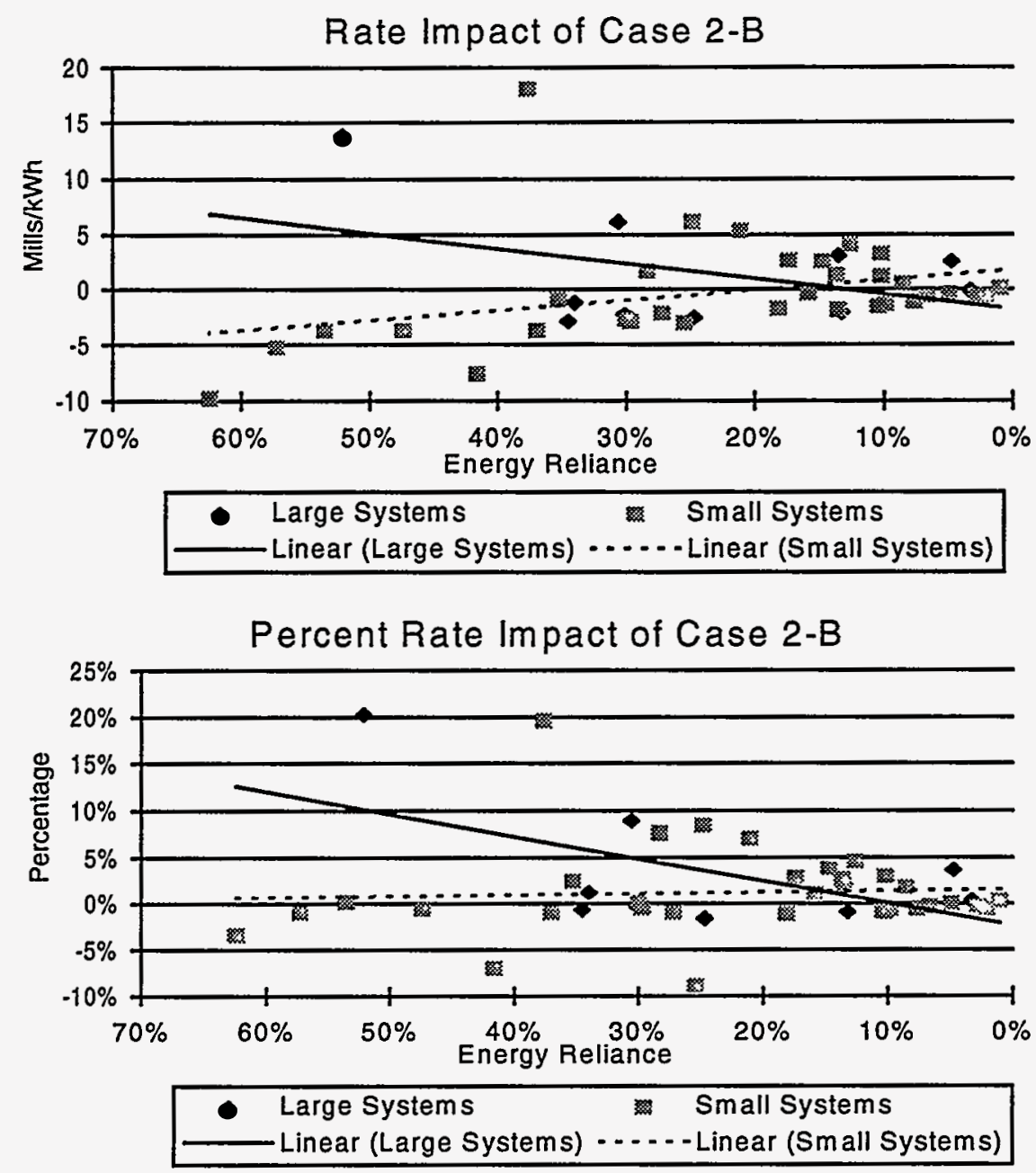

FIGURE 17 Impacts of Alternative 2-B: Peaking Alternative/Low Fluctuating Flow Supply Option

capacity allocations increase by $12 \%$. The top graph shows that rates relative to baseline rates increase by as much as $2 \phi$, but the median increase is less than $0.5 \%$. The bottom graph shows that the percentage rate impact ranges from $-10 \%$ to $+20 \%$. Most systems have negligible rate impacts.

\subsubsection{Alternative 2-C: Peaking Alternative/Steady Flow Supply Option}

Figure 18 shows the percentage retail rate impacts relative to those of the baseline case for Alternative 2-C, the peaking marketing alternative with steady flow dam operations. This marketing alternative involves changes in quantities of capacity and energy that are the same as in the two preceding cases. Because of restrictions on operation of the dams, Alternative 2-C includes Western wholesale power energy charges that are $86 \%$ higher than those of the baseline case. Since offsetting costs and benefits are associated with changes in Western's capacity and energy allocations, retail rate charges are more widely dispersed across utility systems than in Alternatives NA-B and NA-C. 


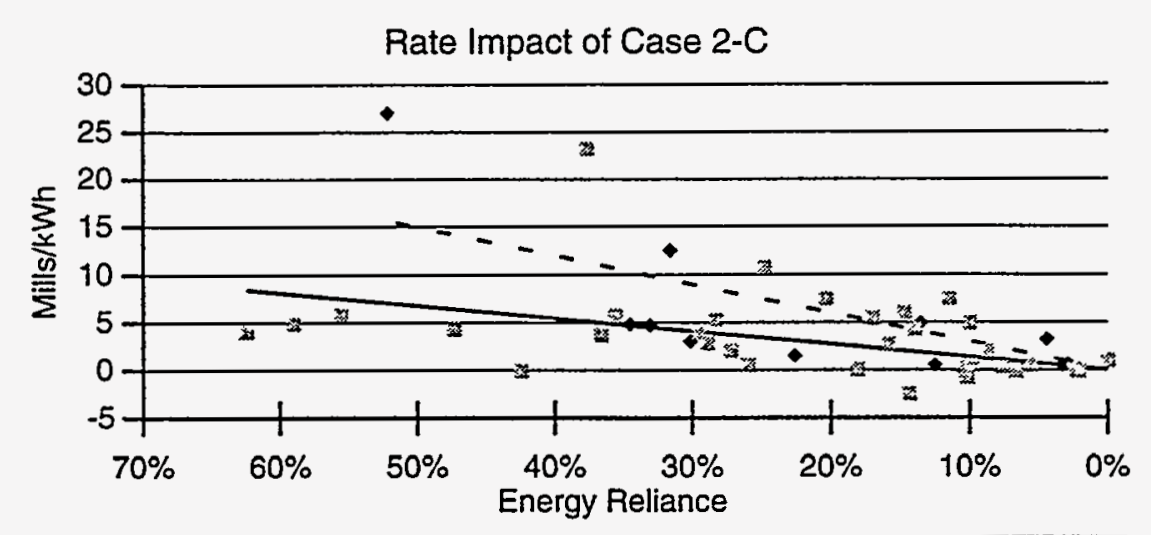

- Large Systems

Small Systems

Linear (Large Systems)

-.. Linear (Small Systems)

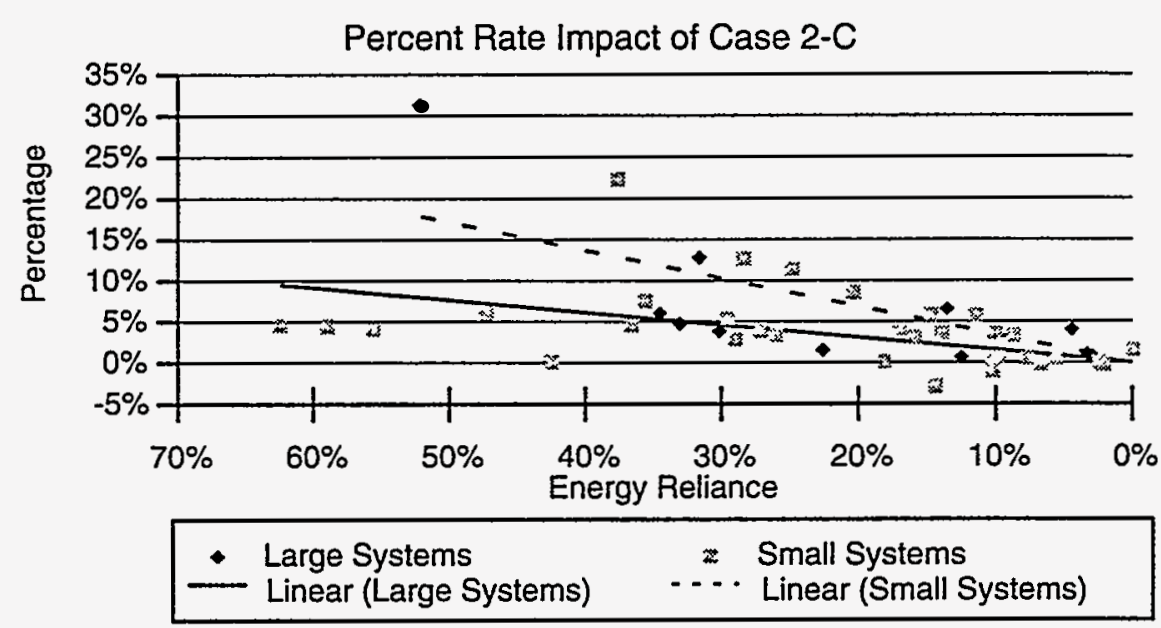

FIGURE 18 Impacts of Alternative 2-C: Peaking Alternative/Steady Flow Supply Option

The top graph of Figure 18 shows that the retail rate increases range between 0 and $2 \phi / \mathrm{kWh}$ for Alternative 2-C relative to those of the baseline case in the year 2000. The bottom graph demonstrates that the percentage impacts are as much as $30 \%$, with a median impact of about $8 \%$. A comparison of Figures 15 and 18 shows that for most preference customers, the impact of Alternative 2-C is less than that of Alternative NA-C, even though the maximum rate impact is greater.

\subsubsection{Alternative 4-A: Low Capacity and Energy Alternative/Full Flexibility Supply Option}

Alternative 4-A is based on low capacity and energy commitments combined with the full flexibility supply option. In the marketing alternatives that assume low capacity and low energy, Western preference customers receive $43 \%$ of the firm capacity and $58 \%$ of the energy that was allocated in the no-action case. In Alternative 4-A, the lower energy and peak allocations enable 
Western's wholesale power rates to be reduced by $29.5 \%$ because more revenue is received from the sale of power in short-term markets. The impacts of reductions in capacity and energy on individual utility systems depend on the cost of Western power relative to the cost of capacity and energy that must be secured from alternative sources. For example, if a utility system has excess capacity and low marginal energy costs, the value of lost capacity and energy may not be significant, and the lower Western rate may yield net benefits in terms of cost of service. Alternatively, if a system has no surplus capacity and a high short-run marginal energy cost, the retail rate impacts of the lower Western power rates will probably not offset the loss of energy and capacity.

Figure 19 shows rate impacts of Alternative 4-A compared with those of the baseline case. The top graph demonstrates that the range of impacts from this case is wide: the maximum impact is $4 \phi / \mathrm{kWh}$, and the median impact is about $1 \phi / \mathrm{kWh}$. The maximum impact for large systems is $2 \phi / \mathrm{kWh}$. The bottom graph shows that in percentage terms, the rate impacts are as much as $50 \%$, with a median impact of approximately 10\%. Rate impacts are positive for most customers, which implies that loss of energy and capacity is not offset by the Western rate decreases.
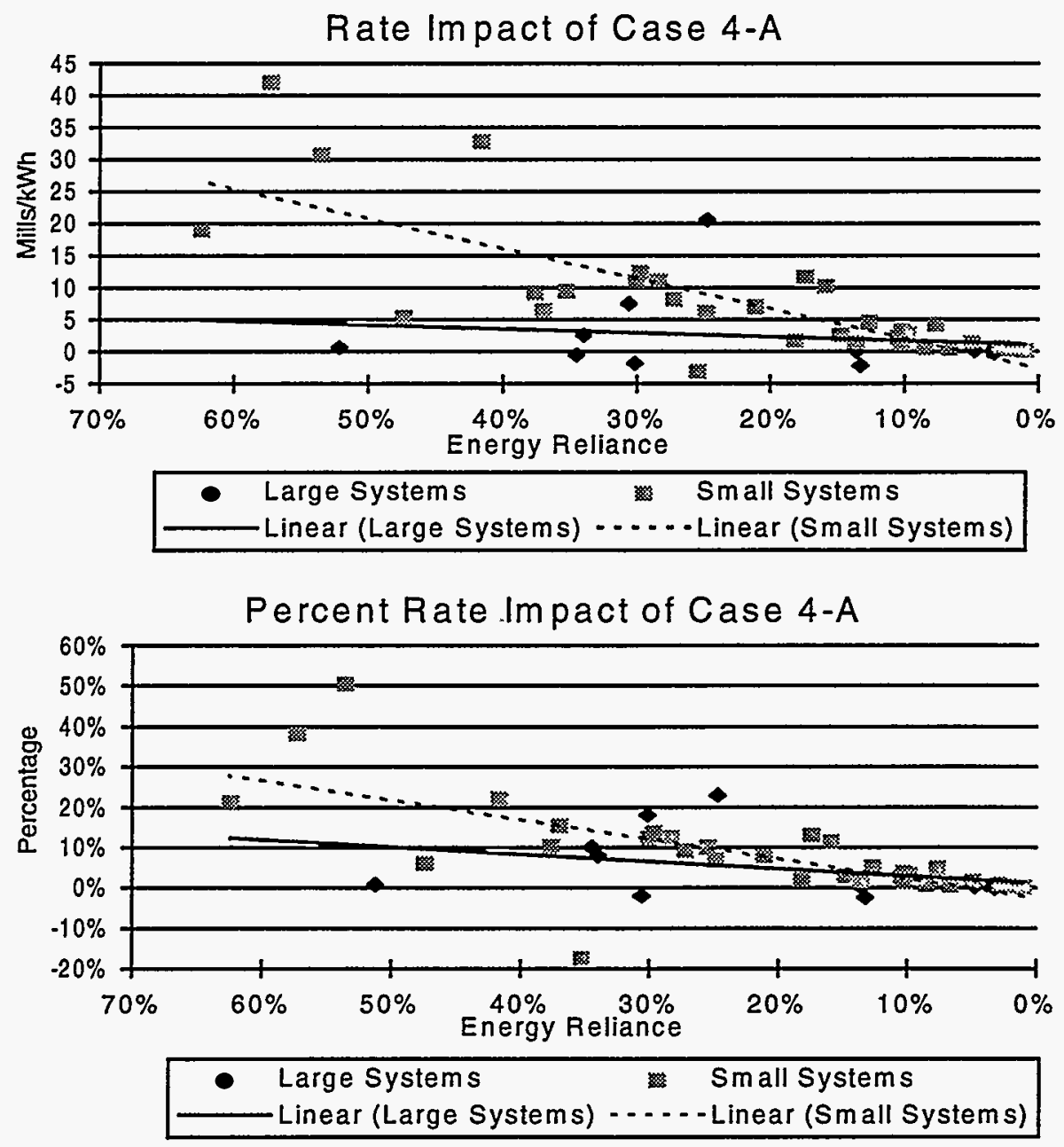

FIGURE 19 Impacts of Alternative 4-A: Low Capacity and Energy Alternative/Full Flexibility Supply Option 


\subsubsection{Alternative 4-B: Low Capacity and Energy Alternative/Low Fluctuating Flow Supply Option}

Alternative 4-B has the same energy and capacity allocations as those of Alternative 4-A, but it is based on an assumption of low fluctuating flows for dam operations. Because of the more restrictive operational assumptions, Western's wholesale rates are 15\% higher in Alternative 4-B than Alternative 4-A. (The Western wholesale power rates are still 14\% below those of the baseline case).

Figure 20 shows the rate impacts of Alternative 4-B compared with those of the baseline case in the year 2000. The top graph shows that rate impacts are as much as $4 \mathrm{~g} / \mathrm{kWh}$ and the median rate impact is $1 \phi / \mathrm{kWh}$. The bottom graph shows that in percentage terms, the impacts are as much as $50 \%$.
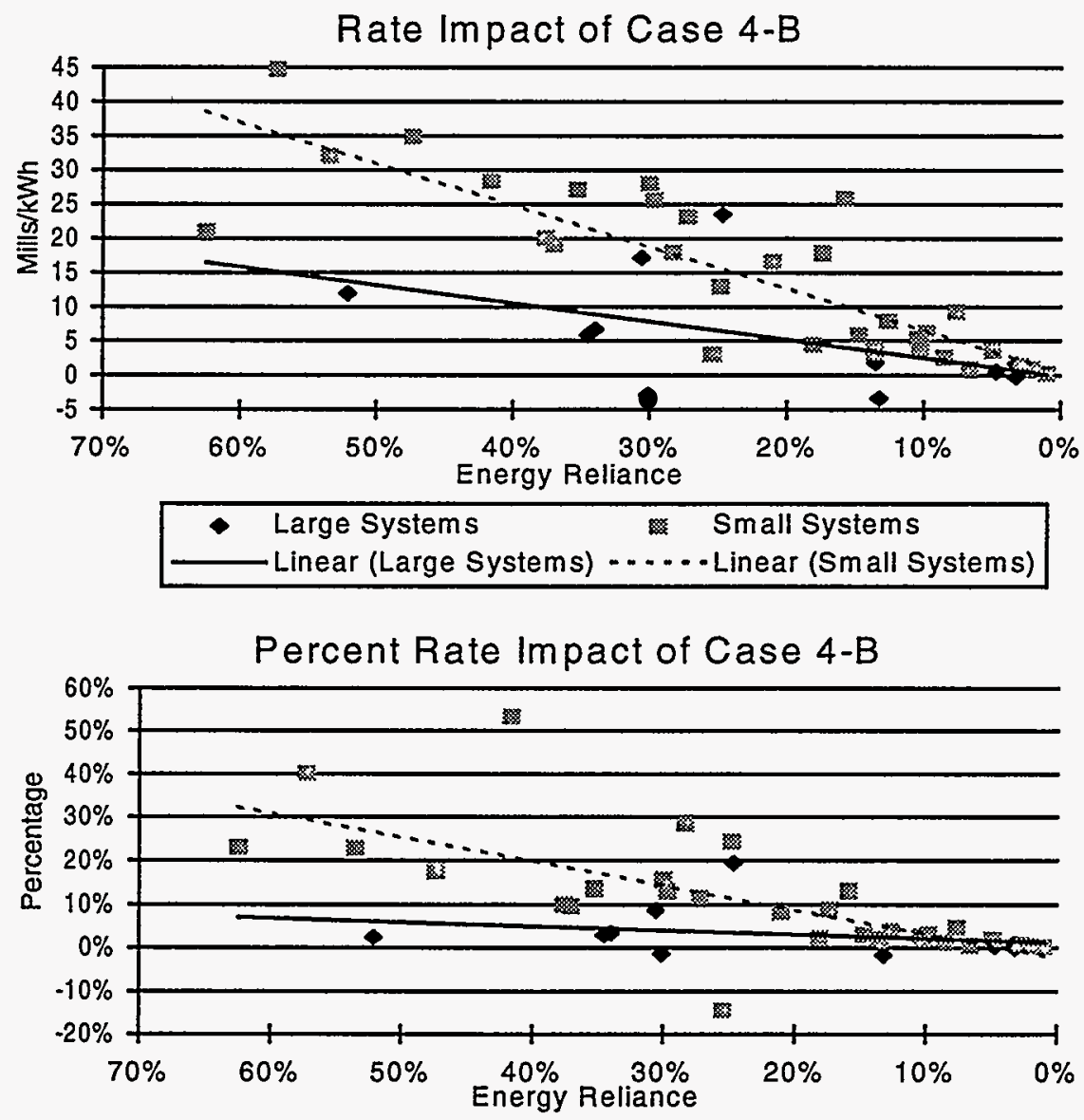

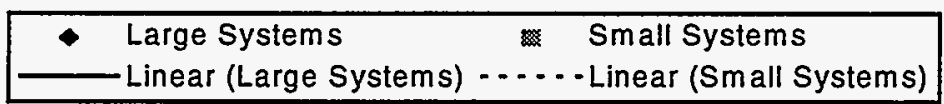

FIGURE 20 Impacts of Alternative 4-B: Low Capacity and Energy Alternative/Low Fluctuating Flow Supply Option 


\subsubsection{Alternative 4-C: Low Capacity and Energy Aiternative/Steady Flow Supply Option}

Figure 21 shows the retail rate impacts of Alternative 4 with the steady flow supply option in the year 2000-Alternative 4-C. This marketing alternative involves reductions in the allocation of capacity and energy to Western customers. Offsetting the reduced power allocations are reductions in Western's wholesale power rates. In this case, Western's wholesale power rates are $35 \%$ above those of the baseline case and $49 \%$ above the rates for Alternative 4-B.

Figure 21 demonstrates the rate impacts of Alternative 4-C compared with the baseline case. The top graph shows that the impact on retail rates relative to that of the baseline case ranges from negligible amounts to almost $5 \phi / \mathrm{kWh}$. Five utility systems have rate impacts of more than $2 \phi / \mathrm{kWh}$, and the median impact is approximately $1 \% / \mathrm{kWh}$. The bottom graph shows that in percentage terms, the retail rate impacts range from $-8 \%$ to $+60 \%$. A comparison of Figures 15 and 21 shows that
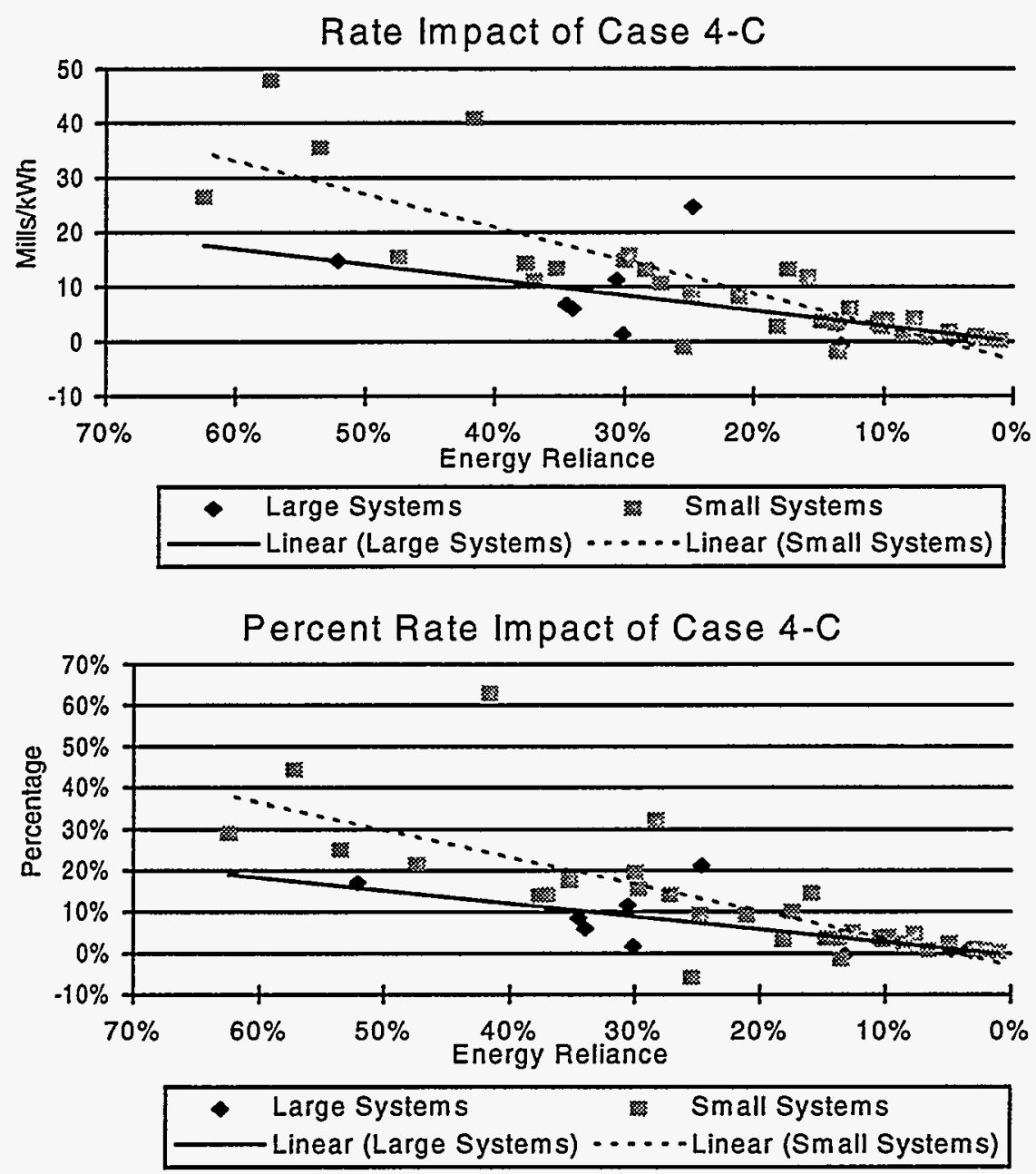

FIGURE 21 Impacts of Alternative 4-C: Low Capacity and Energy Alternative/Steady Flow Supply Option 
because of the differing costs of securing replacement capacity and energy, the distribution of impacts varies more for Alternative 4 than for cases with less change in Western's commitment levels.

\subsubsection{Alternative 5-A: Baseload Alternative/Full Flexibility Supply Option}

Alternative 5-A is based on a $48 \%$ reduction in allocation of Western capacity to preference customers compared with the baseline case but similar energy allocations. Western's wholesale firm rate is $6.6 \%$ above that of the baseline case in this marketing alternative. The impacts of this alternative on individual utility systems depend on the relative cost of securing replacement capacity. If a system has adequate capacity, the impacts may not be very large; if a system needs to replace the reduced Western capacity, rate impacts can be significant.

The top graph of Figure 22 shows that Alternative 5-A results in rates that are higher than those in the No Action Alternative and that the maximum impact is almost $4 \varnothing / \mathrm{kWh}$. It demonstrates
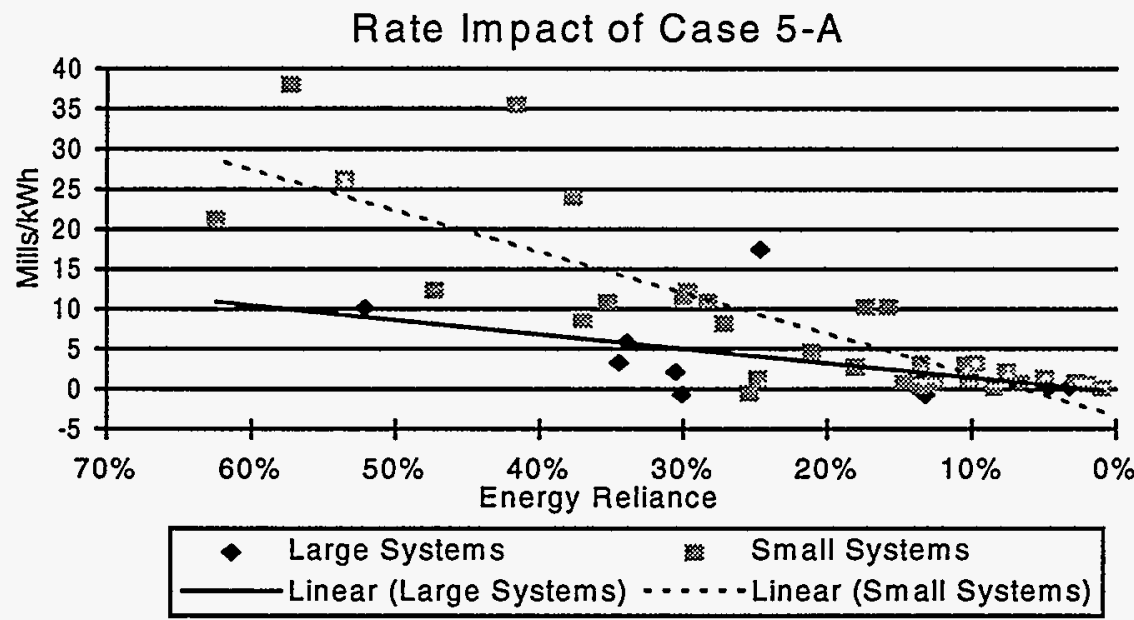

Percent Rate Impact of Case 5-A

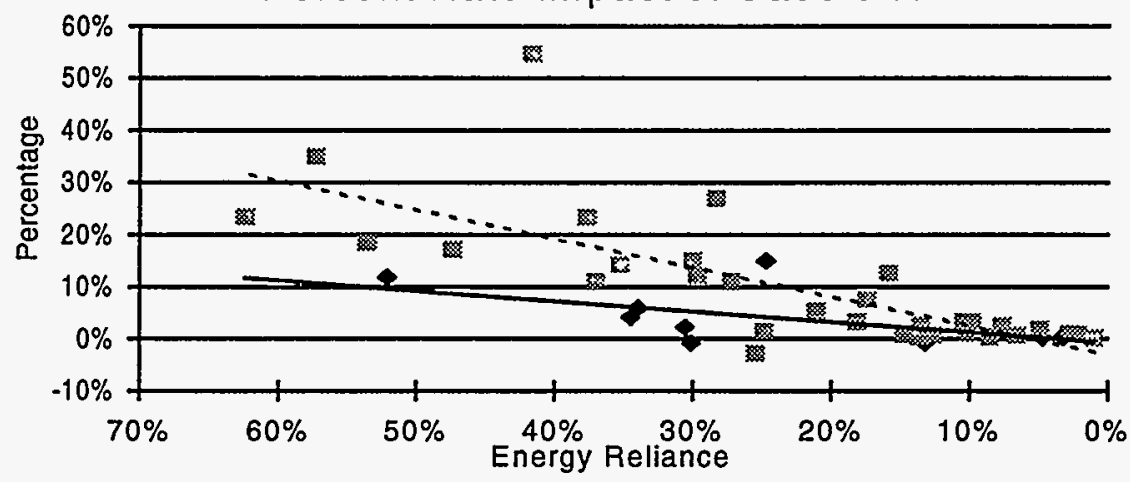

- Large Systems Small Systems

Linear (Large Systems) -...-.--Linear (Small Systems)

FIGURE 22 Impacts of Alternative 5-A: Baseload Alternative/Full Flexibility Supply Option 
that median impacts are approximately $1 \varnothing / \mathrm{kWh}$ and that impacts tend to be greater for small systems than for large systems. The bottom graph shows that 5 small systems have rate impacts of more than $20 \%$ and 15 systems have rate impacts of more than $10 \%$.

\subsubsection{Alternative 5-B: Baseload Alternative/Low Fluctuating Flow Supply Option}

Alternative 5-B is based on a reduced allocation of peak capacity of $48 \%$ combined with low fluctuating flow dam operation assumptions. In this case, Western's wholesale power rate is $34 \%$ above that of the baseline case and $15 \%$ above the wholesale rates in Alternative 5-A. The Western demand charge is $\$ 6.20 / \mathrm{kW} / \mathrm{mo}$ above the demand charge for the baseline case, and the energy charge is $\$ 3.40 / \mathrm{MWh}$ above the energy charge for the baseline case.

Figure 23 shows the rate impacts of Alternative 5-A compared with those of the baseline case. The top graph demonstrates that the retail rate impact is more than $4 \phi / \mathrm{kWh}$ for 2 systems and
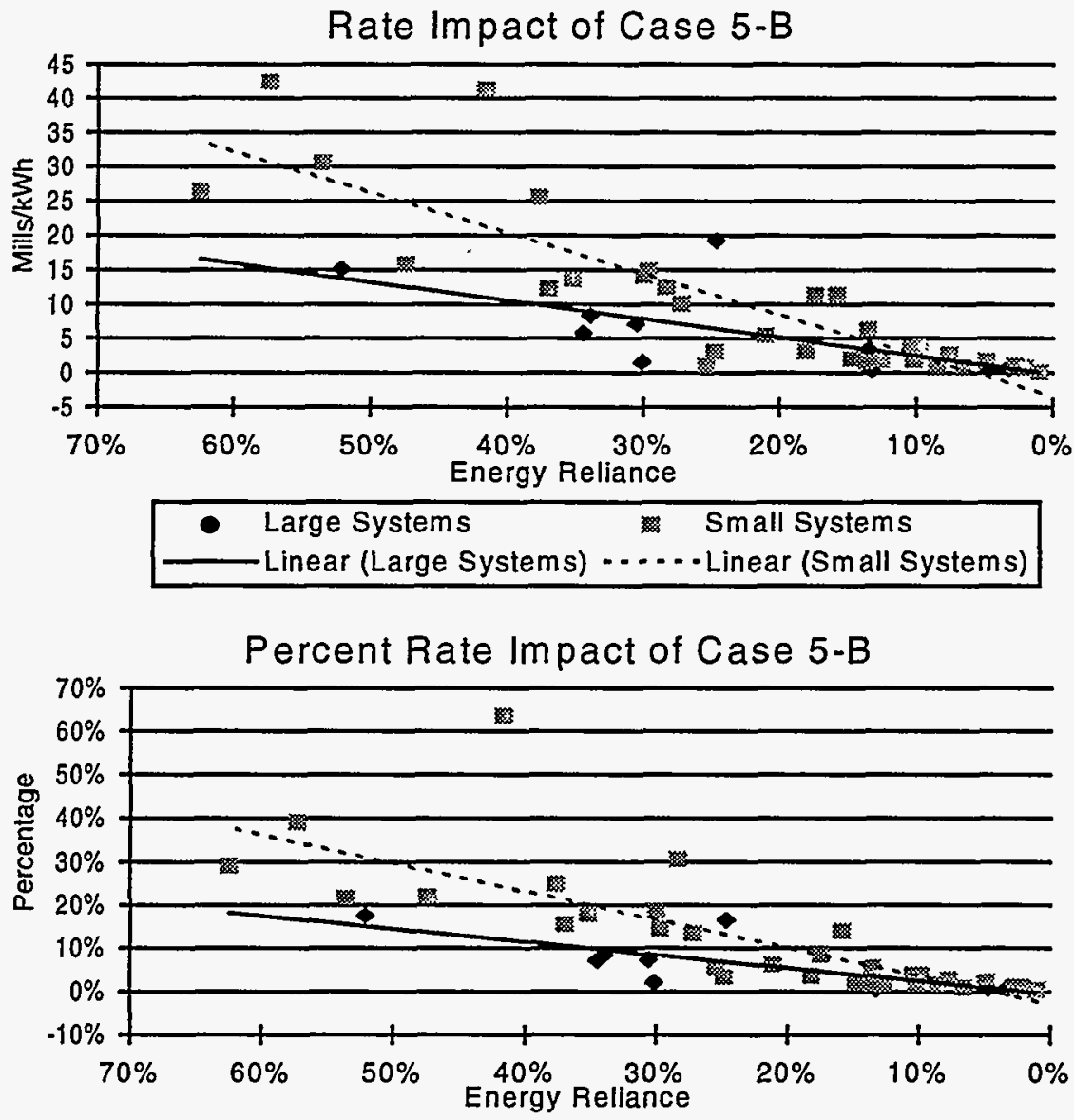

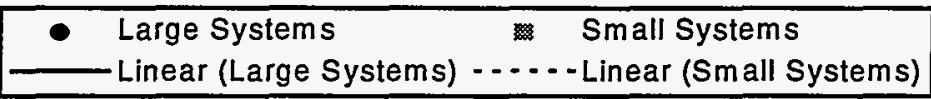

FIGURE 23 Impacts of Alternative 5-B: Baseload Alternative/Low Fluctuating Flow Supply Option 
more than $1 \notin / \mathrm{kWh}$ for 10 systems. The bottom graph shows that the rate impact is more than $20 \%$ for 6 small systems and more than $10 \%$ for 15 systems. As with Alternative 5-A, the rate impact is greater on small systems than large systems.

\subsubsection{Alternative 5-C: Baseload Alternative/Steady Flow Supply Option}

Alternative 5-C is based on Western reducing its commitment of capacity in firm contracts combined with steady flow operational assumptions. This scenario includes energy commitments similar to those of the No Action Alternative but significantly lower capacity commitments. In this alternative, Western wholesale rates are $69 \%$ higher than in the baseline case and $35 \%$ higher than in Alternative 5-B.

Figure 24 shows the rate impacts of Alternative 5-C compared with those of the baseline case. The top graph shows that retail rate impacts in the year 2000 range between 0 and $5 \phi / \mathrm{kWh}$
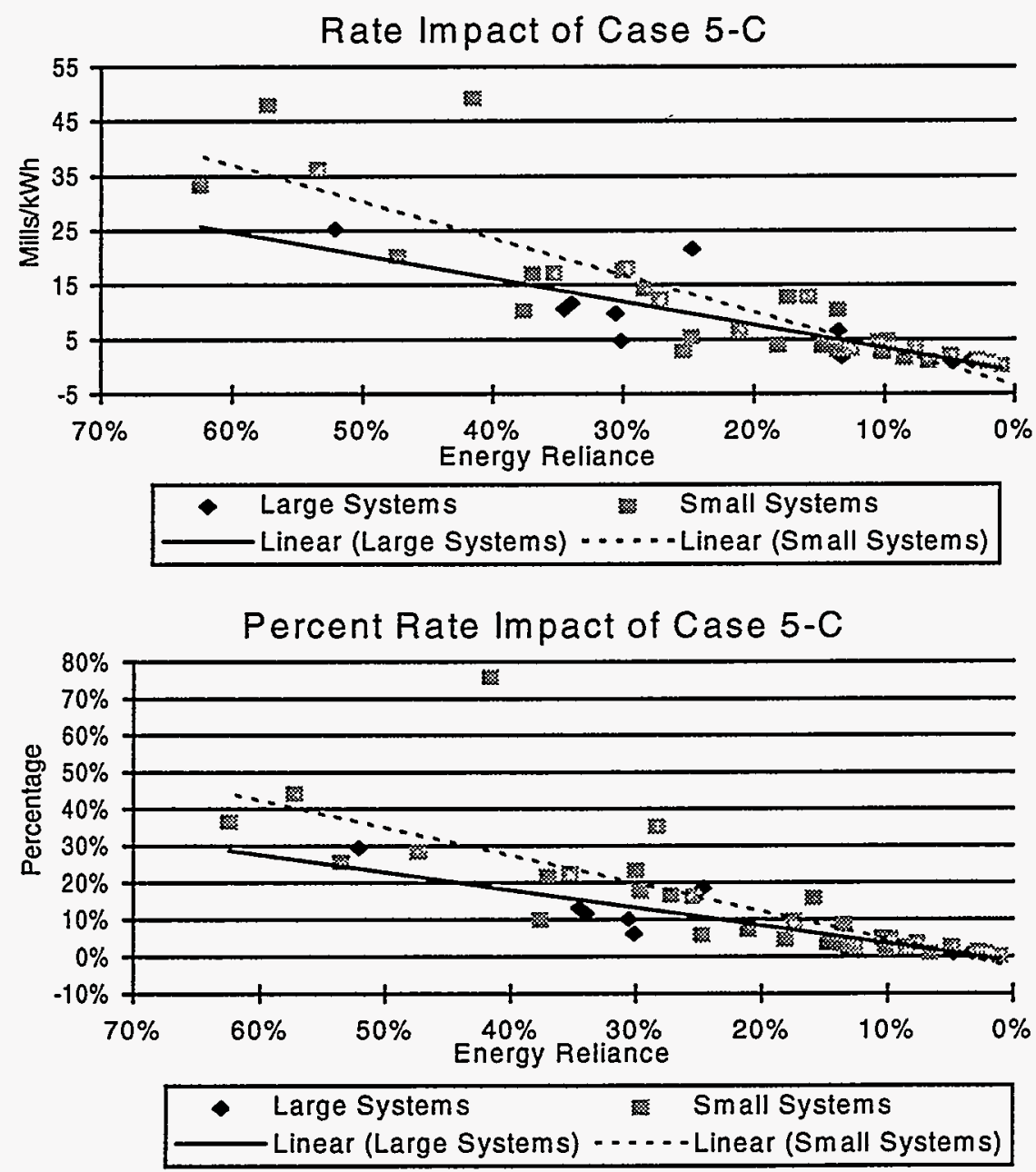

FIGURE 24 Impacts of Alternative 5-C: Baseload Alternative/Steady Flow Supply Option 
relative to those of the baseline case, 7 systems have impacts of more than $2 \phi / \mathrm{kWh}$, and 18 systems have impacts of more than $1 \% / \mathrm{kWh}$. The bottom graph shows that 18 systems have impacts of more than $10 \%$ and 10 systems have impacts of more than $20 \%$.

\subsection{IMPACTS ON RETAIL RATES BY GEOGRAPHIC REGION}

The prior section reviewed the distribution of rate impacts for each marketing alternative on a system-by-system basis. The analysis of rate impacts demonstrated the range of retail impacts from changes in Western contracting policies. In this section, the analysis focuses on average rate impacts arranged by geographic region. To compute geographic retail rate impacts, the rates for each retail utility system (including retail distribution systems that purchase from large systems) are weighted by the relative sales size of the utility system. In other words, if a large system comprises distribution utilities in multiple states, these systems are separated for purposes of the geographic rate impacts. In addition to being classified by state, the impacts are classified according to whether the affected areas are urban or rural. As was the case for analysis of the distribution of impacts on utility systems, the geographic retail rate impact analysis is presented for the year 2000 .

\subsubsection{No Action Alternatives NA-B and NA-C}

Figure 25 presents the impacts of the No Action Alternative. Rate impacts are shown for the states of Utah, Colorado, Arizona, and New Mexico. There are also impacts in Nebraska and Wyoming; however, these impacts are minimal because of the low reliance levels for utility systems in these areas. Each graph shows absolute impacts on electric bills and percentage rate impacts for urban and rural areas. Bill impacts are computed by multiplying the rate impacts by the overall level of demand. The absolute bill impacts are computed as the rate impacts multiplied by baseline case demand. The data in Figure 25 reflect impacts on the retail rates for all consumers who receive power from Western's long-term firm preference customers, but they do not include impacts for utility systems in the regions that are not preference customers of Western.

Figure 25 shows that for the steady flow supply option, the greatest percentage impacts occur in urban Utah (10\%), while the greatest absolute impacts are in urban areas of Colorado (\$32.8 million of bill increases). For the low fluctuating flow option, the average rate impacts are less than $2 \%$ in each area, and the region that is affected the most on an absolute basis is urban Colorado.

\subsubsection{Alternative 2: Peaking (High Capacity, Low Energy)}

Figure 26 presents the geographic impacts of Alternative 2, which reduces Western energy commitment by $42 \%$ while the Western capacity commitment is increased by $14 \%$. The chart shows 

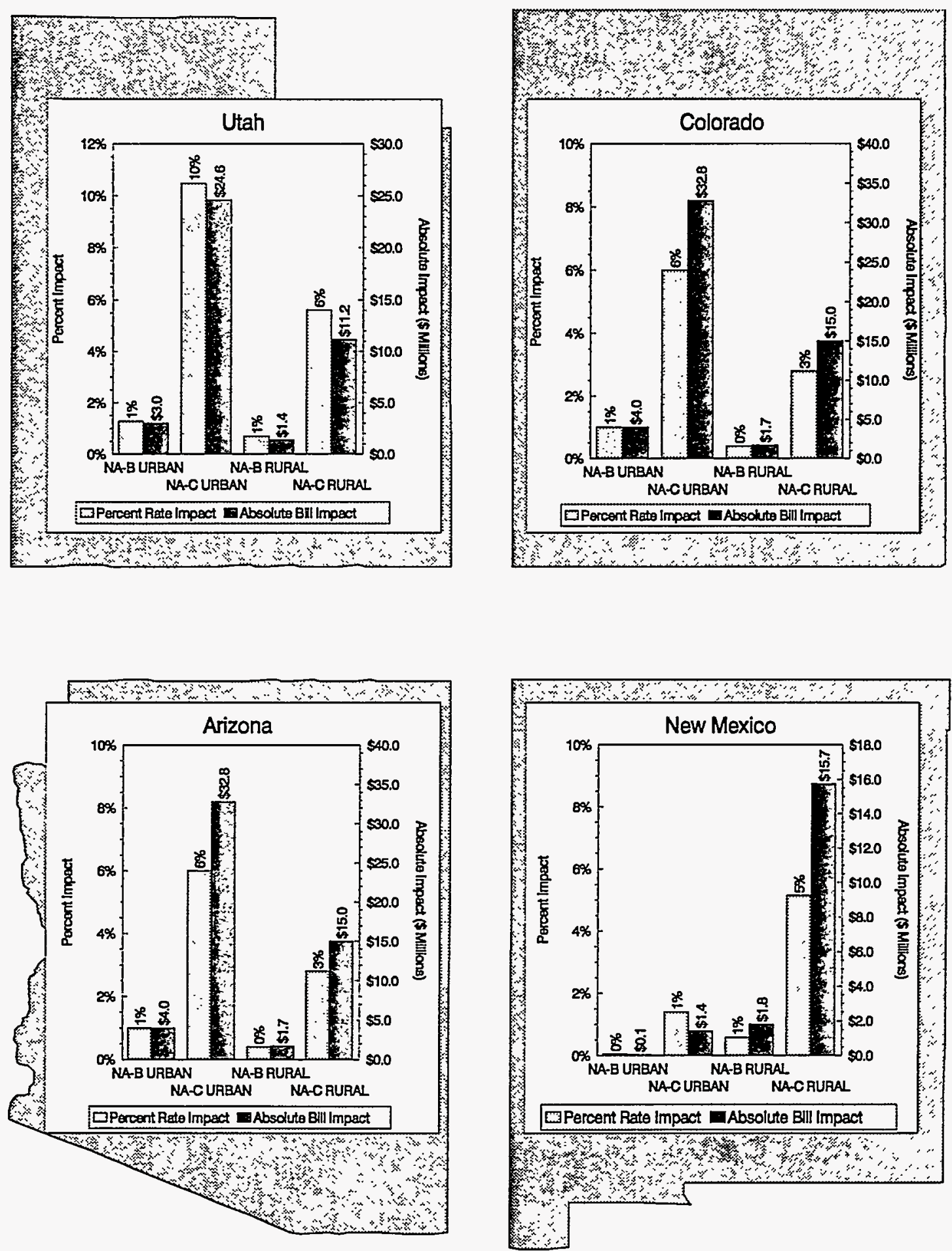

FIGURE 25 Regional Rate Impacts of the No Action Alternative 

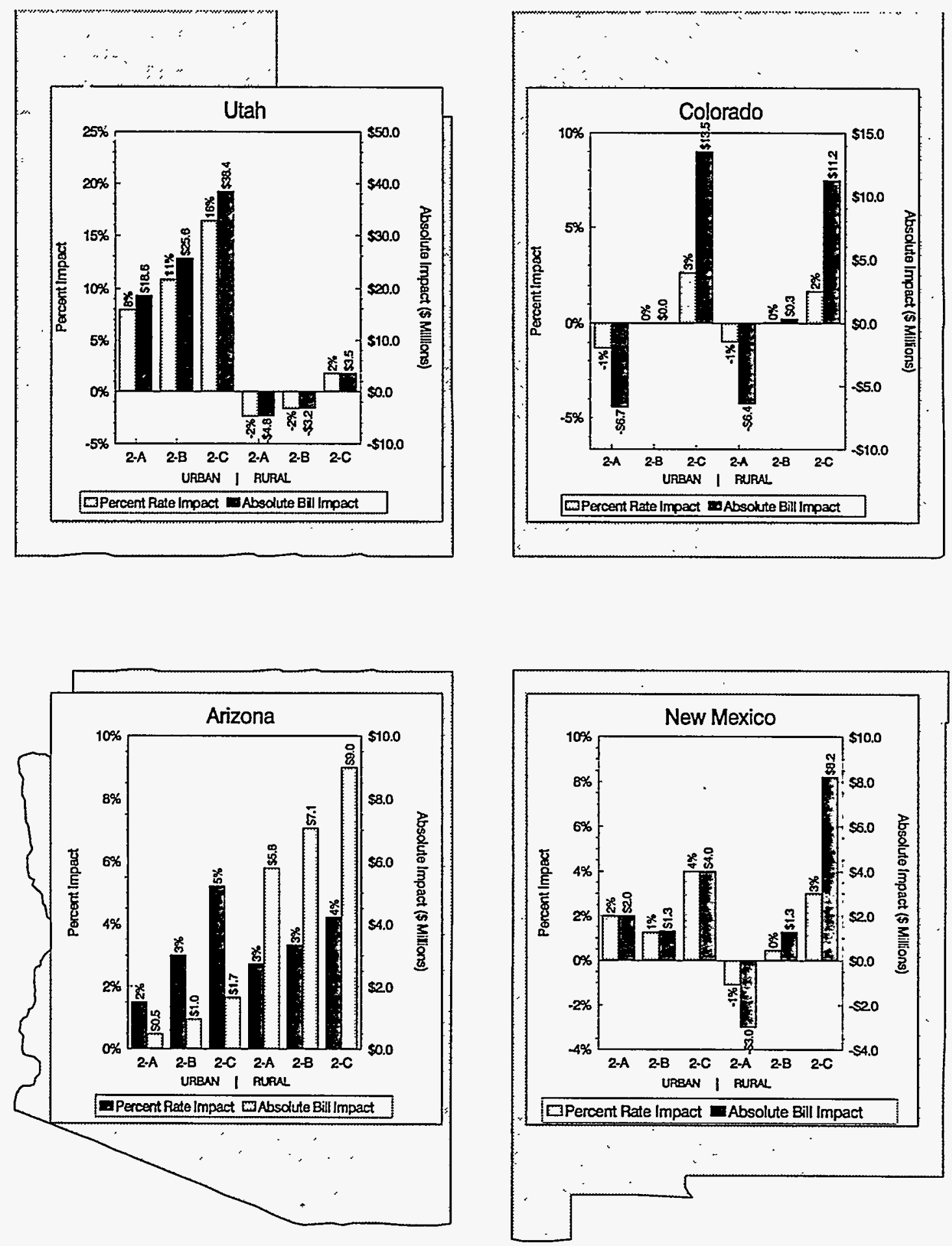

FIGURE 26 Regional Rate Impacts of Alternative 2: Peaking 
geographic rate impacts of the peaking alternative paired with each of the three supply options compared with those of the baseline case. Each graph shows absolute and percentage rate impacts by geographic region for the year 2000 .

Figure 26 demonstrates that for the steady flow supply scenario, the largest absolute and percentage impacts occur in urban Utah (6\% rate increase and a $\$ 38.4$ million bill increase). The impacts in rural Utah are negligible, and the rate increases for all other regions for all of the supply options are less than 5\%. A comparison of Figures 25 and 26 shows that some areas are better off with the no-action alternative (urban Utah, Arizona, and urban New Mexico) while other areas are better off with the peaking alternative (rural Utah, Colorado, and rural New Mexico).

\subsubsection{Alternative 4: Low Capacity and Energy}

Figure 27 demonstrates the geographic rate impacts of Alternative 4, which reduces both capacity and energy to Western's firm customers. The four panels represent the major states that are affected by changes in Western policy. The area that is most heavily affected by the low-capacity, low-energy alternative is rural Utah, which experiences a $23 \%$ rate increase and has a $\$ 45$ million bill impact. Other geographic areas generally have larger impacts from the other marketing alternatives.

\subsubsection{Alternative 5: Baseload (Low Capacity, High Energy)}

Figure 28 shows the geographic rate impacts of the baseload alternative compared with those of the baseline case. As was the case with the low-capacity, low-energy alternative, the area that experiences the largest impacts is rural Utah (a $20 \%$ rate impact and a $\$ 40.5$ million bill increase). In Arizona and New Mexico, the impacts of this alternative are greater than the impacts of the other marketing alternatives. In urban Utah, this alternative has larger impacts than does any other case except Alternative 5, the peaking alternative. In rural Utah, this case has larger impacts than does any case except Alternative 4, the low capacity and energy alternative. In Colorado, this alternative has larger impacts than does any case except the No Action Alternative.

\subsection{IMPACTS ON THE USE OF ELECTRIC POWER}

The direct impact of changes in Western's marketing alternatives occurs through retail rates. However, the dollar expenditures incurred by ultimate retail consumers of electric power are a function of both retail rates and the level of electricity usage. ${ }^{18}$ Changes in rates affect changes in usage through the mechanism of price elasticity of demand.

18 Actual retail tariffs include customer charges, energy charges, and demand charges, which often vary by season and time of use. This means that electric bills are a function of more than simply usage and rate per kilowatt-hour. Electric bills are also influenced by demand-side management. 

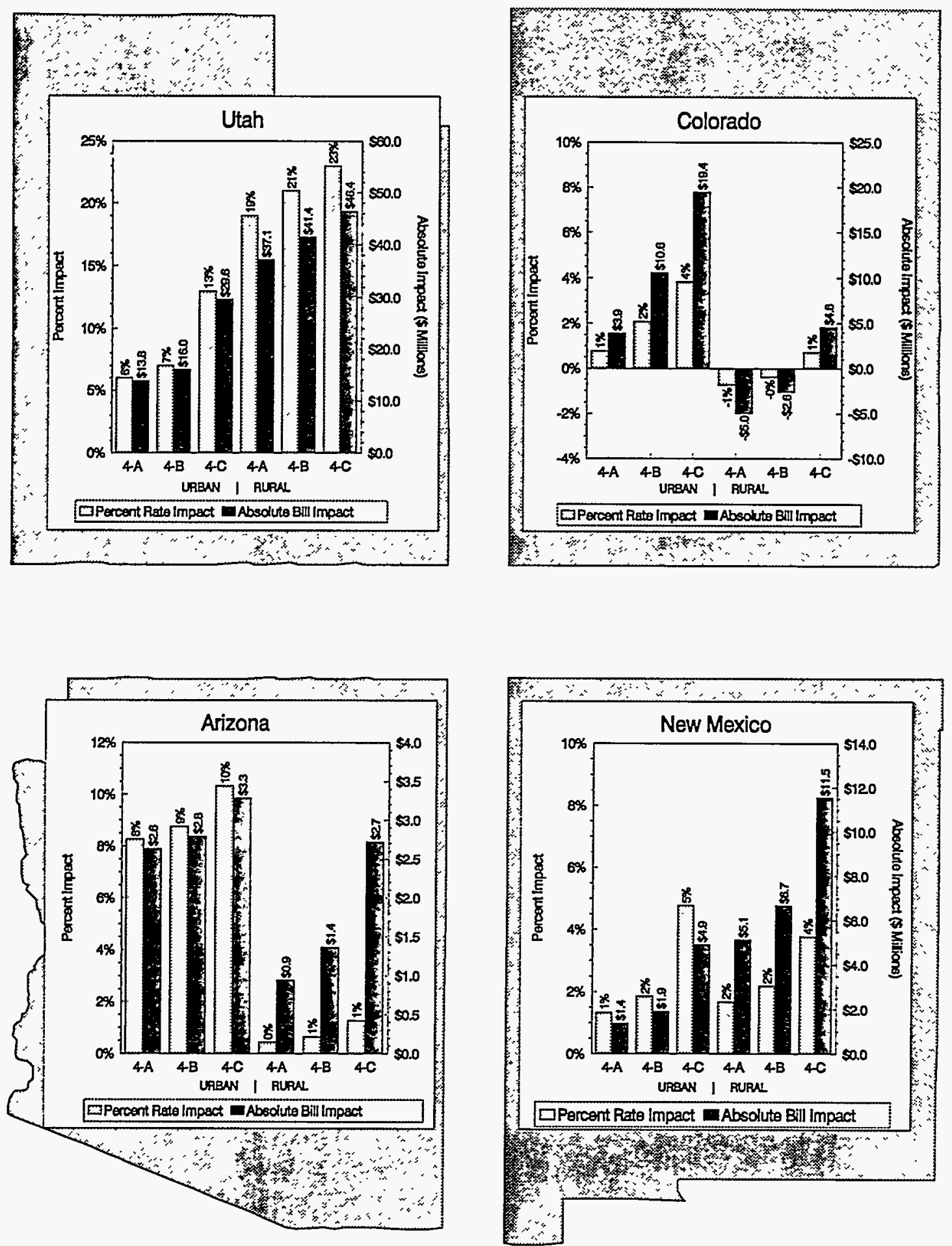

FIGURE 27 Regional Rate Impacts of Alternative 4: Low Capacity and Energy 

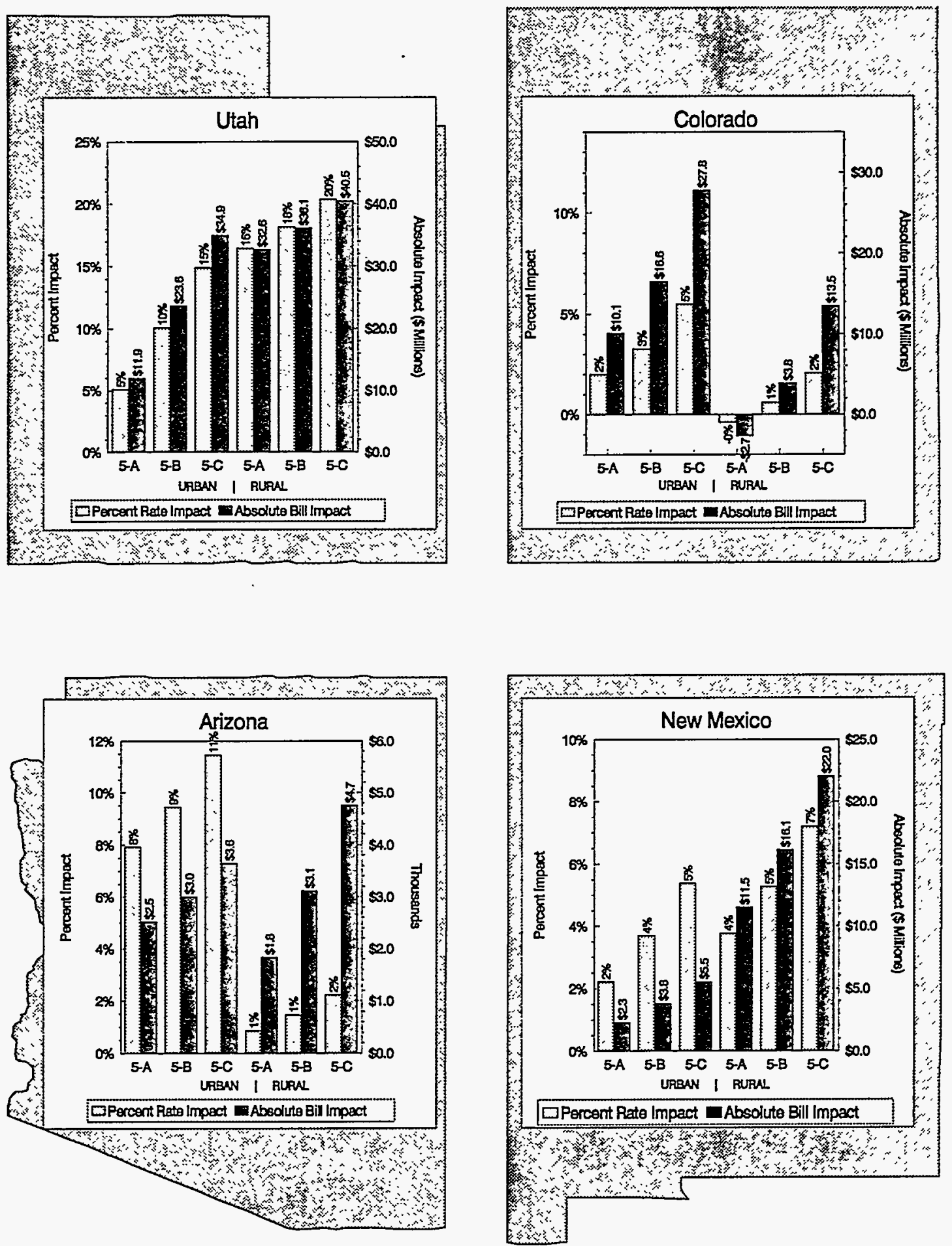

FIGURE 28 Regional Rate Impacts of Alternative 5: Baseload 
In this section, the changes in electricity usage that arise from changes in rates are reviewed. To demonstrate how changes in Western's marketing programs affect electricity usage, changes in sales relative to the baseline case are illustrated on a system-by-system basis. The impacts on electricity usage affect the ultimate electric bills for consumers and have additional environmental impacts that arise from different levels of required output through electricity generating facilities.

To demonstrate the impacts of alternative marketing programs on electricity use, percentage impacts on electricity use relative to the baseline case are compared and arranged according to percentage reliance on Western energy. The impacts on electricity usage are expressed as annual impacts relative to the baseline case for the year 2000. The results are presented for a particular year; they do not represent a cumulative change over several years.

\subsubsection{No Action Alternative}

Figure 29 shows the impact on electricity demand in the year 2000 for cases that have the baseline commitment level but different supply options. The graph shows that usage impacts are as much as $2 \%$ in the low fluctuating alternative (NA-B) and $9 \%$ in the steady flow alternative (NA-C).
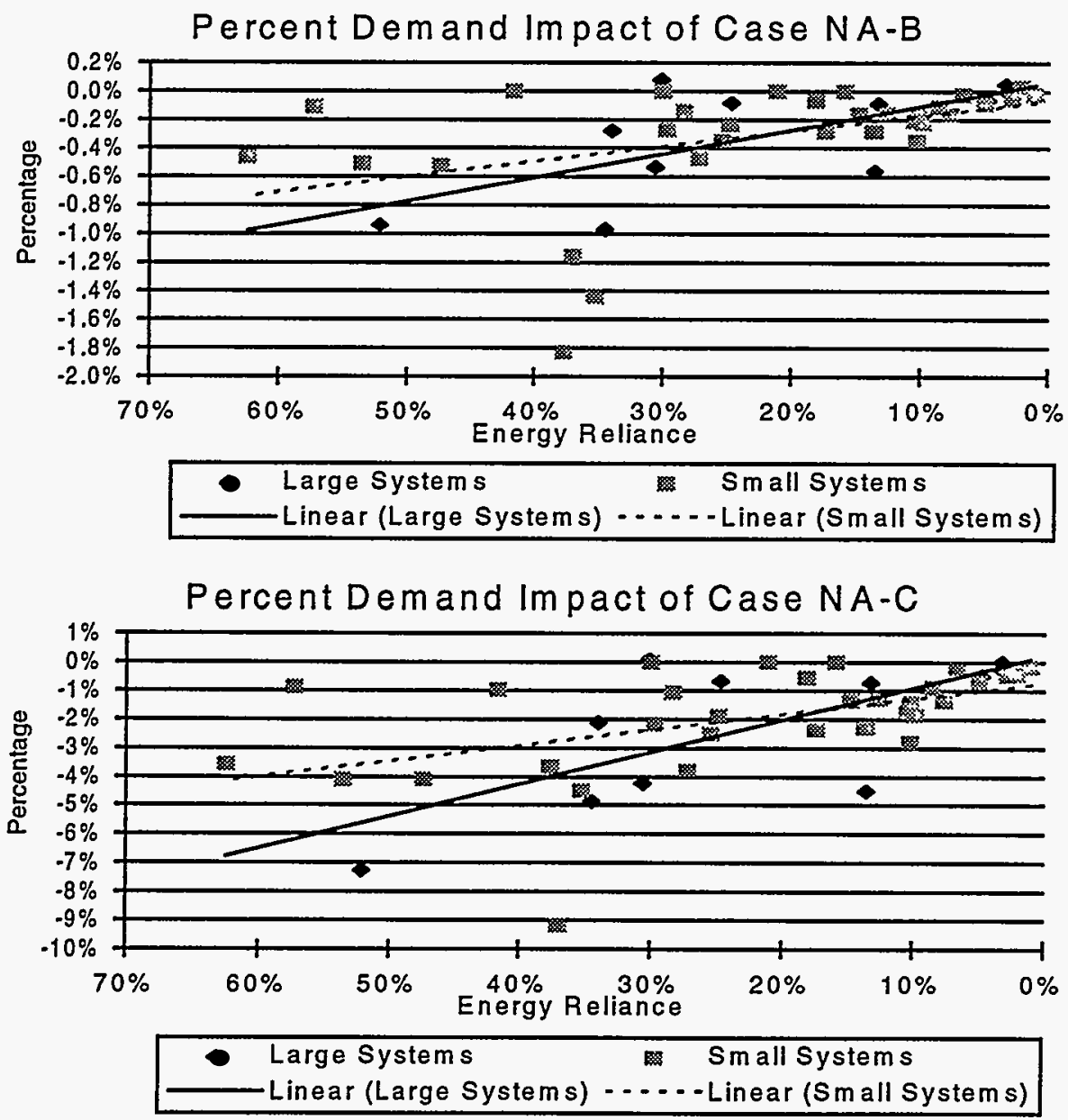

FIGURE 29 Demand Impacts of the No Action Alternative 


\subsubsection{Other Marketing Alternatives}

Figure 30 shows the impact on electricity demand in cases where energy is reduced but capacity is similar to that of the baseline case. The graph shows that in the year 2000, demand impacts are a maximum of $6 \%$ under the full flexibility supply option in the peaking marketing alternative; $6.5 \%$ under the low fluctuating flow alternative in the low-energy, low-capacity marketing alternative; and $13 \%$ under the steady flow supply option in the baseload alternative.

\subsubsection{Overall Average Impacts}

Figure 31 demonstrates the average impacts across all utility systems for the various marketing alternatives and supply operation scenarios. It shows that the case with the largest impact is the baseload marketing alternative with steady flow dam operations. In this case, the annual increase in electric bills is $\$ 161$ million in the year 2000 . Assuming steady flow supply operations, the case with the smallest impact is the peaking marketing alternative, with an aggregate increase of $\$ 95$ million in electric bills. The figure shows that the percentage impact in the baseload case with restrictive supply operations is $8 \%$, while the increase in the peaking alternative is $4 \%$.

\subsection{IMPACTS ON REPRESENTATIVE UTILITY SYSTEMS}

Up to this point, the description of impacts has focused on the distribution of impacts at a point in time and the regional rate impacts arranged by marketing commitment and dam operation option. In other words, for a given combination of marketing alternative and supply option, the analysis has concentrated on the level and distribution of impacts for the alternative. To demonstrate the rate and usage impacts on individual utility systems from alternative marketing programs, additional detail on representative systems is presented in this section. ${ }^{19}$

To present impacts on select utility systems, four representative small systems and three representative large systems are reviewed. For each representative system, the following impacts are presented:

- Retail rates from each marketing alternative and supply option over time,

- The impacts on the amount of electric power sold in each alternative,

19 In developing the power systems analysis, certain confidential data provided by utilities were used in measuring total production costs. In the rate and financial task, the confidential data were not directly used; instead, aggregate production cost data were used. The data on specific utility systems are presented only in terms of relative proportions and do not identify the name of the utility system. This ensures that no confidential data are indirectly presented in this document. 

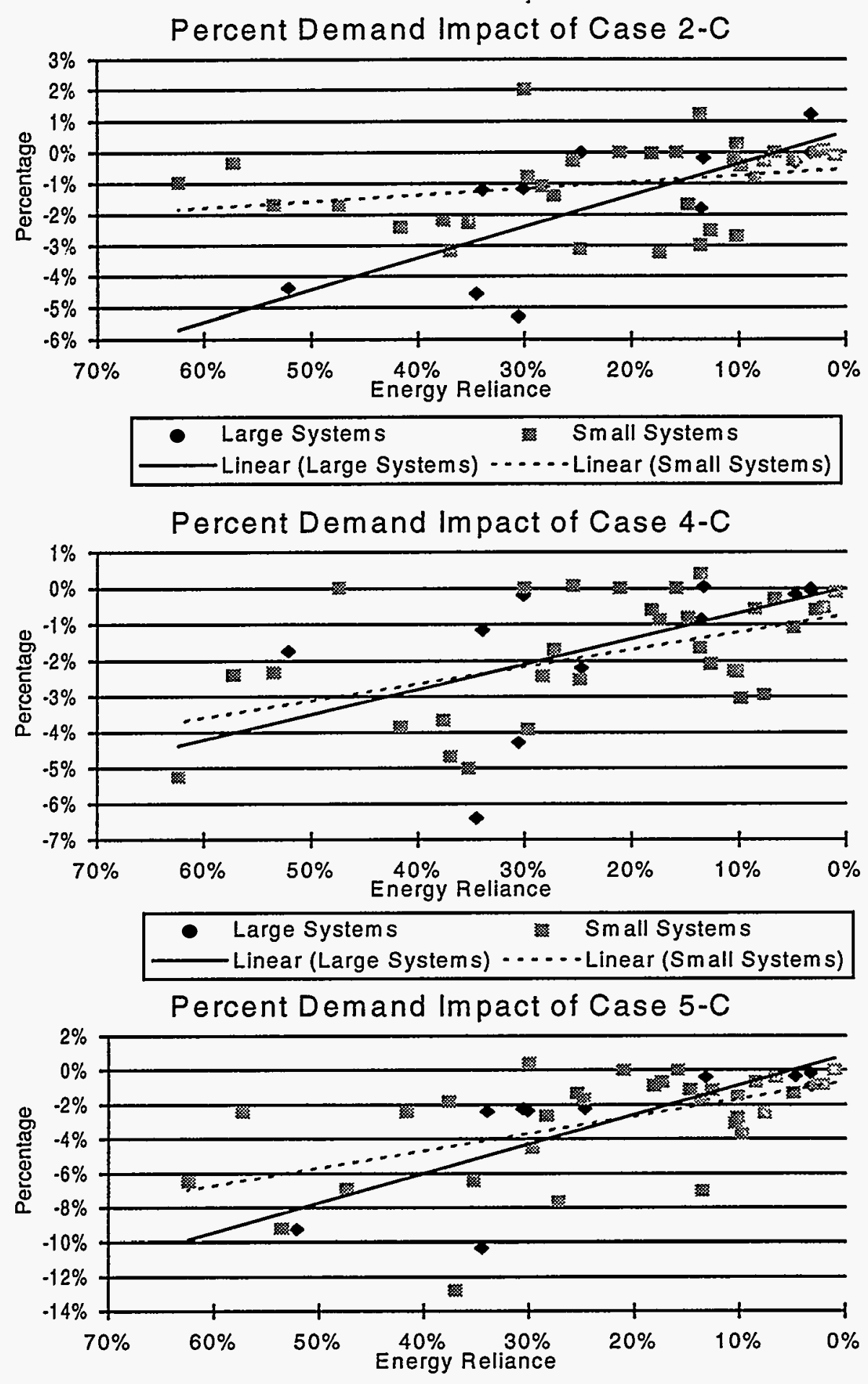

FIGURE 30 Impacts on Demand for Electricity 


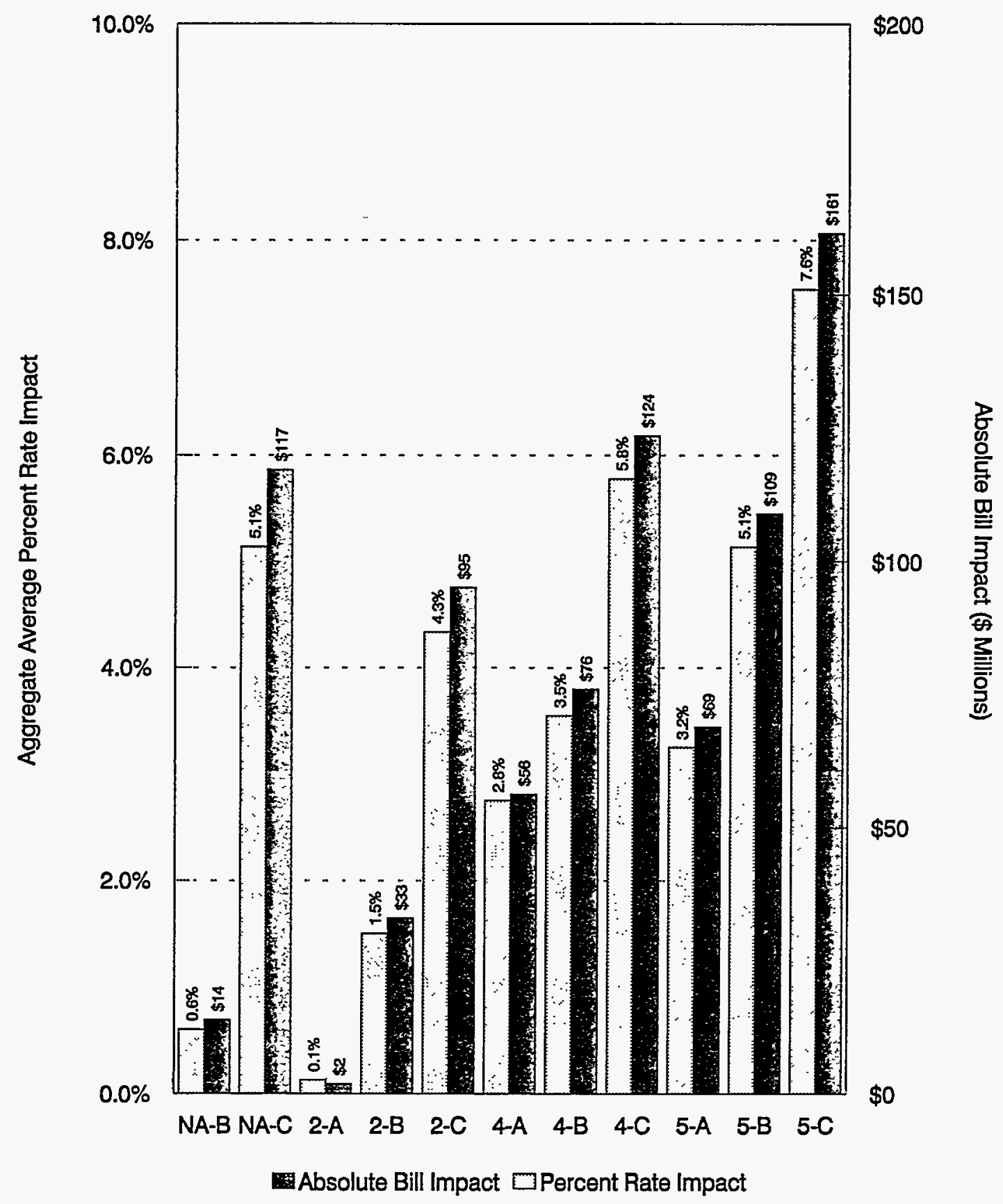

FIGURE 31 Aggregate Impacts of Each Alternative 
- The impacts on retail rates relative to the baseline case over time,

- The impact on the index of energy sales over time, and

- The impact on the relative reliance on Western for capacity and energy requirements.

Although only seven systems are presented, a similar system-by-system analysis has been prepared for each of the large and small utility systems modeled.

\subsubsection{Relative Reliance on Western for Capacity and Energy}

Figure 32 shows the relative reliance on Western to meet peak load and energy requirements for the first representative large system, and Figure 33 shows the relative reliance for the first representative small system. For the large system, the percentage of peak and energy reliance on Western was approximately $32 \%$ before revisions in marketing alternatives. The top graph of Figure 32 shows that for the No Action Alternative and Alternative 2 (peaking), the percentage reliance on Western to meet peak load remains consistent with historical levels, while for Alternative 4 (low energy and capacity) and Alternative 5 (baseload), the percent reliance on peak declines to approximately $15 \%$. The percentage reliance declines over time because of the growth in peak load. Alternative NA-C has higher peak reliance than the baseline case because the peak load is reduced in the steady flow supply scenario because of the effects of price elasticity of demand. With lower peak loads, the percentage reliance on Western remains higher.

The top graph of Figure 32 shows that the percentage reliance on Western to meet energy requirements remains at approximately $30 \%$ in the No Action Alternative, is approximately $27 \%$ in the Alternative 5 (baseload), and declines to below 20\% in Alternative 4 (low capacity and energy) and Alternative 2 (peaking). As was the case with the relative reliance on peak load, the reliance declines over time because of increases in sales, and the percentage reliance is higher in Alternative NA-C than the baseline case because of price elasticity of demand.

Figure 33 shows that for the representative small system, the reliance percentages have trends similar to those for the large system. The peak reliance remains at approximately $30 \%$ for the No Action Alternative and Alternative 2 (peaking), while reliance declines to approximately $15 \%$ for Alternative 4 (low capacity and energy) and Alternative 5 (baseload). In terms of energy output, the No Action Alternative and Alternative 5 (baseload) remain at approximately 45\%, while Alternative 4 (low energy and capacity) and Alternative 2 (peaking) reduce the reliance to approximately $25 \%$. 

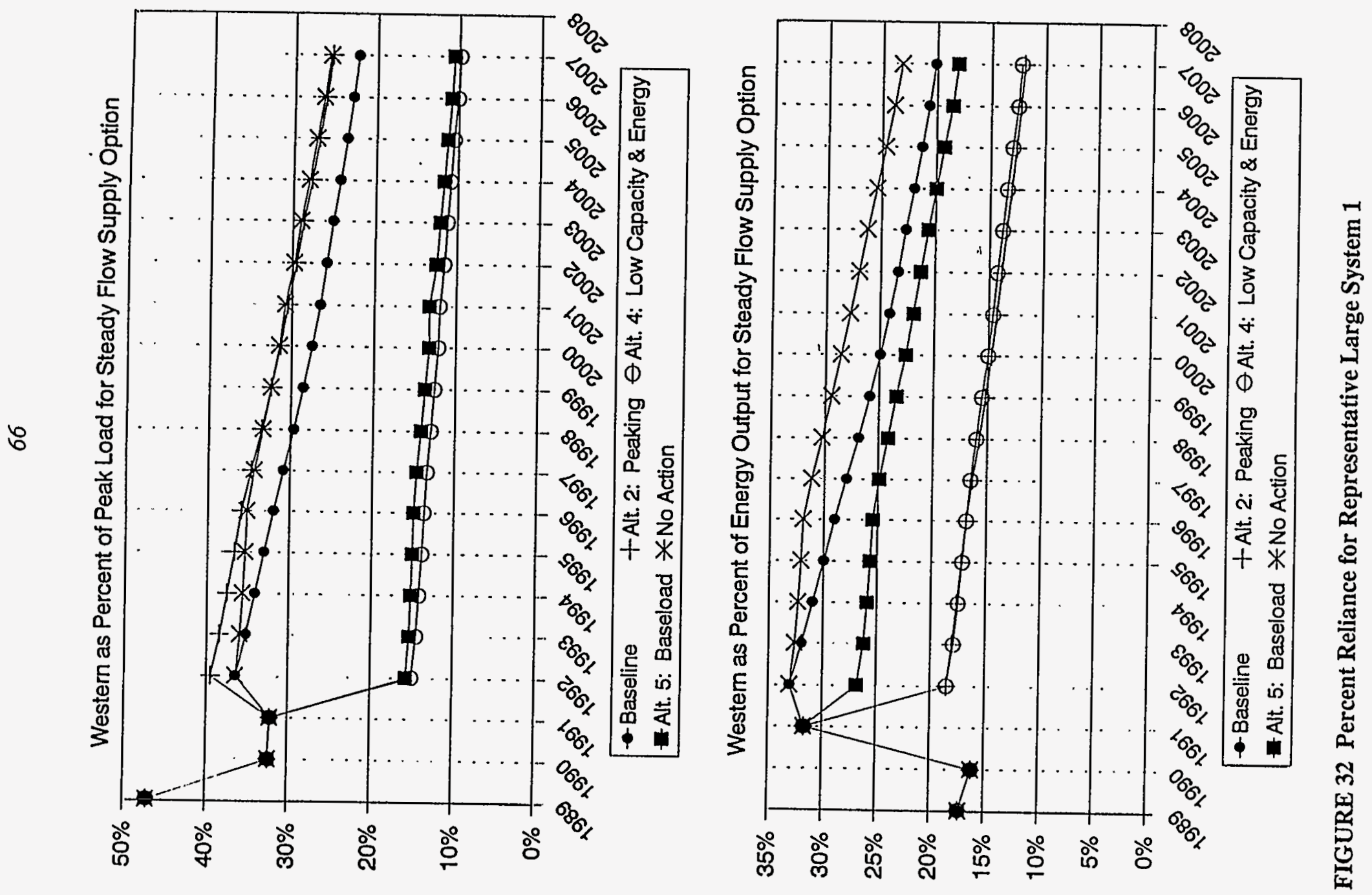


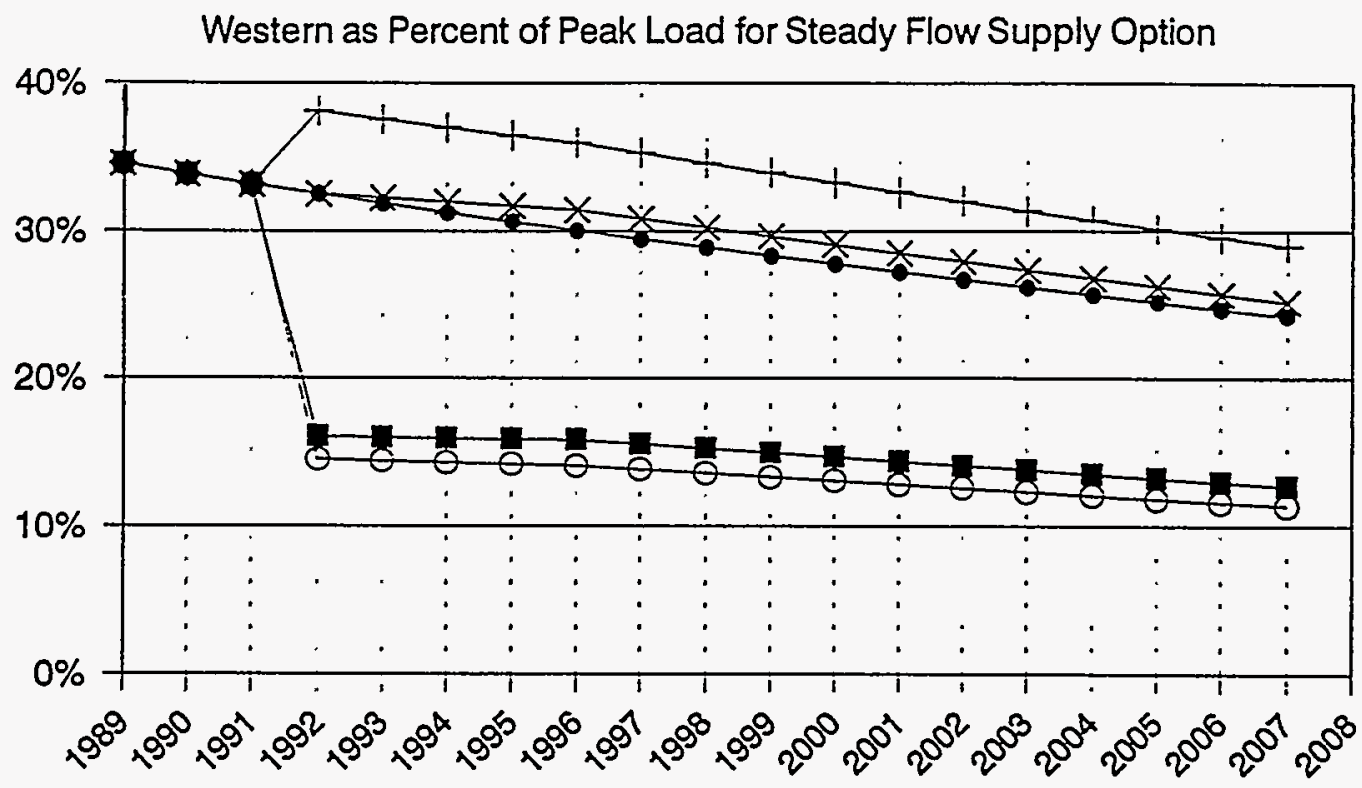

-Baseline

+Alt. 2: Peaking $\ominus$ Alt. 4: Low Capacity \& Energy

- Alt. 5: Baseload $*$ No Action

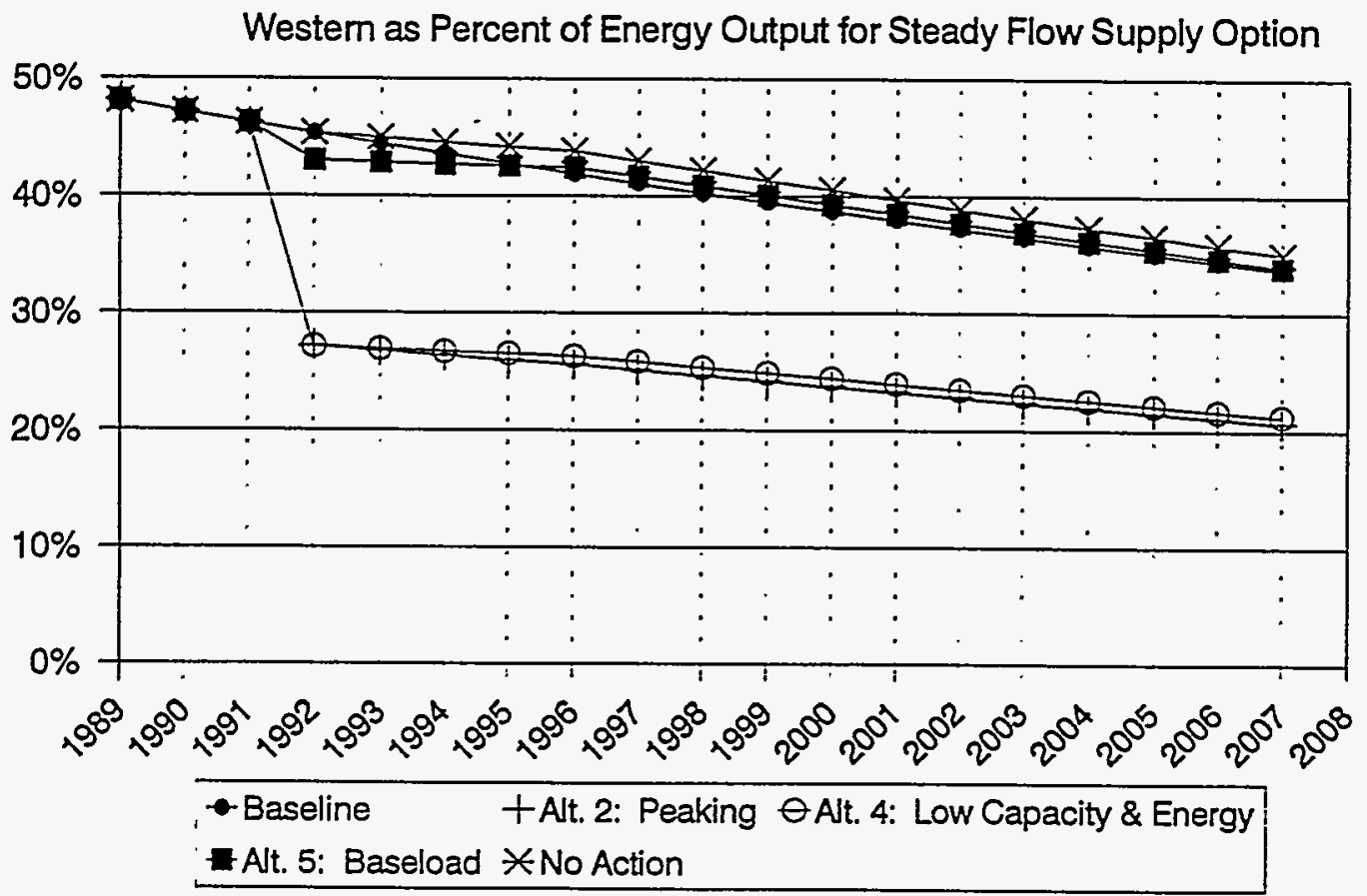

FIGURE 33 Percent Reliance for Representative Small System 1 
The patterns of reliance percentages in various alternatives for the other representative systems described in the following are similar to the patterns shown in Figures 32 and 33 . Obviously, the initial levels may be somewhat different.

\subsubsection{Retail Rates over Time}

Figure 34 shows the impacts on average retail rates over the period from 1993 through 2008 relative to the baseload case for the four selected large systems. The graph in the upper left shows the impacts for the first representative system, the graph in the upper right is for the second system, the graph in the lower left is for the third system, and the graph in the lower right is for the fourth system. In the systems that have the highest impact in the No Action Alternative, the loss of Western capacity is not very costly, and the primary impacts arise from changes in Western rates - primarily the energy rate. For the first two systems, the largest impact is for Alternative NA-C, while for the third system, the greatest impact occurs for the baseload marketing alternative. As discussed earlier, the reason for the different impacts is based on the relationship between the cost of alternative capacity and changes in the cost of Western power.

Figure 35 shows the rate impacts for the four representative small systems. For system 1 , the impacts are greatest at 22\% for Alternative 5 (baseload) and lowest for Alternative 2 (peaking), which implies that the cost of replacement capacity is high relative to the cost of replacement energy. The graph in the upper right shows that system 2 also has the highest impacts from Alternative 5 (baseload) and Alternative 4 (low energy and capacity). Since the impacts are greater in Alternatives 4-A and 5-A than in Alternative NA-C, the loss of capacity has more impact than Western rate increases (Western rate increases are greatest in Alternative NA-C).

The graph in the lower left of Figure 35 shows that for representative system 3, the largest impacts occur for Alternative 2 (peaking) and Alternative 4 (low capacity and energy). This result implies that for system 3 , the cost of replacement energy is high relative to the cost of capacity. The graph in the lower right shows that system 4 has impacts similar to those of systems 1 and 2 . A comparison of Figures 34 and 35 demonstrates that large systems are generally more influenced by Western's rates, while small systems are more affected by loss of allocated Western capacity.

\subsubsection{Annual Rate Impacts Relative to the Baseline Case}

Figure 36 shows the annual rate impacts relative to the baseline case (NA-A: No Action Alternative with full flexibility) over the 25 -year study period for the selected large utility systems, and Figure 37 shows the rate relative to the baseline case for the representative small systems. In these charts, the data represent the index as compared with the baseline case. For example, if rates are $20 \%$ above the baseline case, the index value is 120 . In Figures 36 and 37, the steady flow supply option is compared with the baseline case. 

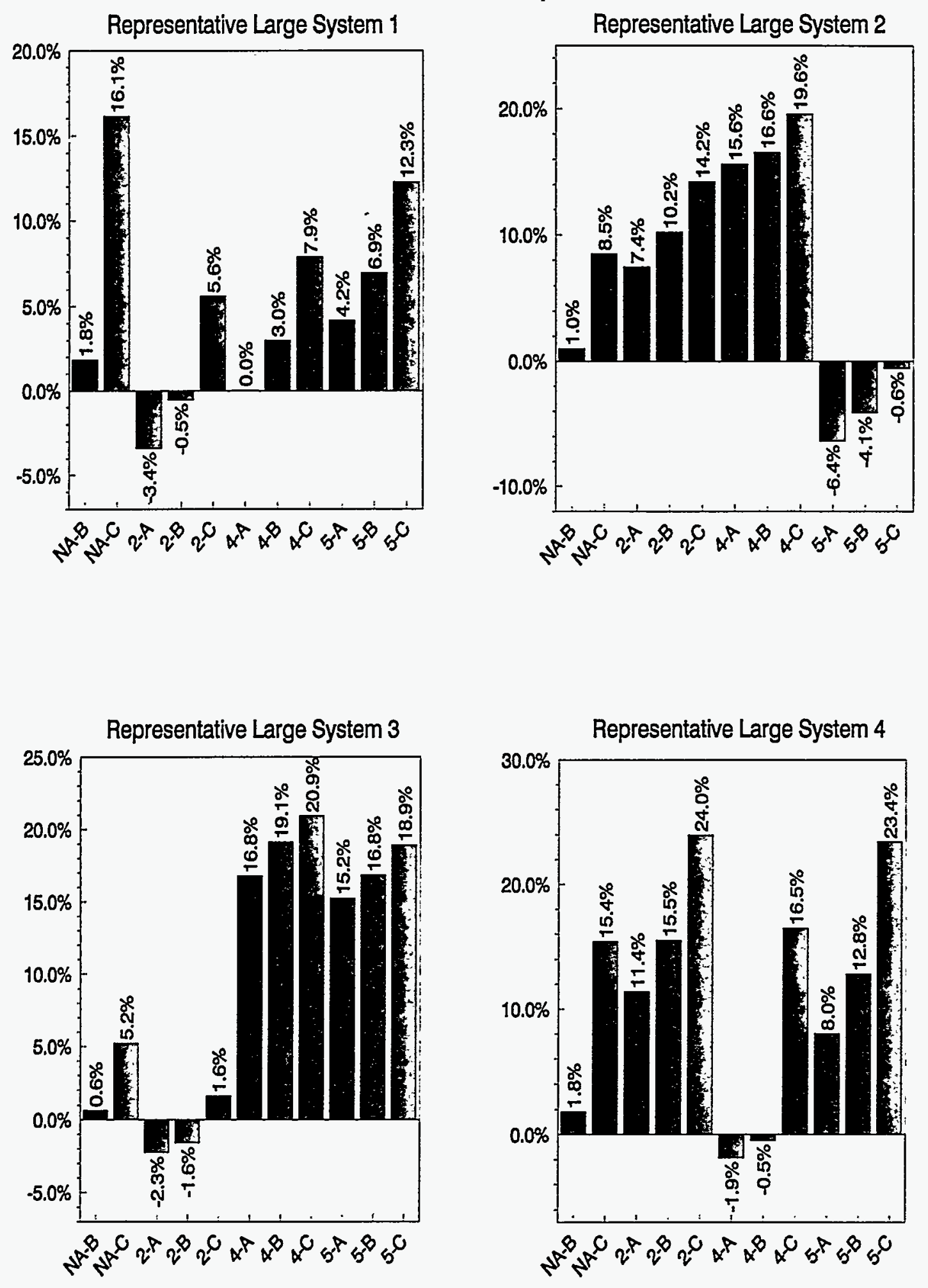

FIGURE 34 Average Rate Impacts over 25-Year Period for Large Systems 

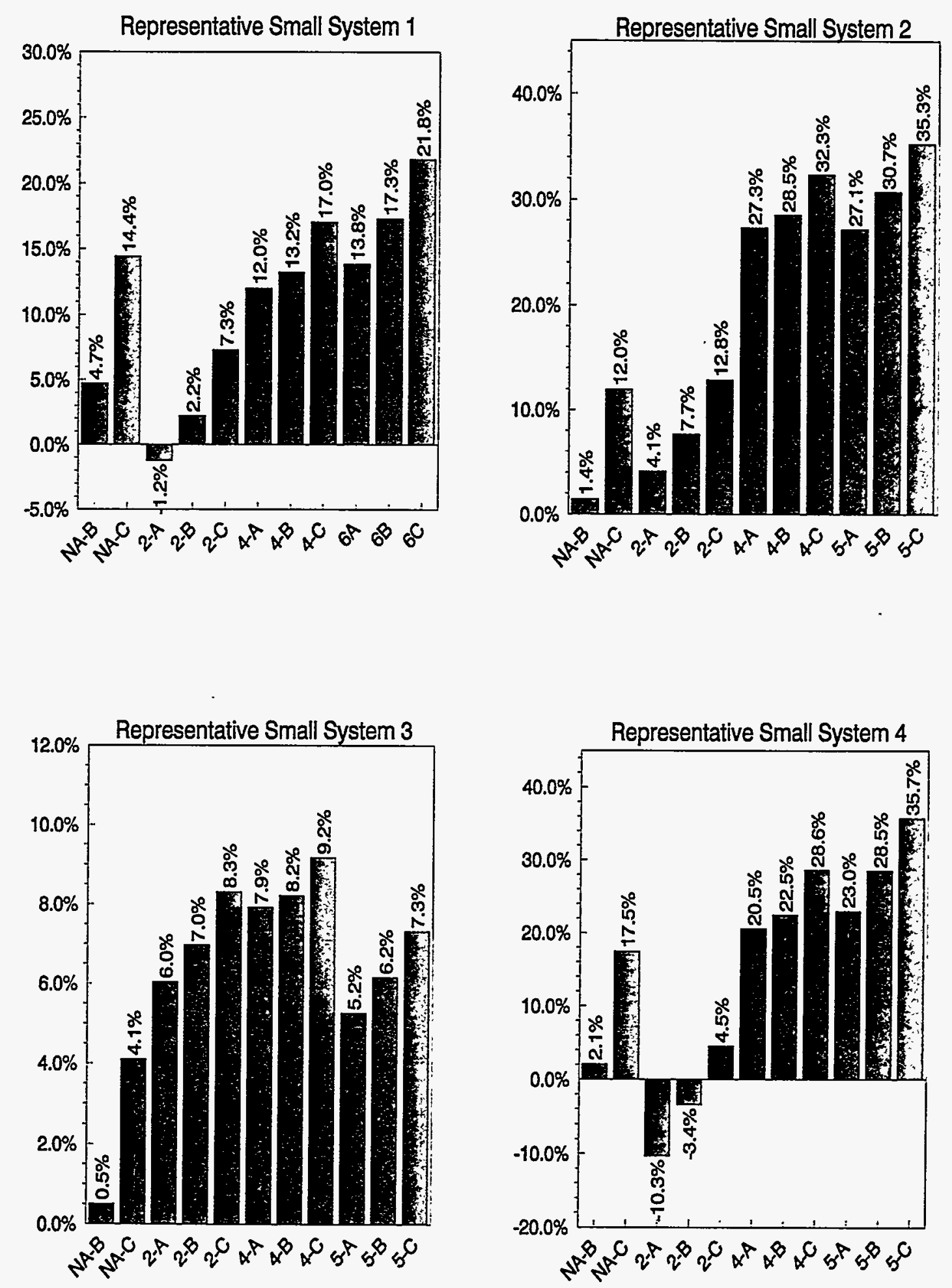

FIGURE 35 Average Rate Impacts over 25-Year Period for Small Systems 
Representative Large System 1

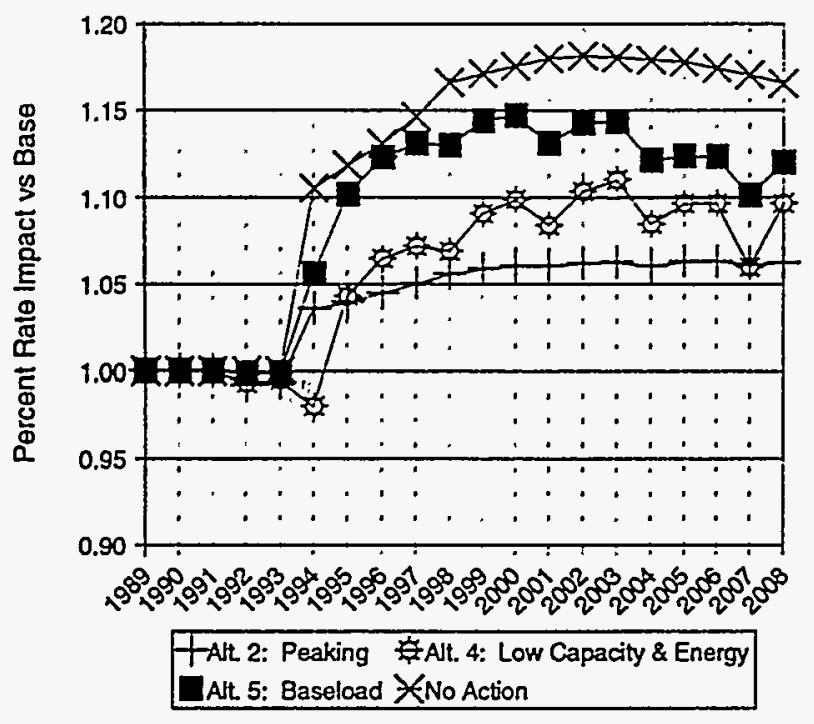

Representative Large System 3

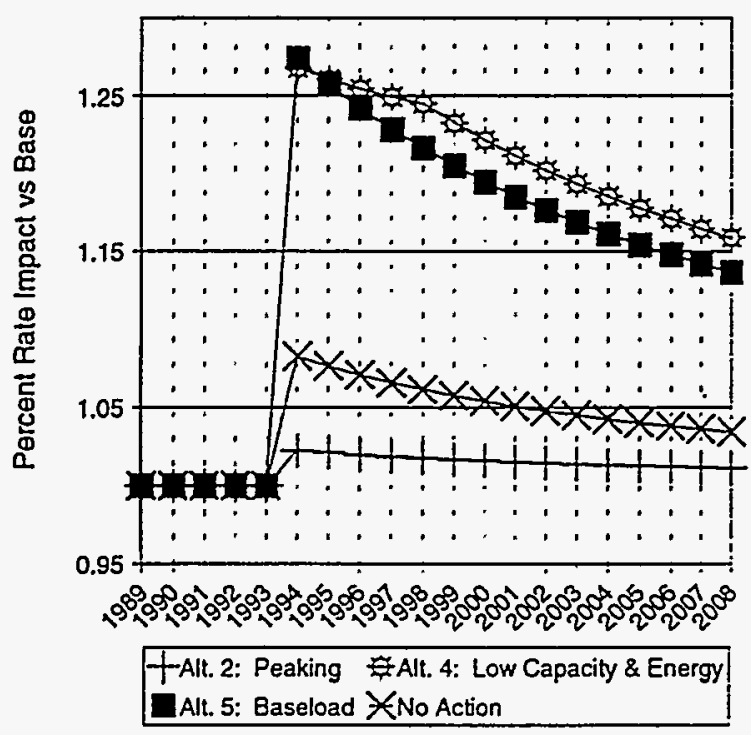

Representative Large System 2

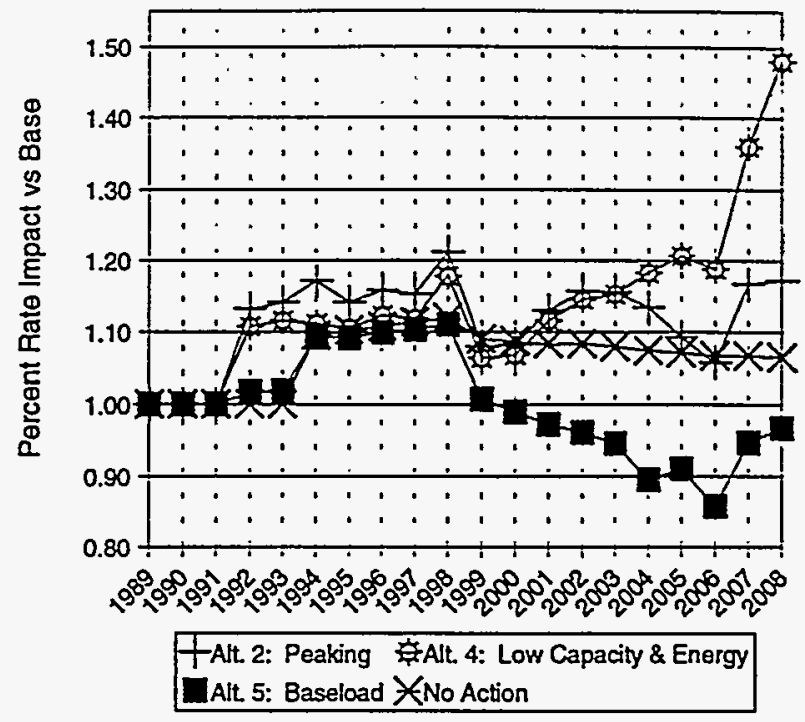

Representative Large System 4

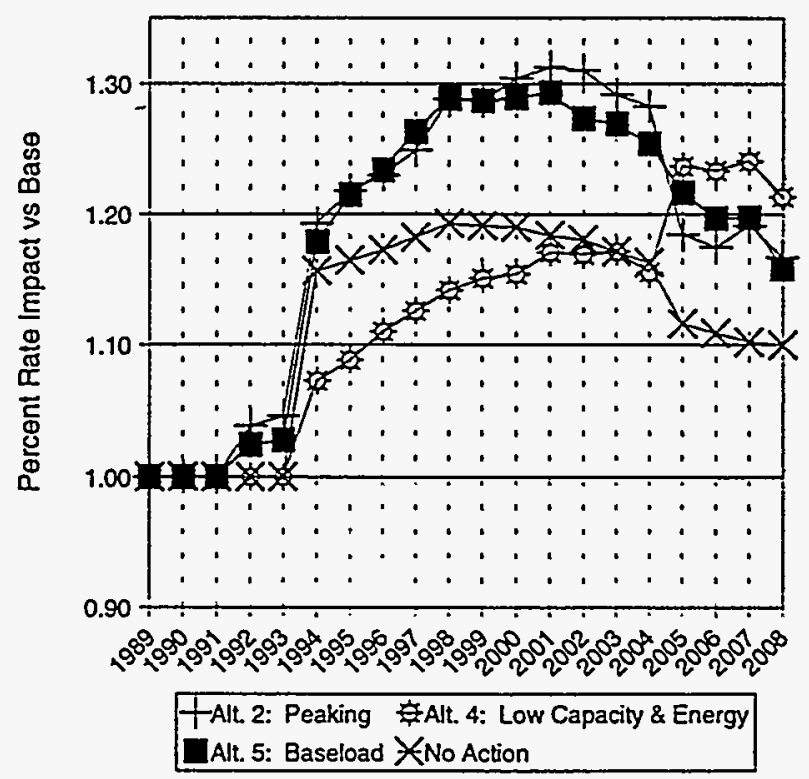

FIGURE 36 Annual Rate Impacts over Time for Large Systems 
Representative Small System 1

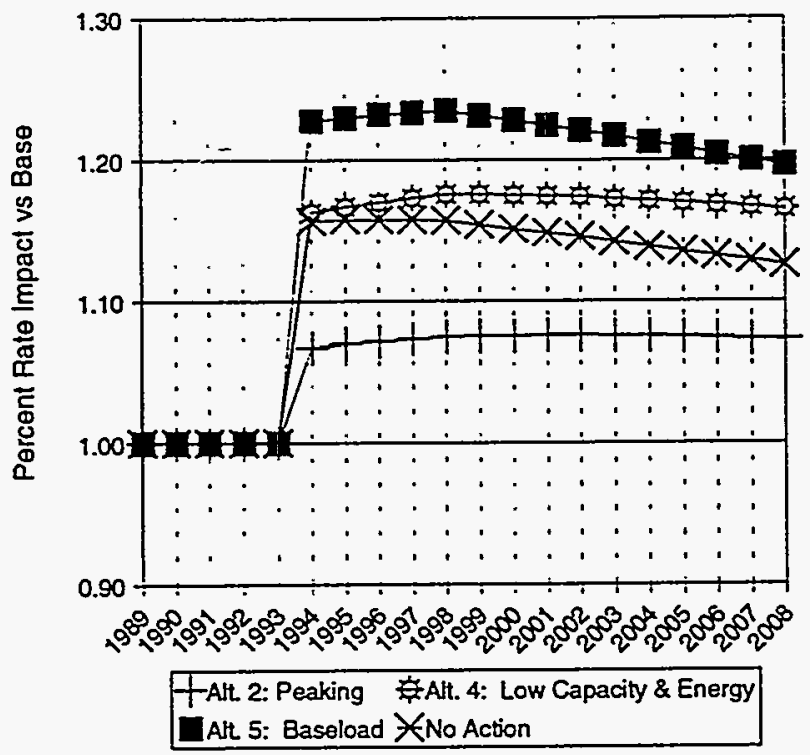

Representative Small System 3

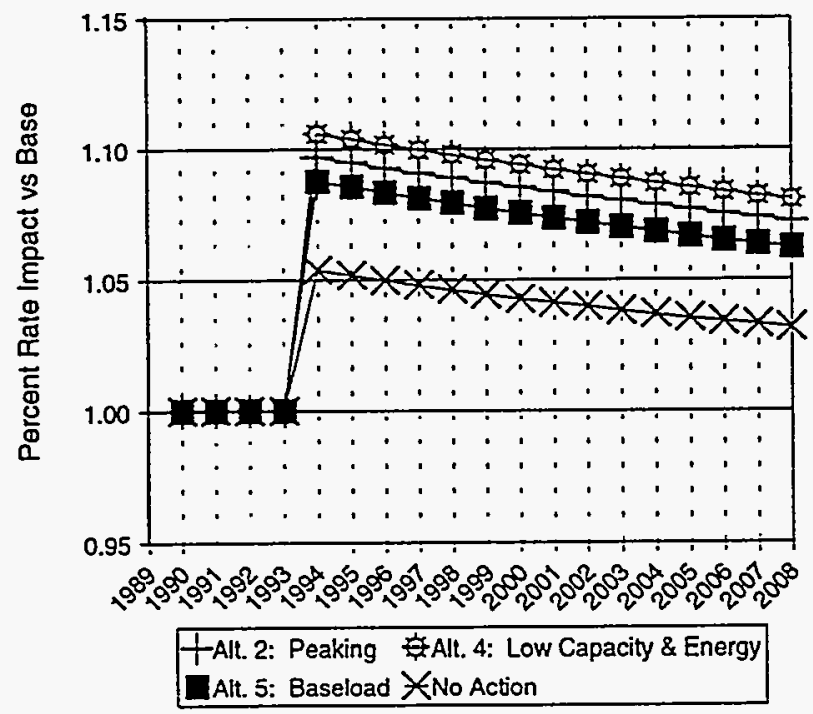

Representative Small System 2

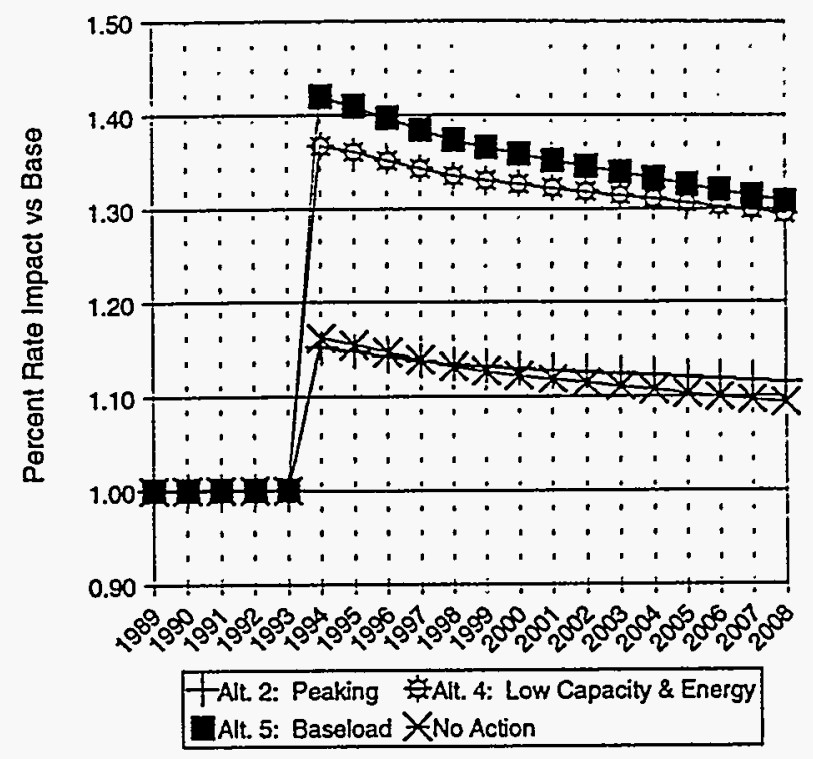

Representative Small System 4

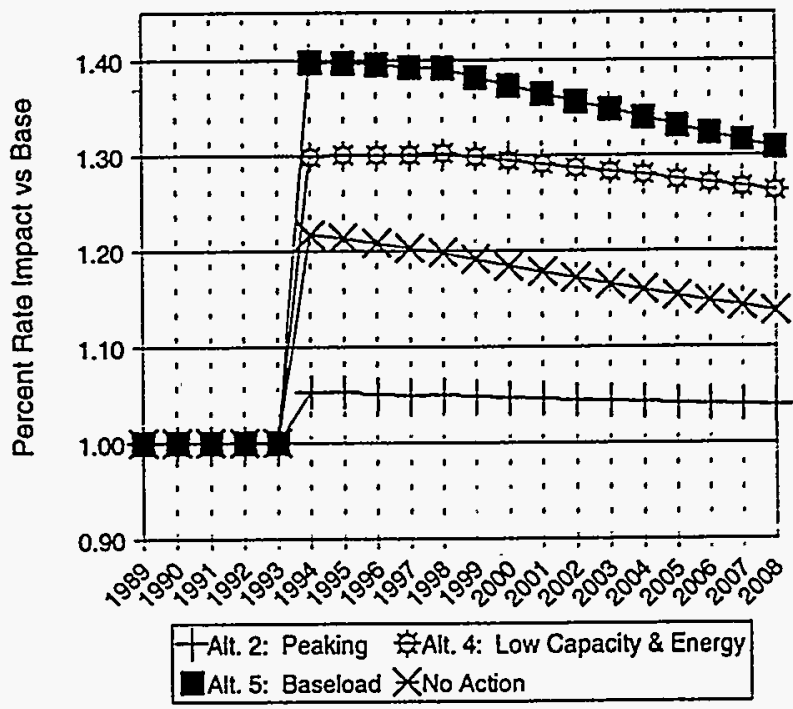

FIGURE 37 Annual Rate Impacts over Time for Small Systems 
For the large utility systems shown in Figure 36, the impacts on retail rates are highest for representative system 1 in the early years. The rate impacts lessen over time because the percentage reliance on Western declines with increases in load. For example, for representative system 3 , the largest rate impact for Alternative 5 (baseload) and Alternative 4 (low capacity and energy) is almost $30 \%$, while the average impact is approximately $20 \%$. For systems 3 and 4 , the rate impacts are highest for Alternative 5 (baseload). For all of the selected systems, the impacts in Alternative 2 (peaking) are relatively small. The impacts reflect the fact that alternative capacity must be secured.

Figure 37 shows that for the small systems, the rate impacts are highest in the years following the change in allocation. For example, for the representative system, the maximum impact in Alternative 5-C is about 25\% compared with the $21.8 \%$ average impact over the entire period. For representative system 2 , the largest rate impact is above $40 \%$ in Alternative 5 (baseload), while the average impact over the entire period as shown in Figure 36 is approximately $35 \%$.

\subsubsection{Average Usage Impacts}

Figures 38 and 39 show the impacts on usage of electricity for the small and large representative systems. Each graph presents the average usage impacts relative to the baseline case over the 25-year period of the study. The usage impacts are a direct result of price elasticity of demand based on price changes. Figure 38 shows that for the small systems, the usage impacts range from a $1.4 \%$ increase to a $5.2 \%$ decrease. For all of the representative systems, the largest decrease occurs for Alternative 5 (baseload). Figure 39 shows that for the large systems, the usage impacts vary from $+0.9 \%$ to $-10.1 \%$. Figure 38 shows that representative system 1 has demand reductions of more than $10 \%$ in the No Action Alternative with steady flow; the largest impacts for representative systems 2 and 3 are for Alternative 4 (low capacity and energy); and the largest impacts for representative system 4 are for Alternative 2 (peaking).

\subsubsection{Year-by-Year Usage Impacts}

Figures 40 and 41 show the relative impacts on electricity usage under different marketing commitment alternative scenarios for the representative small and large utility systems. As was the case for year-by-year rate impacts, the usage impacts are expressed as a percentage of the baseline case. The usage impacts arise because of the impacts of price elasticity of demand - a rate change relative to the baseline case causes changes in electricity use. The baseline case and the steady flow supply option are presented on an annual basis. 

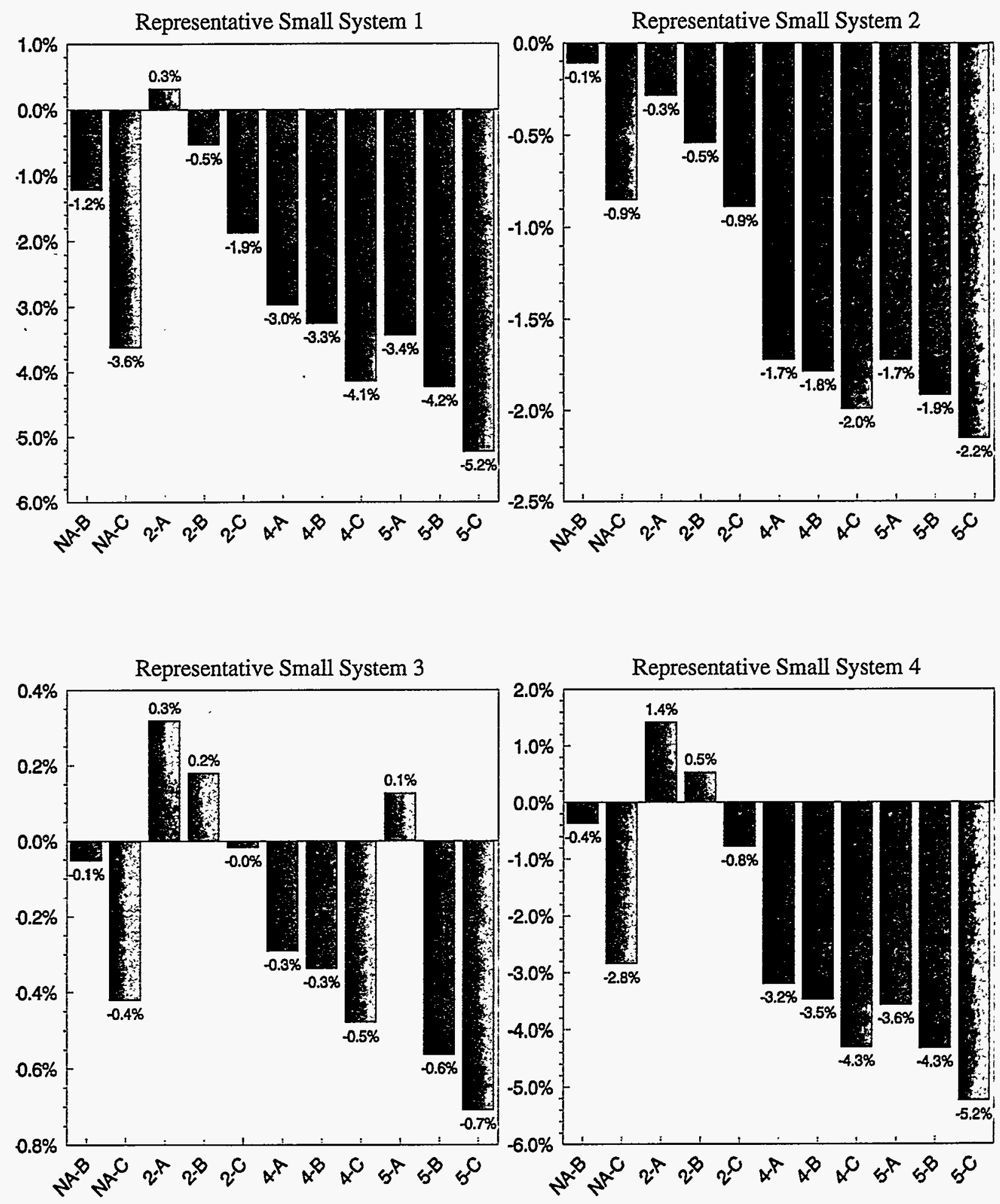

FIGURE 38 Average Usage Impact over 25-Year Period for Small Systems 

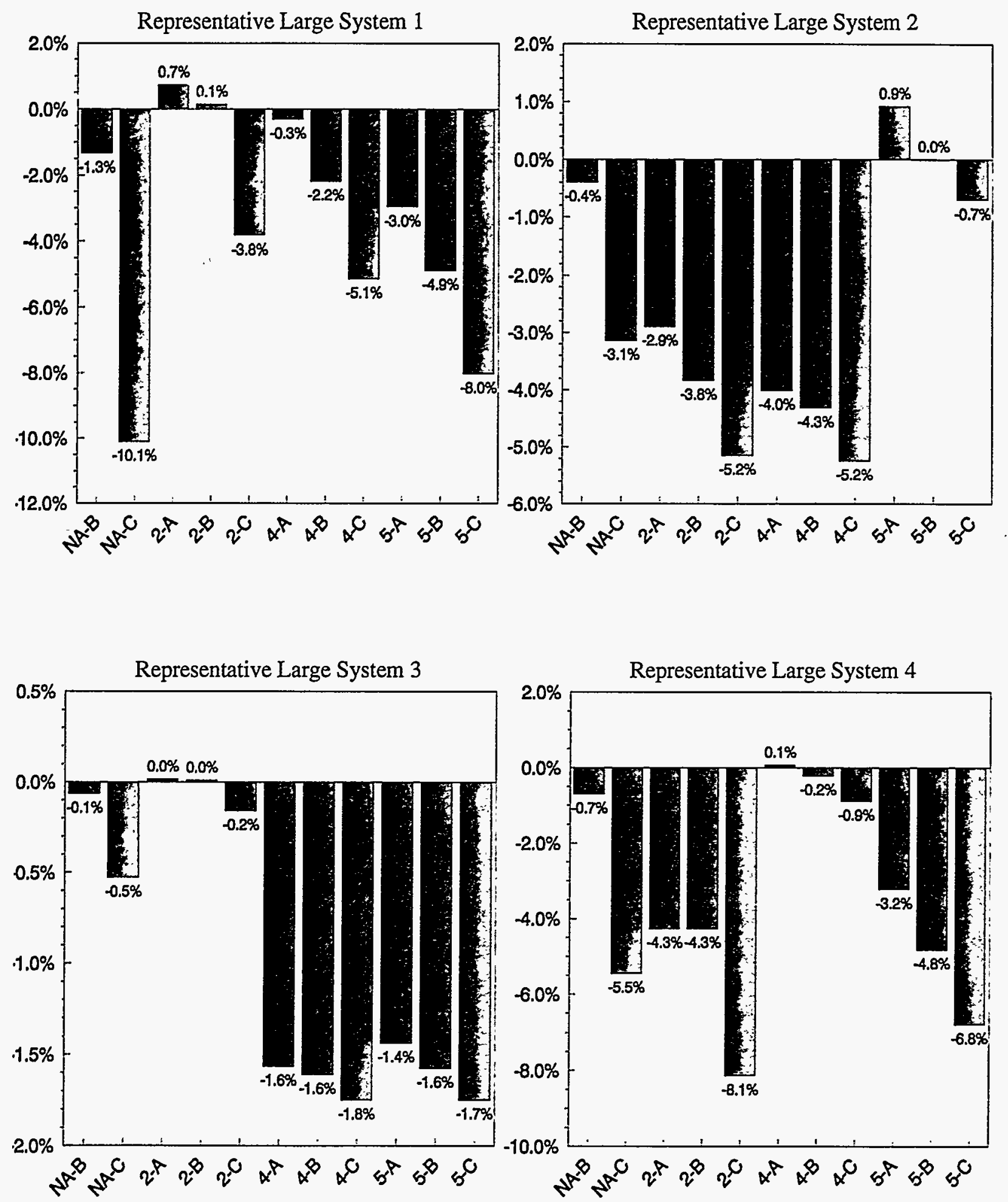

FIGURE 39 Average Usage Impact over 25-Year Period for Large Systems 
Representative Small System 1

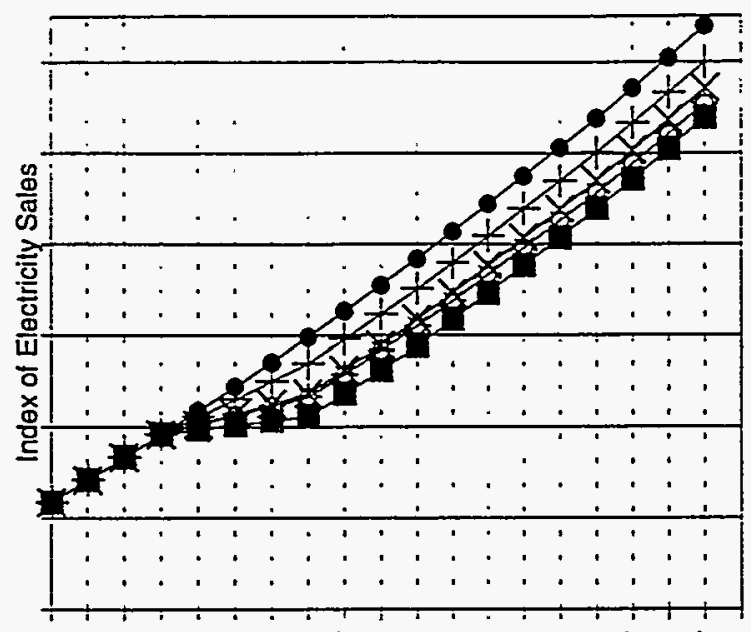

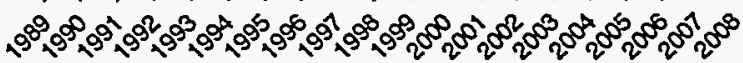
Baseline $\quad$ †Alt. 2: Peaking Alt. 4: Low Capacity \& Energy
Elt. 5: Baseload No Action

\section{Representative Small System 2}

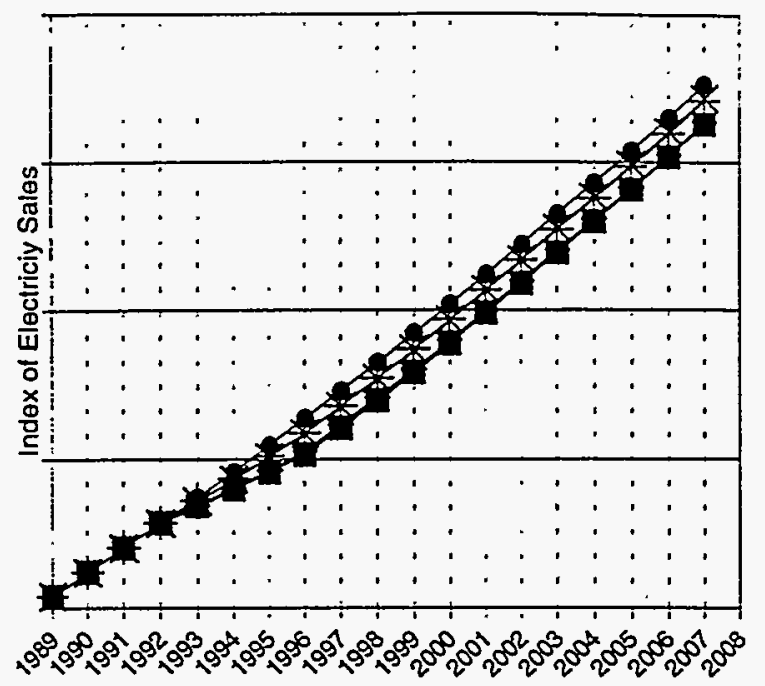

- Baseline TAlt. 2: Peaking Alt. 4: Low Capacity \& Energy Latt. 5: Baseload $*$ No Action
Representative Small System 3

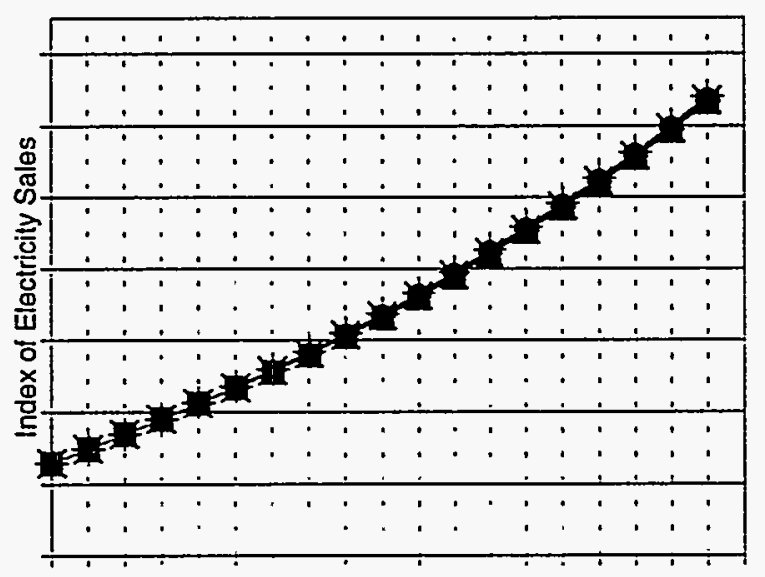

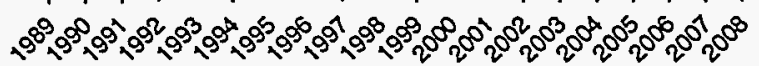

Baseline TAlt. 2: Peaking Alt. 4: Low Capacity \& Energy Ealt. 5: Baseload $*$ No Action

\section{Representative Small System 4}

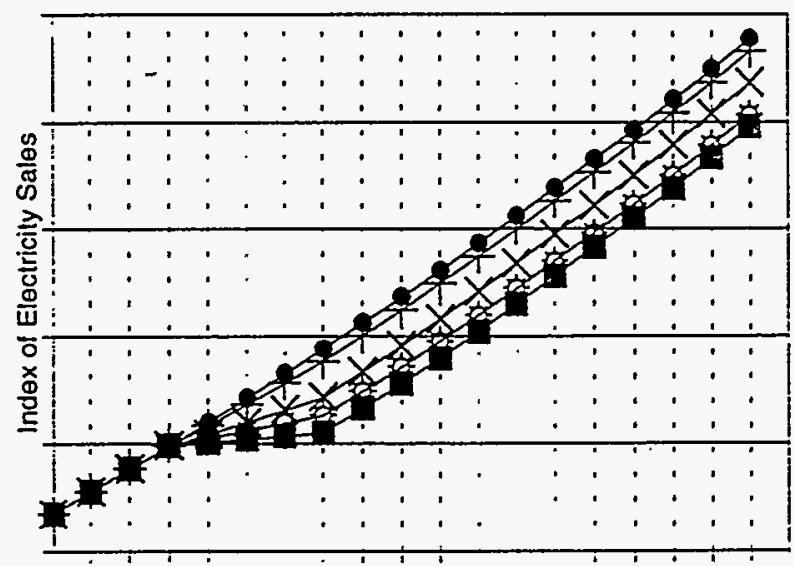

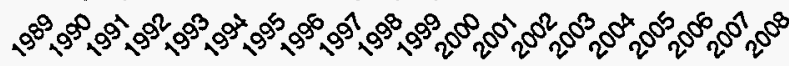

Baseline TAlt. 2: Peaking Alt. 4: Low Capacity \& Energy

DAlt. 5: Baseload $X_{\text {No Action }}$

FIGURE 40 Annual Index of Usage over Time for Small Systems 


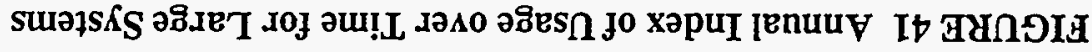

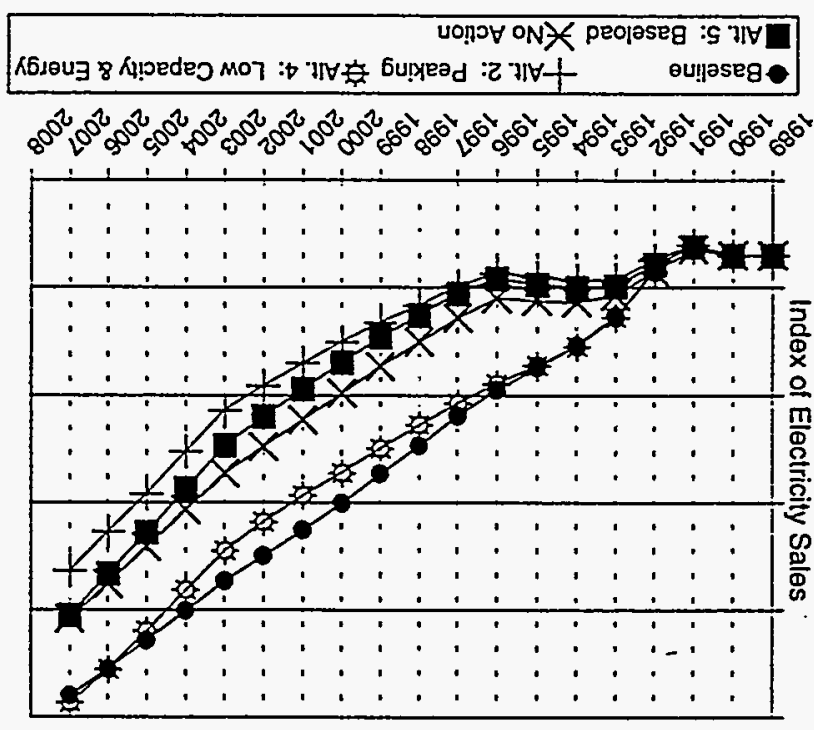

† سәฺรא

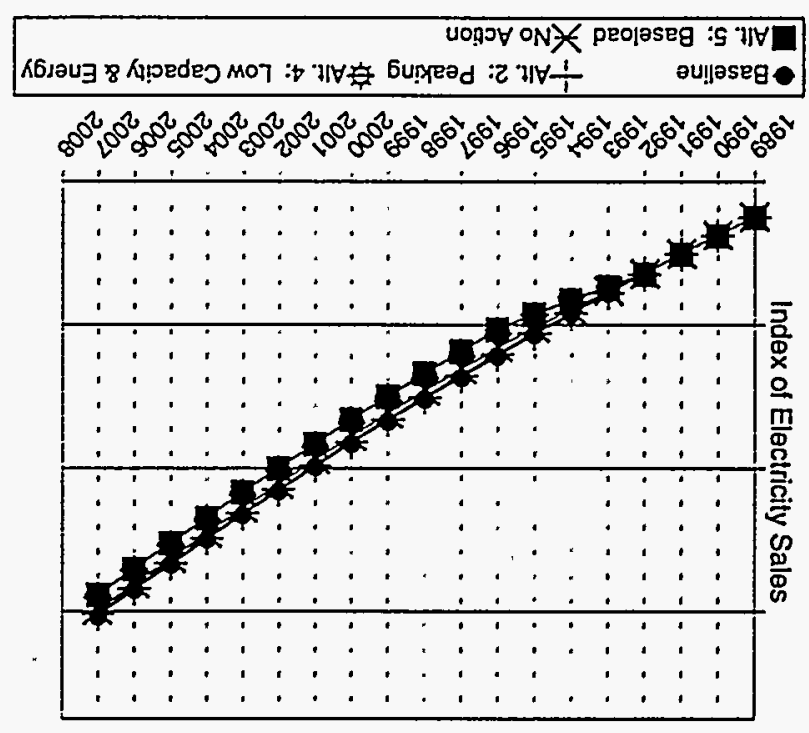

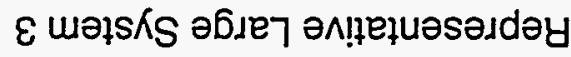

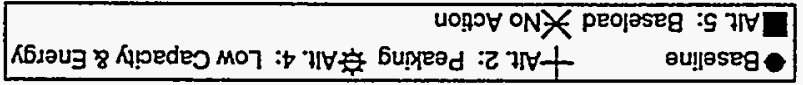

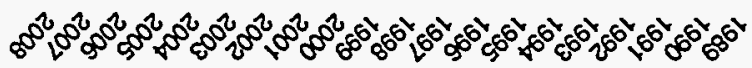

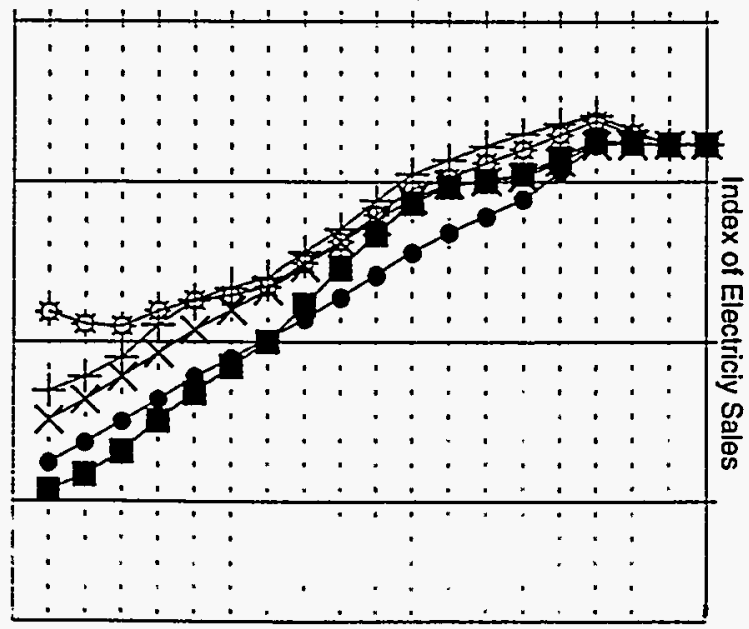

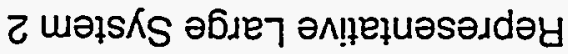

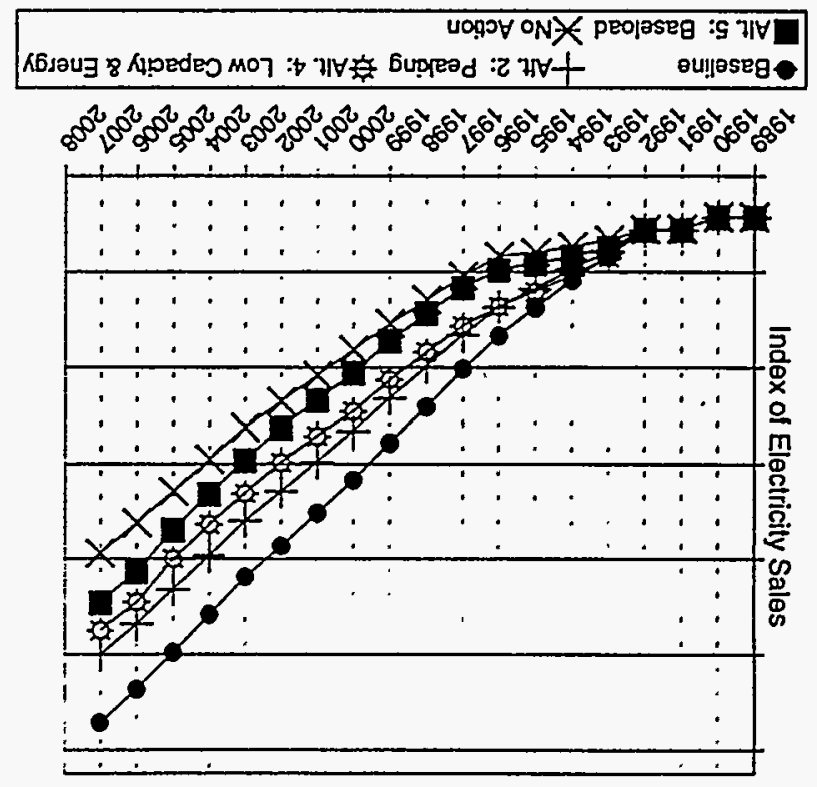

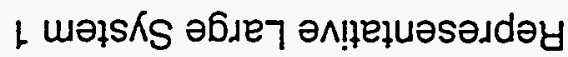




\section{FINANCIAL VIABILITY IMPACTS}

In addition to impacts on retail rates and usage of electricity, potential financial impacts on utility systems from alternative marketing programs were evaluated for the EIS. There is a direct relationship between the financial condition of the utilities that sell power and the prices that consumers pay for electricity. For example, if the cost of service increases because of changes in Western's power contracts and retail rates remain unchanged for an individual utility system, the impact of the cost increase is deteriorating financial condition of the utility, including lower debt service coverage and increased debt leverage. Alternatively, if the entire cost increase is passed on to the customers of the utility in the form of higher electric rates, there is no financial impact on the utility system. As changes in costs occur, individual utility systems must decide whether to increase or decrease the utility's financial health or to increase or decrease rates to utility customers.

Even though most preference customers do not have outside equity investors, financial distress from cost-of-service increases is possible for many of Western's preference customers. There have been notable cases of financial distress for cooperative utility systems (e.g., the Colorado-Ute and Sunflower bankruptcies and debt restructuring at Cajun Electric, Big Rivers, Wabash Valley, and Soyland) and for municipal systems (e.g., Washington Public Power System).

The relationship between rates and financial viability was addressed in S\&P (1991, p. 4):

Co-ops are generally high-cost electric suppliers. About three-quarters of distribution coops have rates higher than those of competing utilities, while, for most of these, the rate disparity exceeds $15 \%$.... The degree to which a co-op is able to maintain competitively priced power will distinguish stronger co-ops from weaker ones in the years ahead, as rates are a primary indicator of a co-op's financial flexibility. Generally, co-ops with rates that are affordable given local economic conditions are in a better competitive position. Furthermore, co-ops that absorb rate increases gradually and avoid "rate shock" will be stronger from a credit perspective.

These comments confirm that utility systems cannot simply increase rates without regard to competitive pressures. In addition to rates and the existing financial status, other factors that influence financial viability are territorial integrity and the contract status between wholesale and distribution systems.

The wholesale rates are particularly important because of the potential of member distribution systems to abrogate contracts. S\&P (1991, pp. 3, 6, and 7) states: 
Promulgation of rules by REA has accelerated in response to repeated challenges to the wholesale power contracts that have traditionally bound member distribution systems to their G\&Ts. Although they have been consistently upheld when challenged, the industry acknowledges the need to strengthen these contracts by formally and explicitly delineating a distributor's contractual obligation to its G\&T. Certainly, the willingness of G\&Ts on their own to strengthen their legal obligations, as Plains Electric Generation \& Transmission Cooperative has done by including in its contract specific limitations on system takeovers, supports this notion. ... The best security for assuring a binding commitment between member and G\&T is competitively priced power, sound relations between the two parties, and efficient system operations. Therefore, system economics, in addition to a cooperative's basic contract obligations, will provide credit support. . . . Additionally, current and future rate competitiveness of a co-op is an important factor in determining the potential for customer attrition. Accordingly, cooperatives with little territorial protection and a weak competitive position are most vulnerable to credit deterioration.

The integrity of a distribution cooperative's service territory is central to the analysis of its creditworthiness. There is no national policy governing cooperatives' service territories, nor is there a uniform method of control over them. Rather, the degree of territorial support varies by state, as do the remedies for service area takeover. Likewise, delineation of service territories and resolution of associated disputes typically rest with state regulatory commissions. Protection of service territory is a critical concern of cooperative managers and of Standard and Poor, because without a captive customer base, timely debt repayment cannot always be ensured.

The potential impact that changes in Western's wholesale power contract terms may have on the financial condition of individual utility systems is reviewed as part of the EIS. This analysis is conducted on the basis of (1) a review of the existing financial structure of the utility systems, (2) a determination of which utility systems may not be able to pass along increases in cost of service to retail consumers, (3) an analysis of rate increase constraints for utility systems, and (4) modeling the financial impacts from changes in Western's marketing programs based on the rate constraints.

\subsection{REVIEW OF EXISTING FINANCIAL STRUCTURE}

The existing structure of utility systems was reviewed by examining the TIER, also referred to as the interest coverage ratio. The reason for focusing on the interest coverage ratio is shown in the following excerpt from S\&P (1991, pp. 4 and 5):

The financial performance of a G\&T and each of its member systems reflects the strength of the other analytical factors reviewed by S\&P. Finances of its members 
are reviewed independent of the G\&Ts, although S\&P recognizes the interrelationships between them. . . . In practice, equity has traditionally been built at the retail, or distribution, level. Similarly, times interest earned (TIER) and debt service coverage (DSC) ratios have, appropriately, been higher for distribution coops. S\&P holds that a continuation of this trend is appropriate, so long as it is accompanied by a strong financing contract and underlying member support. ... Rural co-ops' dependence on the federal government for financial support dates back to REA's inception. Co-ops have traditionally benefited from low-cost and readily available capital funds - first $2 \%$ and $5 \%$ loans, then guarantees. ... The mortgage agreement grants to REA, and any other borrower to which REA extends a lien accommodation, a first lien on the property and revenues of the G\&T. Furthermore, it requires the G\&T to design its rates with a view to maintaining sufficient financial ratios, i.e., times interest earned ratio (TIER) and debt service coverage (DSC), for an average of two out of three years. On a practical level, REA's powers do not ensure timely repayment of a co-op's obligations, as has been witnessed in a number of cases. Its role, however, can serve to ensure ultimate repayment.

Table 8 shows interest coverage ratios for utility systems that were modeled. The high- and lowreliance breakdown is consistent with the PDEIS as described therein.

TABLE 8 Baseline Coverage Ratio by Reliance Level

\begin{tabular}{lc}
\hline Utility Category/Coverage Ratio & $\begin{array}{c}\text { Number of } \\
\text { Utility Systems }\end{array}$ \\
\hline Low reliance & \\
Coverage ratio $<1.1$ & 5 \\
$1.1 \leq$ coverage ratio $<2.0$ & 7 \\
Coverage ratio $\geq 2.0$ & 10 \\
High reliance & \\
Coverage ratio $<1.1$ & 3 \\
$1.1 \leq$ coverage ratio $<2.0$ & 5 \\
Coverage ratio $\geq 2.0$ & 13 \\
Total & 43 \\
\hline
\end{tabular}




\subsection{DETERMINATION OF UTILITY SYSTEMS THAT HAVE POTENTIAL ADVERSE IMPACTS}

The utility systems that are used to measure financial distress are the small utility systems and the wholesale portion of the large systems that receive power directly from Western. There are two primary reasons for concentrating the financial viability analysis on those utility systems that receive power directly from Western:

- Utility systems that receive power directly are faced with the issue of passing on cost changes rather than absorbing them, but some of these systems may have the choice not to take Western power.

- Utility systems that receive capacity and energy directly from Western tend to have more significant amounts of assets and debts and weaker existing financial conditions. Therefore, if there is any question of financial distress, it will generally involve these systems.

\subsection{RATE INCREASE CONSTRAINTS}

In evaluating the potential of utility systems to experience financial distress from changes in Western's contract terms, constraints were imposed on the amount of rate increases. For the retail rate analysis, rates were computed by setting the interest coverage ratio or the net margin to a prespecified level derived from historical analysis. In this portion of the analysis, rates, rather than the level of interest coverage, are constrained. When rates are constrained, impacts on financial indicators such as the interest coverage ratio can be evaluated.

The retail rate constraints were established on the basis of evaluation of the retail rates of neighboring utility systems. Depending on the existing rate differences, varying percentage increases above the baseline case were allowed. The investor-owned utility systems used as a basis for comparison include Arizona Public Service, Colorado Public Service, Public Service of New Mexico, and PacifiCorp (the Utah Power and Light division). For example, if a cooperative utility system in the baseline case has rates that are $15 \%$ below those of Arizona Public Service, the rate constraint may be $20 \%$ above that of the baseline case (allowing for the fact that cooperatives generally have higher rates than investor-owned systems).

Table 9 demonstrates financial viability impacts on Western's preference customers based on the number of utility systems that fall into various coverage ratio categories. The number of utilities that could end in financial distress, based on declines in interest coverage ratio to below 1.1, 
TABLE 9 Coverage Ratio by Utility Category and Marketing Alternative

\begin{tabular}{|c|c|c|c|c|c|c|c|}
\hline \multirow[b]{3}{*}{ Alternative } & \multicolumn{6}{|c|}{ Number of Utility Systems, by Reliance and Coverage Ratio } & \\
\hline & \multirow{2}{*}{$\begin{array}{l}\text { Supply } \\
\text { Option }\end{array}$} & \multicolumn{3}{|c|}{ Low Reliance } & \multicolumn{3}{|c|}{ High Reliance } \\
\hline & & $\mathrm{CR}<1.1$ & $1.1 \leq \mathrm{CR}<2$ & $\mathrm{CR} \geq 2$ & $\mathrm{CR}<1.1$ & $1.1 \leq \mathrm{CR}<2$ & $\mathrm{CR} \geq 2$ \\
\hline No Action & $\begin{array}{l}\text { A } \\
\text { B } \\
\text { C }\end{array}$ & $\begin{array}{l}5 \\
6 \\
6\end{array}$ & $\begin{array}{l}7 \\
6 \\
6\end{array}$ & $\begin{array}{l}10 \\
10 \\
10\end{array}$ & $\begin{array}{l}3 \\
4 \\
6\end{array}$ & $\begin{array}{l}5 \\
4 \\
2\end{array}$ & $\begin{array}{l}13 \\
13 \\
13\end{array}$ \\
\hline 1 & $\begin{array}{l}\mathrm{A} \\
\mathrm{B} \\
\mathrm{C}\end{array}$ & $\begin{array}{l}5 \\
5 \\
5\end{array}$ & $\begin{array}{l}7 \\
7 \\
7\end{array}$ & $\begin{array}{l}10 \\
10 \\
10\end{array}$ & $\begin{array}{l}3 \\
3 \\
3\end{array}$ & $\begin{array}{l}5 \\
5 \\
5\end{array}$ & $\begin{array}{l}13 \\
13 \\
13\end{array}$ \\
\hline 2 & $\begin{array}{l}\mathrm{A} \\
\mathrm{B} \\
\mathrm{C}\end{array}$ & $\begin{array}{l}7 \\
7 \\
7\end{array}$ & $\begin{array}{l}5 \\
5 \\
5\end{array}$ & $\begin{array}{l}10 \\
10 \\
10\end{array}$ & $\begin{array}{l}4 \\
4 \\
5\end{array}$ & $\begin{array}{l}4 \\
4 \\
3\end{array}$ & $\begin{array}{l}13 \\
13 \\
13\end{array}$ \\
\hline 3 & $\begin{array}{l}\text { A } \\
\text { B } \\
\text { C }\end{array}$ & $\begin{array}{l}6 \\
6 \\
6\end{array}$ & $\begin{array}{l}6 \\
6 \\
6\end{array}$ & $\begin{array}{l}10 \\
10 \\
10\end{array}$ & $\begin{array}{l}4 \\
4 \\
5\end{array}$ & $\begin{array}{l}4 \\
4 \\
3\end{array}$ & $\begin{array}{l}13 \\
13 \\
13\end{array}$ \\
\hline 5 & $\begin{array}{l}\text { A } \\
\text { B } \\
\text { C } \\
\text { A } \\
\text { B } \\
\text { C }\end{array}$ & $\begin{array}{l}5 \\
5 \\
5 \\
6 \\
6 \\
5\end{array}$ & $\begin{array}{l}5 \\
5 \\
5 \\
6 \\
6 \\
5\end{array}$ & $\begin{array}{l}10 \\
10 \\
10 \\
10 \\
10 \\
10\end{array}$ & $\begin{array}{l}6 \\
6 \\
6 \\
5 \\
6 \\
6\end{array}$ & $\begin{array}{l}2 \\
2 \\
2 \\
3 \\
2 \\
2\end{array}$ & $\begin{array}{l}13 \\
13 \\
13 \\
13 \\
13 \\
13\end{array}$ \\
\hline 6 & $\begin{array}{l}\text { A } \\
\text { B } \\
\text { C }\end{array}$ & $\begin{array}{l}6 \\
6 \\
6\end{array}$ & $\begin{array}{l}6 \\
6 \\
6\end{array}$ & $\begin{array}{l}10 \\
10 \\
10 \\
\end{array}$ & $\begin{array}{l}4 \\
4 \\
5\end{array}$ & $\begin{array}{l}4 \\
4 \\
3 \\
\end{array}$ & $\begin{array}{l}13 \\
13 \\
13 \\
\end{array}$ \\
\hline
\end{tabular}


increases from three to six systems in the steady flow supply scenario for Alternatives NA, 4, and 5. When interest coverage declines, external funding requirements increase, and the debt levels increase.

S\&P (1991, p. 3) states:

Rural economies were hit hard in the late 1970 s and early-to-mid-1980s. The simultaneous effects of the farm economy crisis and the precipitous oil price decline hit the heart of the co-ops' service territory - rural America. In the 1970s, rural population growth had outpaced that of urban centers as Americans moved to the heartland. This trend reversed itself in the early 1980 s as the agricultural recession took hold, and has since stabilized. Typifying most rural economies are concentrated economic bases, usually in mining, agricultural, or manufacturingrelated industries. Correspondingly, unemployment rates usually exceed national averages, while income trails that of urban areas. Members of Plains Electric exhibit such characteristics. However, its system strengths somewhat mitigate these economic concerns. 


\section{REFERENCES}

Bodmer, E., and R. Fisher, 1993, unpublished data, Argonne National Laboratory, Argonne, Ill., Jan. 13.

Fisher, R., and E. Bodmer, 1993, attachment to memorandum from R. Fisher and E. Bodmer to T. Allison, Argonne National Laboratory, Argonne, Ill., Nov. 22.

Morey, M.J., and D. Ungson, 1993, Statistical Analysis of the Demand for Electricity and Forecasts of Demand and Load Growth by Major Rate Class and System for Customers of the Westem Area Power Administration, The Center for Regulatory Studies, Bloomington, Ill., April.

Onstad, D.O., 1993, personal communication, Arizona Power Authority, Phoenix, Ariz.

S\&P, 1991, "Special Report: Rural Electric Co-ops," Standard and Poor's Creditweek, June.

Veselka, T., et al., 1995, Impacts of Western Area Power Administration's Power Marketing Alternatives on Electric Utility Systems, ANL/DIS/TM-10, Argonne National Laboratory, Decision and Information Sciences Division, Argonne, Ill. 